\title{
Optimization of Naphthyridones into Selective TATA- Binding Protein Associated Factor 1 (TAF1) Bromodomain Inhibitors
}

\section{Supporting Information}

Michael. A. Clegg, ${ }^{+, \neq}$Natalie H. Theodoulou, ${ }^{+,}{ }^{\ddagger}$ Paul Bamborough, ${ }^{+}$Chun-wa Chung, ${ }^{+}$Peter D. Craggs, ${ }^{\dagger}$ Emmanuel H. Demont, ${ }^{+}$Laurie J. Gordon, ${ }^{+}$Gemma M. Liwicki, ${ }^{+}$Alex Phillipou, ${ }^{+}$Nicholas C. O. Tomkinson, ${ }^{\ddagger}$ Rab K. Prinjha, ${ }^{+}$ Philip G. Humphreys ${ }^{+*}$

${ }^{\dagger}$ GlaxoSmithKline R\&D, Stevenage, Hertfordshire SG1 2NY, United Kingdom

${ }^{\ddagger}$ WestCHEM, Department of Pure and Applied Chemistry, Thomas Graham Building, University of Strathclyde, 295 Cathedral Street, Glasgow, G1 1XL, United Kingdom

*Corresponding Author: E-mail address: philip.g.humphreys@gsk.com

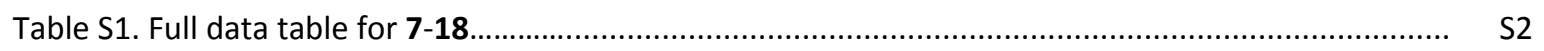

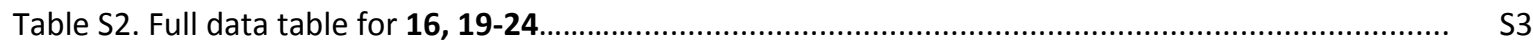

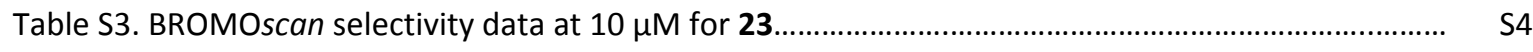

Table S4. Dose-Response BROMOscan data for 23................................................................................ S5

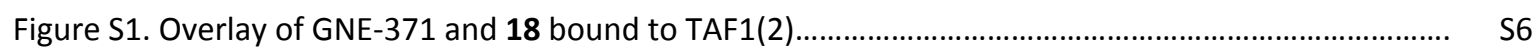

Figure S2. Correlation between TAF1(2) TR-FRET and BROMOscan data............................................... S7

Figure S3. Correlation between BRD4(1) TR-FRET and BROMOscan data............................................... S8

Figure S4. Correlation between BRD4(2) TR-FRET and BROMOscan data................................................ S8

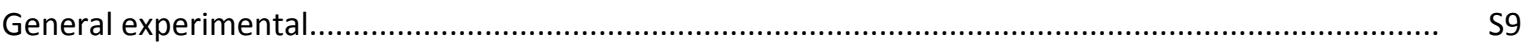

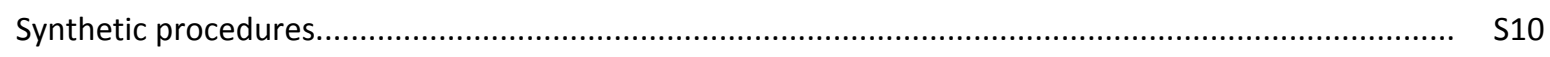

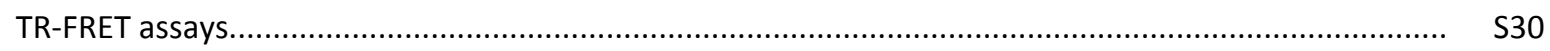

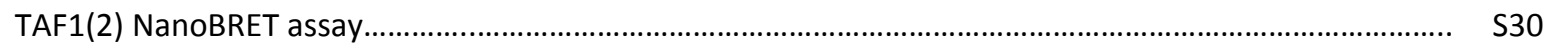

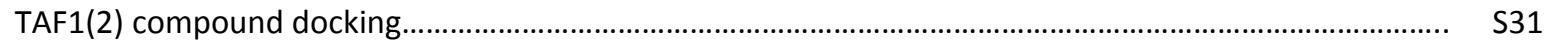

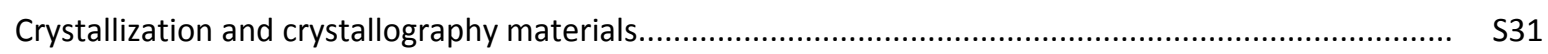

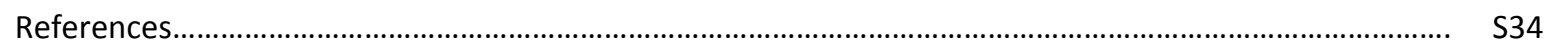




\begin{tabular}{|c|c|c|c|c|c|c|c|}
\hline Compound & TAF1(2) pIC 50 & TAF1(2) LE & BRD4(1) plC 50 & ATAD2A plC 50 & $\begin{array}{c}\text { Chrom } \\
\log D_{\mathrm{pH7} .4}\end{array}$ & $\begin{array}{c}\text { CLND } \\
\text { Solubility } \\
(\mu \mathrm{g} / \mathrm{mL})\end{array}$ & $\begin{array}{c}\text { AMP } \\
(\mathrm{nm} / \mathrm{s})\end{array}$ \\
\hline 7 & $6.8 \pm 0.06(3)$ & 0.31 & $5.9 \pm 0.08(4)$ & $5.8 \pm 0.1(3)$ & 0.3 & $\geq 144$ & $<3$ \\
\hline 8 & $6.7 \pm 0.01(4)$ & 0.35 & $5.6 \pm 0.1(5)$ & $5.7 \pm 0.02(2)$ & 1.2 & $\geq 72$ & $<3$ \\
\hline 9 & $6.5 \pm 0.15(3)$ & 0.33 & $5.7 \pm 0.04(2)$ & $5.6(1)$ & 1.5 & 117 & $<3$ \\
\hline 10 & $6.3(1)$ & 0.30 & $5.6 \pm 0(2)$ & $5.9 \pm 0.05(2)$ & 1.1 & $\geq 176$ & $<3$ \\
\hline 11 & $7.1 \pm 0.11$ (3) & 0.33 & $5.2 \pm 0.04(2)$ & $5.7 \pm 0.18$ & 1.6 & 68 & $<3$ \\
\hline 12 & $7.3 \pm 0.17(2)$ & 0.33 & $5.6 \pm 0.1(2)$ & $6.0 \pm 0.01(2)$ & 1.2 & 29 & 11 \\
\hline 13 & $6.0 \pm 0.48(3)^{2}$ & 0.27 & $5.7 \pm 0.06(2)$ & $5.0 \pm 0.07(3)$ & 2.8 & 22 & 13 \\
\hline 14 & $6.2 \pm 0.06(2)$ & 0.29 & $4.9 \pm 0.06(2)$ & $5.0 \pm 0.01(2)$ & 3.1 & 49 & $<10$ \\
\hline 15 & $6.4 \pm 0.01(2)$ & 0.30 & $4.8 \pm 0.13(2)$ & $4.9 \pm 0.01(2)$ & 0.8 & 75 & $<10$ \\
\hline 16 & $7.5 \pm 0.29(5)$ & 0.35 & $5.2 \pm 0.14(6)$ & $4.7 \pm 0.01(2)$ & 1.2 & 71 & $<5$ \\
\hline 17 & $<4(3)$ & - & $5.2 \pm 0.03(2)$ & n.d. & 1.4 & $\geq 206$ & $<7$ \\
\hline 18 & $7.5 \pm 0.1(5)$ & 0.33 & $5.6 \pm 0.06(2)$ & $6.2 \pm 0.01(2)$ & 0.2 & 34 & 8 \\
\hline
\end{tabular}

Table S1. Full data from Tables 1, including mean $\mathrm{pIC}_{50}$, standard deviation, and the number of test occasions in the TAF1(2), BRD4(1) and ATAD2A assays. n.d.=not determined

${ }^{1} \operatorname{TAF} 1(2) \mathrm{LE}=(1.37 \times \operatorname{TAF} 1(2) \mathrm{plC} 50) /$ heavy atom count

21 out of 4 test occasions, $\mathrm{plC}_{50}:<5$ 


\begin{tabular}{|c|c|c|c|c|c|c|}
\hline Compound & $\begin{array}{c}\text { TAF1(2) } \\
\text { pK }_{i}\end{array}$ & $\begin{array}{c}\text { TAF1(2) } \\
\text { LE }^{\mathrm{a}}\end{array}$ & $\begin{array}{c}\text { BRD4(1) } \\
\text { pK }_{i}\end{array}$ & $\begin{array}{c}\text { Chrom } \\
\log D_{\mathrm{pH} 7.4}\end{array}$ & $\begin{array}{c}\text { CLND } \\
\text { Solubility } \\
(\mu \mathrm{g} / \mathrm{mL})\end{array}$ & $\begin{array}{c}\text { AMP } \\
(\mathrm{nm} / \mathrm{s})\end{array}$ \\
\hline 16 & $9.4(2)$ & 0.44 & $5.7(1)$ & 1.2 & 71 & $<5$ \\
\hline 19 & $9.0(2)$ & 0.41 & $<5.3(2)$ & 1.6 & 116 & $<10$ \\
\hline 20 & $7.3(2)$ & 0.32 & $<5.3(2)$ & 2.9 & $\geq 196^{b}$ & 220 \\
\hline 21 & $8.9(2)$ & 0.41 & $6.1(2)$ & 1.3 & $\geq 386^{b}$ & $<3$ \\
\hline 22 & $9.7(2)$ & 0.43 & $6.2(2)$ & 1.7 & $\geq 201$ & $<7$ \\
\hline 23 & $9.1(2)$ & 0.39 & $<5.4(2)$ & 2.7 & $24^{b}$ & 62 \\
\hline 24 & $6.7(2)$ & 0.26 & $<5(2)$ & 3.9 & $28^{b}$ & 176 \\
\hline
\end{tabular}

Table S2. Full data from Tables 2-3, including mean $\mathrm{pIC}_{50}$ and the number of test occasions in the TAF1(2) and BRD4(1) assays.

${ }^{a} \operatorname{TAF} 1(2) L E=\left(1.37 \times \operatorname{TAF} 1(2) \mathrm{pK}_{\mathrm{i}}\right) /$ heavy atom count

${ }^{\mathrm{b}}$ CAD solubility $(\mu \mathrm{g} / \mathrm{mL})$ 


\begin{tabular}{|c|c|}
\hline Bromodomain & $\begin{array}{c}\text { Percentage inhibition @ } 10 \mu \mathrm{M} \\
23\end{array}$ \\
\hline ATAD2A & 24 \\
\hline ATAD2B & 33 \\
\hline BAZ2A & 32 \\
\hline BAZ2B & 85 \\
\hline BRD1 & 61 \\
\hline BRD2(1) & 63 \\
\hline BRD2(2) & 83 \\
\hline BRD3(1) & 67 \\
\hline BRD3(2) & 92 \\
\hline BRD4(1) & 73 \\
\hline BRD4(2) & 99 \\
\hline BRD7 & 97 \\
\hline BRD9 & 100 \\
\hline BRDT(1) & 54 \\
\hline BRDT(2) & 98 \\
\hline BRPF1 & 94 \\
\hline BRPF3 & 53 \\
\hline CECR2 & 95 \\
\hline CREBBP & 0 \\
\hline EP300 & 44 \\
\hline FALZ & 78 \\
\hline GCN5L2 & 34 \\
\hline PBRM1(2) & 0 \\
\hline PBRM1(5) & 0 \\
\hline PCAF & 34 \\
\hline SMARCA2 & 0 \\
\hline SMARCA4 & 0 \\
\hline TAF1(2) & 100 \\
\hline TAF1L(2) & 74 \\
\hline TRIM24 & 2 \\
\hline TRIM33 & 0 \\
\hline WDR9(2) & 23 \\
\hline
\end{tabular}

Table S3. Selectivity profile of compound $\mathbf{2 3}$ in the BROMOscan panel (DiscoverX Corp). 


\begin{tabular}{cc}
\hline Bromodomain & $\mathbf{2 3}$ \\
\hline BAZ2B & $6.0(2)$ \\
BRD4(1) & $<5.3(2)$ \\
BRD4(2) & $6.1(2)$ \\
BRD9 & $7.4(2)$ \\
BRPF1 & $5.3(2)$ \\
CECR2 & $6.0(2)$ \\
TAF1(2) & $9.1(2)$ \\
\hline
\end{tabular}

Table S4. Selectivity profile of compound $\mathbf{2 3}$ in the BROMOscan panel (DiscoverX Corp). 


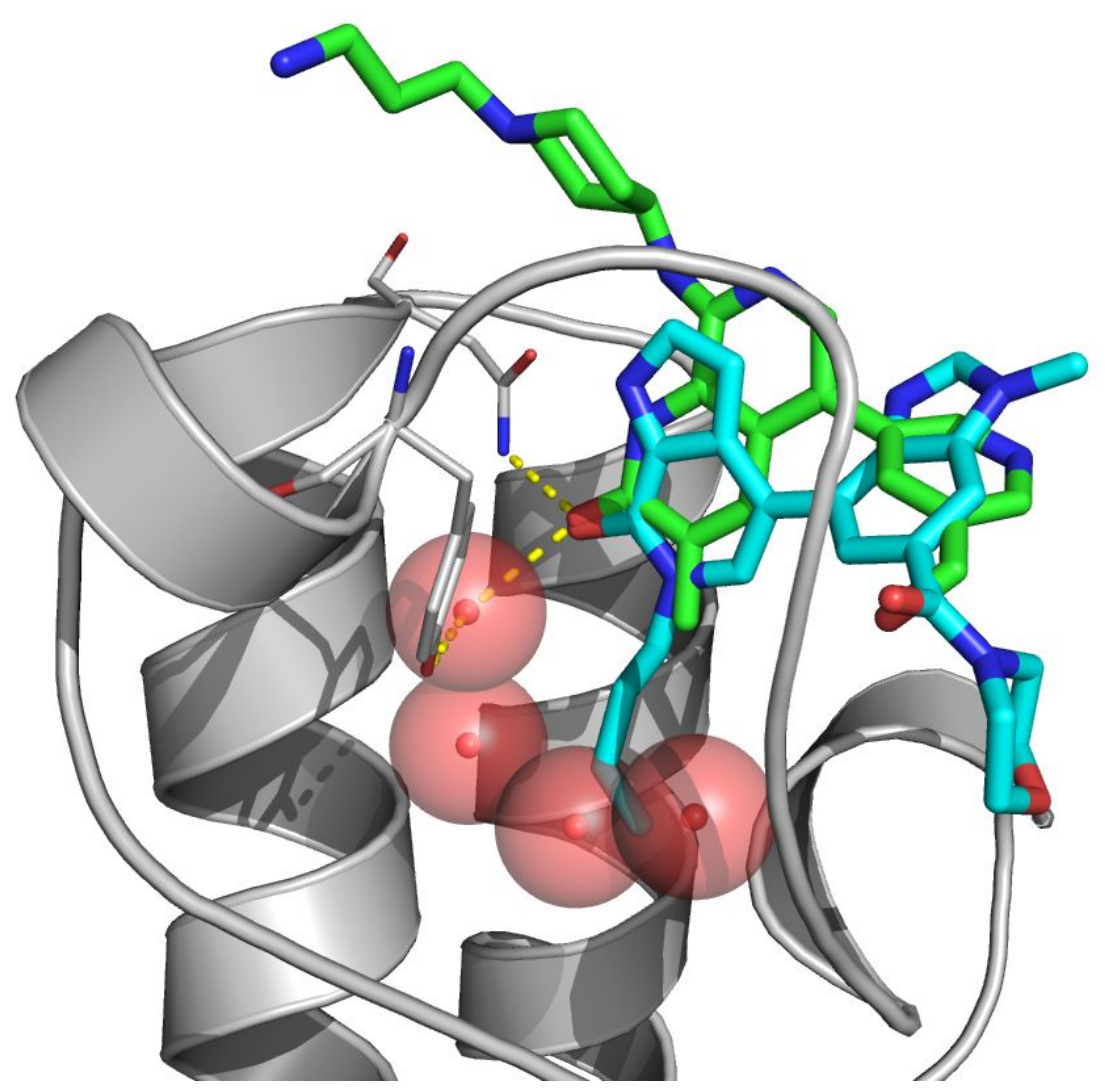

Figure S1. Overlay of GNE-371 (blue) with compound 18 (green) bound to TAF1(2) (grey) to compare the position of the acetyl lysine methyl mimetics. ${ }^{1}$ PDB code 6DF7 utilized for GNE-371 and TAF1(2) protein, compound 18 taken from PDB code 7P4S. 


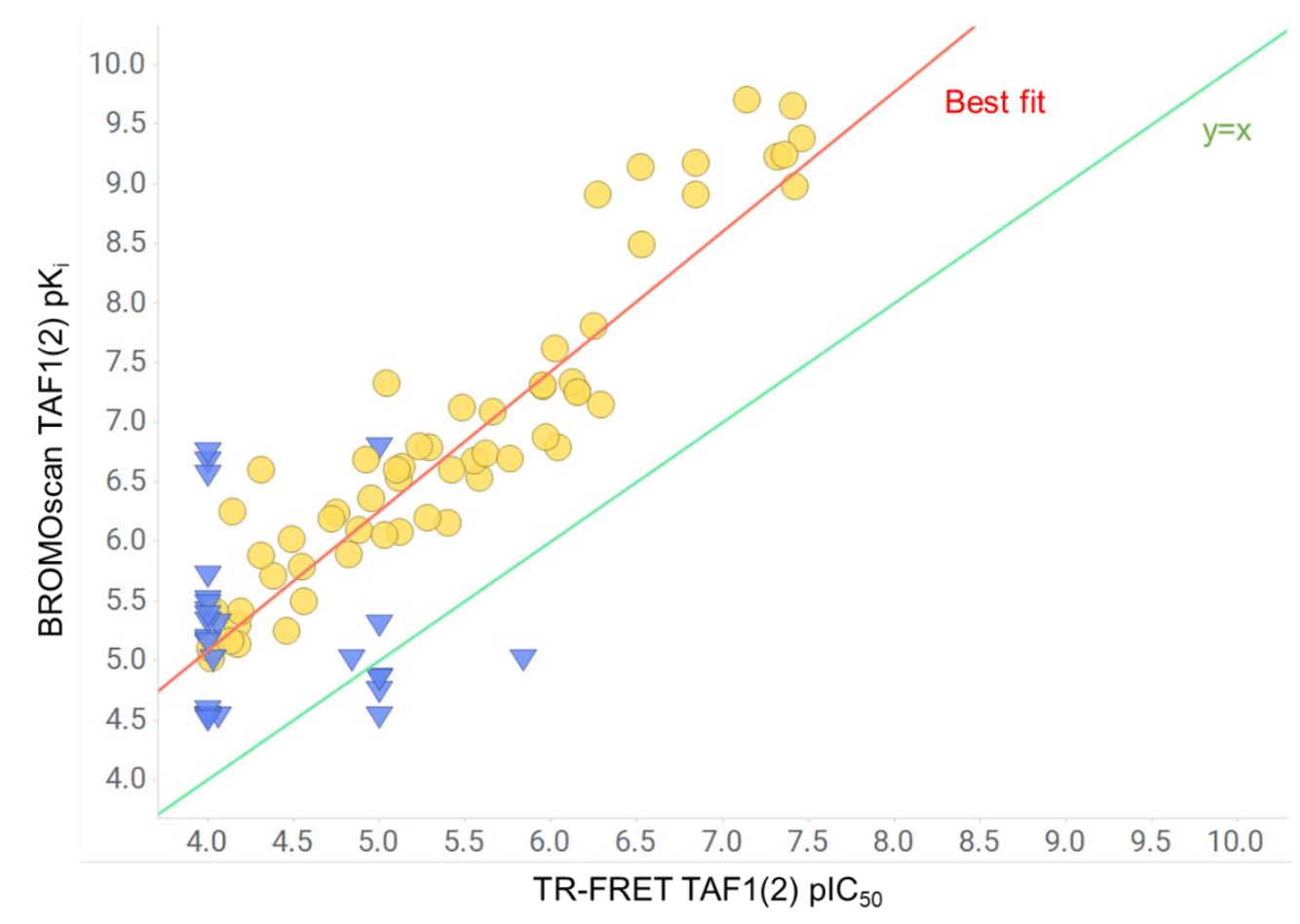

Figure S2. Correlation of 88 unrelated compounds with TAF1(2) TR-FRET and BROMOscan data. Blue triangles indicate " $<$ " values and the line of unity is green. The best fit line in red has an $R^{2}=0.76$ and an equation BROMOscan TAF1(2) pKi $=0.39+(1.17 \times$ TR-FRET TAF1(2) plC 50$)$. 


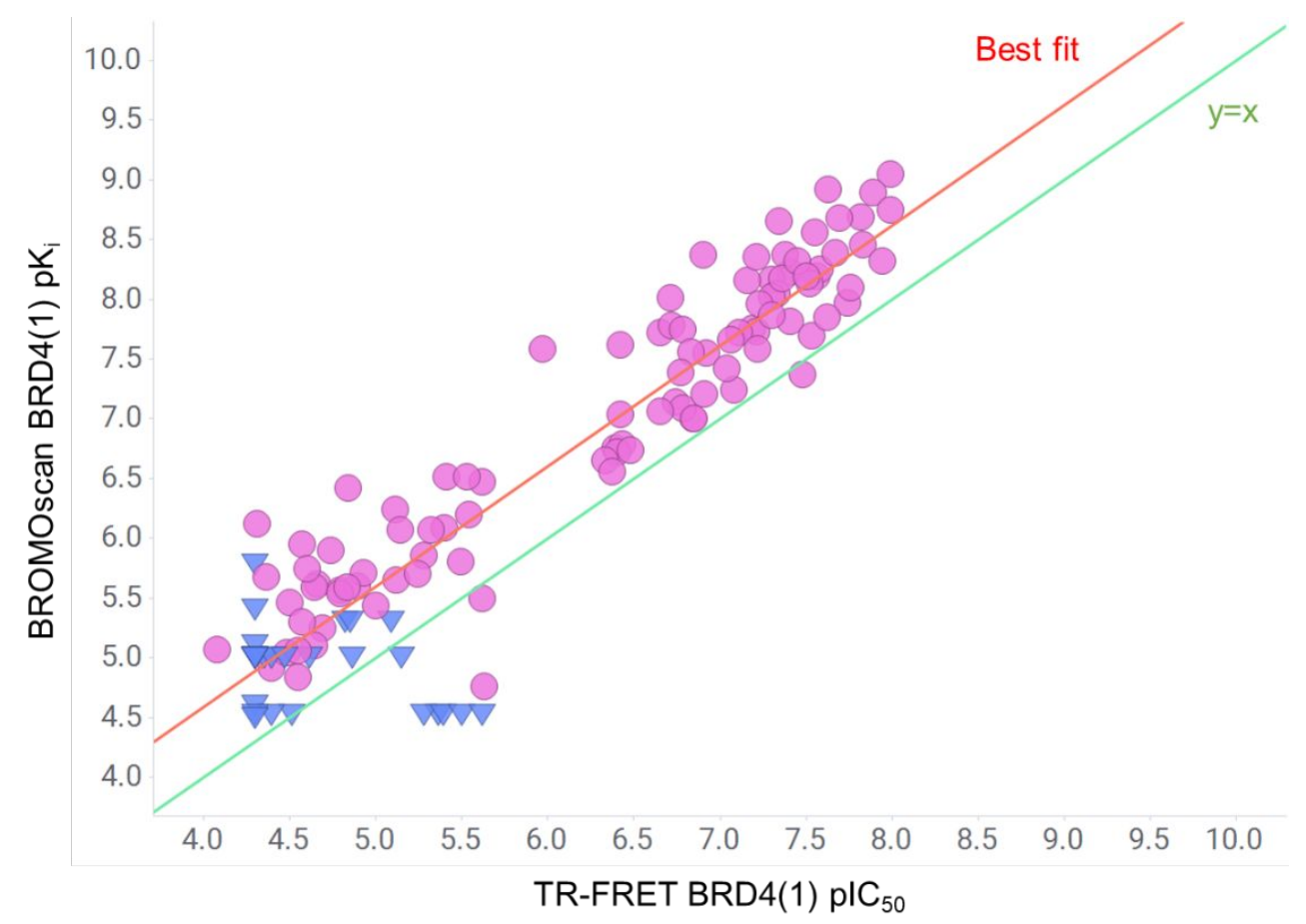

Figure S3. Correlation of 128 unrelated compounds with BRD4(1) TR-FRET and BROMOscan data. Blue triangles indicate " $<$ " values and the line of unity is green. The best fit line in red has an $R^{2}=0.87$ and an equation BROMOscan BRD4(1) $\mathrm{pK}_{\mathrm{i}}=0.56+\left(1.01 \times \mathrm{TR}-\mathrm{FRET}\right.$ BRD4(1) $\left.\mathrm{pIC}_{50}\right)$.

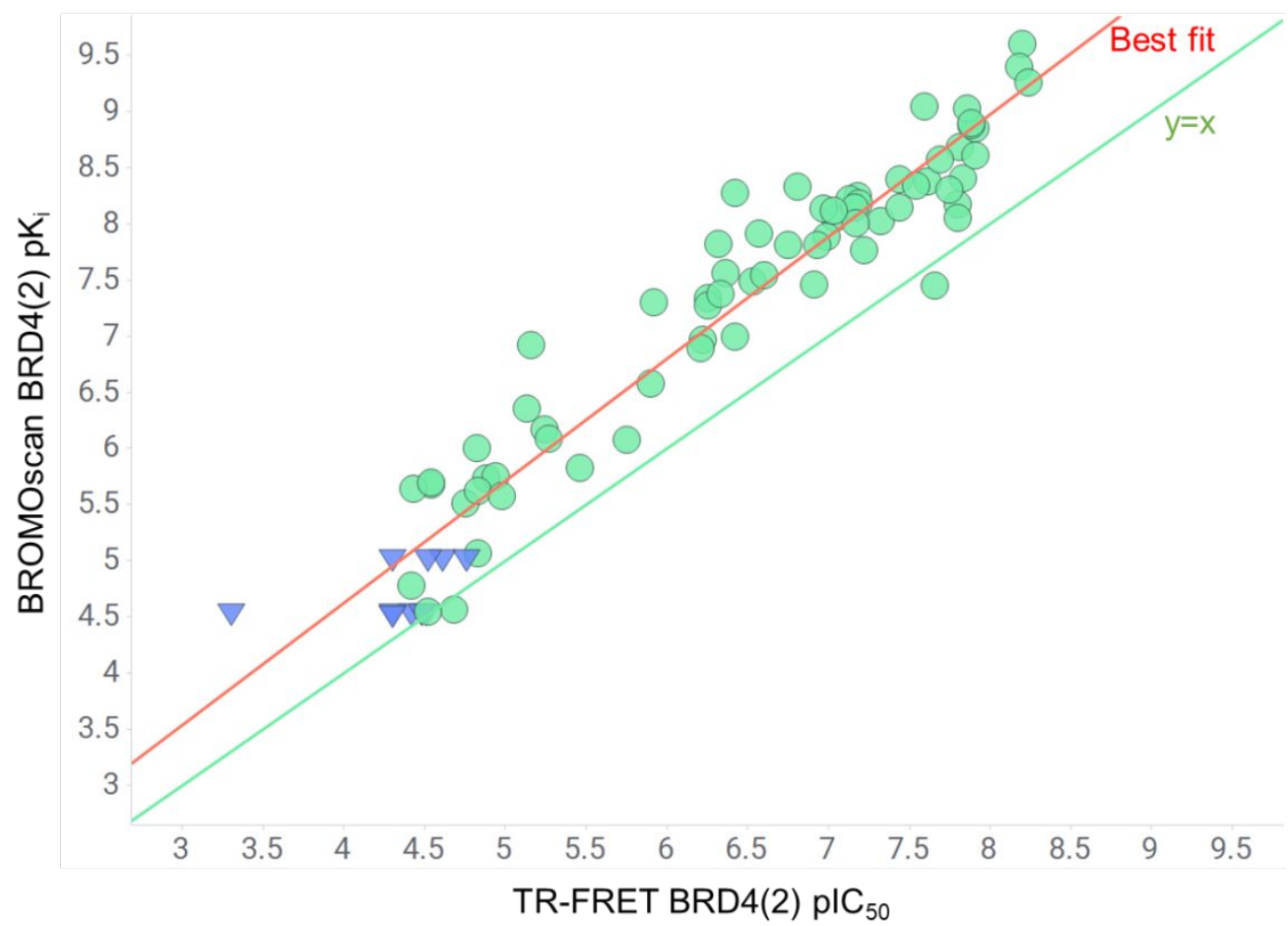

Figure S4. Correlation of 78 unrelated compounds with BRD4(2) TR-FRET and BROMOscan data. Blue triangles indicate " $<$ " values and the line of unity is green. The best fit line in red has an $R^{2}=0.92$ and an equation BROMOscan BRD4(2) pKi $=0.28+(1.09 \times$ TR-FRET BRD4(2) pIC 50 ). 


\section{General Experimental}

All solvents were purchased from Sigma Aldrich and commercially available reagents were used as received. All reactions were followed by TLC analysis (TLC plates GF254, Merck) or LCMS (liquid chromatography mass spectrometry) using a Waters ZQ instrument.

NMR spectra were recorded at ambient temperature unless otherwise stated using standard pulse methods on any of the following spectrometers and signal frequencies: Bruker $\mathrm{AV}-400\left({ }^{1} \mathrm{H}=400 \mathrm{MHz},{ }^{13} \mathrm{C}=100.6 \mathrm{MHz}\right)$, Bruker AV-500 $\left({ }^{1} \mathrm{H}=500 \mathrm{MHz},{ }^{13} \mathrm{C}=125.8 \mathrm{MHz}\right)$, Bruker AVII+ $600\left({ }^{1} \mathrm{H}=600 \mathrm{MHz},{ }^{13} \mathrm{C}=150.9 \mathrm{MHz}\right)$. Chemical shifts are reported in ppm and are referenced to tetramethylsilane (TMS) or the following solvent peaks: $\mathrm{CDCl}_{3}$ $\left({ }^{1} \mathrm{H}=7.27 \mathrm{ppm},{ }^{13} \mathrm{C}=77.00 \mathrm{ppm}\right)$, DMSO- $d_{6}\left({ }^{1} \mathrm{H}=2.50 \mathrm{ppm},{ }^{13} \mathrm{C}=39.51 \mathrm{ppm}\right)$ and $\mathrm{CD}_{3} \mathrm{OD}\left({ }^{1} \mathrm{H}=3.31 \mathrm{ppm},{ }^{13} \mathrm{C}=\right.$ $49.15 \mathrm{ppm}$ ). Coupling constants are quoted to the nearest $0.1 \mathrm{~Hz}$ and multiplicities are given by the following abbreviations and combinations thereof: $s$ (singlet), $d$ (doublet), $t$ (triplet), q (quartet), $m$ (multiplet), br (broad). Column chromatography was performed on pre-packed silica gel columns using a Biotage SP4, Biotage Isolera or Teledyne ISCO CombiFlash instrument.

High resolution mass spectra (HRMS) were recorded on a Micromass Q-Tof Ultima hybrid quadrupole time-offlight mass spectrometer, with analytes separated on an Agilent 1100 Liquid Chromatograph equipped with a Phenomenex Luna C18(2) reversed phase column (100 mm x $2.1 \mathrm{~mm}, 3 \mu \mathrm{m}$ packing diameter). LC conditions were $0.5 \mathrm{~mL} / \mathrm{min}$ flow rate, $35^{\circ} \mathrm{C}$, injection volume $2-5 \mu \mathrm{L}$. Gradient elution with $(\mathrm{A}) \mathrm{H}_{2} \mathrm{O}$ containing $0.1 \%(\mathrm{v} / \mathrm{v})$ formic acid and (B) acetonitrile containing $0.1 \%(\mathrm{v} / \mathrm{v})$ formic acid. Gradient conditions were initially $5 \% \mathrm{~B}$, increasing linearly to $100 \%$ B over 6 min, remaining at $100 \%$ B for 2.5 min then decreasing linearly to $5 \%$ B over $1 \mathrm{~min}$ followed by an equilibration period of $2.5 \mathrm{~min}$ prior to the next injection.

LCMS analysis was carried out on a Waters Acquity UPLC instrument equipped with a BEH column (50 mm x 2.1 $\mathrm{mm}, 1.7 \mu \mathrm{m}$ packing diameter) and Waters micromass ZQ MS using alternate-scan positive and negative electrospray. Analytes were detected as a summed UV wavelength of $210-350 \mathrm{~nm}$. Three liquid phase methods were used:

Formic $-40{ }^{\circ} \mathrm{C}, 1 \mathrm{~mL} / \mathrm{min}$ flow rate. Gradient elution with the mobile phases as $(\mathrm{A}) \mathrm{H}_{2} \mathrm{O}$ containing $0.1 \%$ volume/volume (v/v) formic acid and (B) acetonitrile containing $0.1 \%(\mathrm{v} / \mathrm{v})$ formic acid. Gradient conditions were initially $1 \%$ B, increasing linearly to $97 \%$ B over $1.5 \mathrm{~min}$, remaining at $97 \%$ B for 0.4 min then increasing to $100 \%$ B over $0.1 \mathrm{~min}$.

High $\mathrm{pH}-40^{\circ} \mathrm{C}, 1 \mathrm{~mL} / \mathrm{min}$ flow rate. Gradient elution with the mobile phases as (A) $10 \mathrm{mM}$ aqueous ammonium bicarbonate solution, adjusted to $\mathrm{pH} 10$ with $0.88 \mathrm{M}$ aqueous ammonia and (B) acetonitrile. Gradient conditions were initially $1 \%$ B, increasing linearly to $97 \%$ B over $1.5 \mathrm{~min}$, remaining at $97 \%$ B for 0.4 min then increasing to $100 \%$ B over $0.1 \mathrm{~min}$.

TFA $-40{ }^{\circ} \mathrm{C}, 1 \mathrm{~mL} / \mathrm{min}$ flow rate. Gradient elution with the mobile phases as $(A) \mathrm{H}_{2} \mathrm{O}$ containing $0.1 \%$ volume/volume (v/v) TFA and (B) acetonitrile containing $0.1 \%(v / v)$ TFA. Gradient conditions were initially $1 \%$, increasing linearly to $97 \%$ B over 1.5 min, remaining at $97 \%$ B for 0.4 min then increasing to $100 \%$ B over 0.1 $\min$.

Mass-directed automatic purification (MDAP) was carried out using a Waters ZQ MS using alternate-scan positive and negative electrospray and a summed UV wavelength of $210-350 \mathrm{~nm}$. Two liquid phase methods were used:

Formic - Sunfire C18 column (100 mm x $19 \mathrm{~mm}, 5 \mu \mathrm{m}$ packing diameter, $20 \mathrm{~mL} / \mathrm{min}$ flow rate) or Sunfire C18 column (150 mm x $30 \mathrm{~mm}, 5 \mu \mathrm{m}$ packing diameter, $40 \mathrm{~mL} / \mathrm{min}$ flow rate). Gradient elution at ambient temperature with the mobile phases as (A) $\mathrm{H}_{2} \mathrm{O}$ containing $0.1 \%$ volume/volume $(\mathrm{v} / \mathrm{v})$ formic acid and (B) acetonitrile containing $0.1 \%(\mathrm{v} / \mathrm{v})$ formic acid.

High pH - Xbridge C18 column (100 mm x $19 \mathrm{~mm}, 5 \mu \mathrm{m}$ packing diameter, $20 \mathrm{~mL} / \mathrm{min}$ flow rate) or Xbridge C18 column (150 mm x $30 \mathrm{~mm}, 5 \mu \mathrm{m}$ packing diameter, $40 \mathrm{~mL} / \mathrm{min}$ flow rate). Gradient elution at ambient temperature with the mobile phases as $(A) 10 \mathrm{mM}$ aqueous ammonium bicarbonate solution, adjusted to $\mathrm{pH} 10$ with $0.88 \mathrm{M}$ aqueous ammonia and $(\mathrm{B})$ acetonitrile.

Melting point analysis was carried out using Buchi M-565 melting point apparatus. Melting points are uncorrected.

IR spectra were obtained on a Perkin Elmer Spectrum 1 FTIR apparatus, with major peaks reported 


\section{Synthetic Procedures}

All compounds for biological test had a minimum purity of at least $90 \%$, apart from compound 10 which was $87 \%$ pure.

The synthesis of compound $\mathbf{8}$ has been described previously. ${ }^{2}$

General Procedure A<smiles>CCOc1ncc(-c2cncc(C)c2)c2nc(OCc3ccccc3)c(C)cc12</smiles><smiles>[R]c1ncc(-c2cncc(C)c2)c2cc(C)c(=O)[nH]c12</smiles>

A mixture of 36 (100 mg, $0.20 \mathrm{mmol})$, amine $(0.60 \mathrm{mmol}, 3$ eq.) and DIPEA (0.07 mL, $0.40 \mathrm{mmol}, 2$ eq.) in MeCN $(1.5 \mathrm{~mL})$ was heated at $140^{\circ} \mathrm{C}$ for $1 \mathrm{~h}$. The reaction mixture was allowed to cool to rt and concentrated in vacuo. The resulting residue was dissolved in TFA ( $2 \mathrm{~mL}, 128$ eq.) and heated at $100{ }^{\circ} \mathrm{C}$ for $0.5 \mathrm{~h}$. The reaction mixture was concentrated in vacuo and the resulting residue was dissolved in $\mathrm{MeOH}(5 \mathrm{~mL})$ and passed through a preconditioned $(\mathrm{MeOH}, 5 \mathrm{~mL})$ amino propyl column $(2 \mathrm{~g})$. The filtrate was concentrated in vacuo and the resulting residue was purified by MDAP (high $\mathrm{pH}$ ). The appropriate fractions were combined, and solvent evaporated in vacuo to the desired product.

tert-Butyl 4-((5-(5-(hydroxymethyl)pyridin-3-yl)-3-methyl-2-oxo-1,2-dihydro-1,7-naphthyridin-8yl)amino)piperidine-1-carboxylate (28)<smiles>Cc1cc2c(-c3cncc(CO)c3)cnc(NC3CCN(C(=O)O)CC3)c2[nH]c1=O</smiles>

To a $20 \mathrm{ml}$ microwave vial was added potassium carbonate $(632 \mathrm{mg}, 4.57 \mathrm{mmol})$, diacetoxypalladium (25.7 $\mathrm{mg}$, $0.114 \mathrm{mmol}),(5-($ hydroxymethyl)pyridin-3-yl)boronic acid² $(350 \mathrm{mg}, 2.287 \mathrm{mmol})$, tert-butyl 4-((5-bromo-3methyl-2-oxo-1,2-dihydro-1,7-naphthyridin-8-yl)amino)piperidine-1-carboxylate ${ }^{2}(500 \mathrm{mg}, 1.143 \mathrm{mmol})$, $\operatorname{di}\left((3 \mathrm{~S}, 5 \mathrm{~S}, 7 \mathrm{~S})\right.$-adamantan-1-yl)(butyl)phosphine (cataCXium $\left.\mathrm{A}^{\circledR}\right)(41 \mathrm{mg}, 0.114 \mathrm{mmol}), 1,4$-dioxane (12 mL), and $\mathrm{H}_{2} \mathrm{O}(6 \mathrm{~mL})$. The reaction mixture was stirred and degassed for 20 min with $\mathrm{N}_{2}$. The reaction vessel was sealed and heated by microwave heating to $100{ }^{\circ} \mathrm{C}$ for $1 \mathrm{~h}$. This process was repeated 6 more times. The reaction mixtures were combined and concentrated under reduced pressure. The residue was partitioned between $\mathrm{CH}_{2} \mathrm{Cl}_{2}$ and $\mathrm{H}_{2} \mathrm{O}$, the organic layer was dried using $\mathrm{MgSO}_{4}$ and then passed through a filter under reduced pressure. The residue $(4.47 \mathrm{~g}$ ) was split into half and each half loaded onto a $100 \mathrm{~g}$ SNAP (Si) cartridge, purified by column chromatography, eluting with $0 \%-20 \% \mathrm{MeOH} / \mathrm{CH}_{2} \mathrm{Cl}_{2}$. The appropriate fractions were combined from both columns and evaporated in vacuo to give $28(2.56 \mathrm{~g}, 5.50 \mathrm{mmol}, 69 \%)$. ${ }^{1} \mathrm{H}$ NMR $\left(400 \mathrm{MHz}, \mathrm{DMSO}-\mathrm{d}_{6}\right) \delta \mathrm{ppm}$ $11.46(\mathrm{~s}, 1 \mathrm{H}), 8.57(\mathrm{~d}, J=2.0,1 \mathrm{H}), 8.46(\mathrm{~d}, J=2.5,1 \mathrm{H}), 7.74-7.71(\mathrm{~m}, 2 \mathrm{H}), 7.52(\mathrm{br} . \mathrm{s}, 1 \mathrm{H}), 6.90(\mathrm{~d}, J=6.4,1 \mathrm{H})$, $5.37(\mathrm{t}, J=5.6,1 \mathrm{H}), 4.63(\mathrm{~d}, J=5.9,2 \mathrm{H}), 4.23-4.20(\mathrm{~m}, 1 \mathrm{H}), 3.94-3.91(\mathrm{~m}, 2 \mathrm{H}), 2.98(\mathrm{br} . \mathrm{s}, 2 \mathrm{H}), 2.08(\mathrm{~s}, 3 \mathrm{H}), 2.02-$ $1.98(\mathrm{~m}, 2 \mathrm{H}), 1.43-1.35(\mathrm{~m}, 10 \mathrm{H})$; LCMS (high pH): $\mathrm{R}_{\mathrm{t}}=0.83 \mathrm{~min}(100 \%)$, LRMS $(\mathrm{M}+\mathrm{H})^{+}$calculated for $\mathrm{C}_{25} \mathrm{H}_{32} \mathrm{~N}_{5} \mathrm{O}_{4}$ 466.2; found 466.4 .

tert-Butyl 4-((5-(5-((carbamoyloxy)methyl)pyridin-3-yl)-3-methyl-2-oxo-1,2-dihydro-1,7-naphthyridin-8yl)amino)piperidine-1-carboxylate (29)<smiles>Cc1cc2c(-c3cncc(COC(N)=O)c3)cnc(NC3CCN(C(C)(C)C)CC3)c2[nH]c1=O</smiles>

Phenyl chloroformate $(0.210 \mathrm{~mL}, 1.675 \mathrm{mmol})$ was added to a solution of $28(0.600 \mathrm{~g}, 1.289 \mathrm{mmol})$ in $\mathrm{CH}_{2} \mathrm{Cl}_{2}$ $(10 \mathrm{~mL})$ and pyridine $(0.208 \mathrm{~mL}, 2.58 \mathrm{mmol})$ at $0{ }^{\circ} \mathrm{C}$. The solution was stirred at the same temp for $2 \mathrm{~h}$, then 
washed with saturated ammonium chloride solution $(10 \mathrm{~mL})$ and the organic layer dried and evaporated in vacuo to give a yellow solid. Ammonium hydroxide $(0.072 \mathrm{~mL}, 1.289 \mathrm{mmol})$ was then added to a solution of the yellow solid in $\mathrm{CH}_{2} \mathrm{Cl}_{2}(10 \mathrm{~mL})$ and DMF $(10 \mathrm{~mL})$ and stirred overnight. The mixture was partitioned between $\mathrm{CH}_{2} \mathrm{Cl}_{2}(20$ $\mathrm{mL})$ and $\mathrm{H}_{2} \mathrm{O}(20 \mathrm{~mL})$, the organic layer was dried through hydrophobic frit and concentrated under reduced pressure. The residue was loaded onto a $25 \mathrm{~g}$ SNAP (Si) cartridge and purified by column chromatography, eluting with $0-10 \% 2 \mathrm{M}$ methanolic ammonia in $\mathrm{CH}_{2} \mathrm{Cl}_{2}$. The appropriate fractions were combined and evaporated in vacuo to give 29 (414 mg, $0.814 \mathrm{mmol}, 63 \%)$. ${ }^{1} \mathrm{H}$ NMR (400 MHz, DMSO-d 6 ) $\delta$ ppm 11.46 (br.s, $1 \mathrm{H}), 8.61(\mathrm{~d}, J=2.0,1 \mathrm{H}), 8.54(\mathrm{~d}, J=2.0,1 \mathrm{H}), 7.78-7.75(\mathrm{~m}, 2 \mathrm{H}), 7.51(\mathrm{br} . \mathrm{s}, 1 \mathrm{H}), 6.92-6.62(\mathrm{~m}, 3 \mathrm{H}), 5.11(\mathrm{~s}, 2 \mathrm{H})$, 4.25-2.20 (m, 2H), 3.94--3.91 (m, 2H), 3.03-2.98 (m, 2H), $2.09(\mathrm{~s}, 2 \mathrm{H}), 2.03-1.99(\mathrm{~m}, 2 \mathrm{H}), 1.43-1.36(\mathrm{~m}, 10 \mathrm{H})$; LCMS (high pH): $\mathrm{R}_{t}=0.87$ min (95\%), LRMS $(M+H)^{+}$calculated for $\mathrm{C}_{26} \mathrm{H}_{33} \mathrm{~N}_{6} \mathrm{O}_{5}$ 509.3; found 509.3.

(5-(3-Methyl-2-oxo-8-(piperidin-4-ylamino)-1,2-dihydro-1,7-naphthyridin-5-yl)pyridin-3-yl)methyl carbamate (7)<smiles>Cc1cc2c(-c3cncc(COC(N)=O)c3)cnc(NC3CCNCC3)c2[nH]c1=O</smiles>

To a stirred solution of 29 (414 mg, $0.814 \mathrm{mmol})$ in $\mathrm{CH}_{2} \mathrm{Cl}_{2}(20 \mathrm{~mL})$ at rt was added $\mathrm{HCl}(4 \mathrm{M}$ in 1,4-dioxane) (4 $\mathrm{mL}, 132 \mathrm{mmol})$. The mixture was stirred at $\mathrm{rt}$ for $30 \mathrm{~min}$. A $5 \mathrm{~g}$ Flash SCX SPE column was pre-equilibriated with $\mathrm{MeOH}(1 \mathrm{CV})$, then the crude product was loaded in $\mathrm{MeOH}$. The column was flushed with $\mathrm{MeOH}(3 \mathrm{CV})$ then with $2 \mathrm{M}$ methanolic ammonia ( $3 \mathrm{CV}$ ). The appropriate fractions were collected and solvent removed in vacuo to give 7 (360 mg, $0.793 \mathrm{mmol}, 97 \%) .{ }^{1} \mathrm{H}$ NMR (400 MHz, DMSO-d 6 ) $\delta \mathrm{ppm} 8.60(\mathrm{~d}, \mathrm{~J}=2.0,1 \mathrm{H}), 8.54(\mathrm{~d}, \mathrm{~J}=2.5,1 \mathrm{H})$, 7.78-7.72 (m, 2H), $7.51(\mathrm{~s}, 1 \mathrm{H}), 6.90-6.61(\mathrm{~m}, 3 \mathrm{H}), 5.11(\mathrm{~s}, 2 \mathrm{H}), 4.09-4.04(\mathrm{~m}, 2 \mathrm{H}), 3.17(\mathrm{~s}, 2 \mathrm{H}), 3.01-2.98(\mathrm{~m}$, $2 \mathrm{H}), 2.59-2.54(\mathrm{~m}, 2 \mathrm{H}), 2.09(\mathrm{~s}, 3 \mathrm{H}), 1.97-1.94(\mathrm{~m}, 2 \mathrm{H}), 1.42-1.32(\mathrm{~m}, 1 \mathrm{H}) ; \mathrm{LCMS}($ high $\mathrm{pH}): \mathrm{R}_{\mathrm{t}}=0.39 \mathrm{~min}(100 \%)$, LRMS $(\mathrm{M}+\mathrm{H})^{+}$calculated for $\mathrm{C}_{21} \mathrm{H}_{25} \mathrm{~N}_{6} \mathrm{O}_{3} 409.2$; found 409.3 .

\section{2-(Benzyloxy)-3-methyl-N-(1-methylpiperidin-4-yl)-1,7-naphthyridin-8-amine (30)}<smiles>Cc1cc2ccnc(NC3CCN(C)CC3)c2nc1OCc1ccccc1</smiles>

1-methylpiperidin-4-amine $(0.40 \mathrm{~mL}, 3.16 \mathrm{mmol})$ was added to a mixture of 2-(benzyloxy)-8-chloro-3-methyl1,7-naphthyridine (25) $)^{2}(600 \mathrm{mg}, 2.11 \mathrm{mmol}), \mathrm{Pd}_{2}(\mathrm{dba})_{3}(154 \mathrm{mg}, 0.17 \mathrm{mmol})$, BrettPhos (113 mg, $\left.0.21 \mathrm{mmol}\right)$, and $\mathrm{NaO}^{t} \mathrm{Bu}(810 \mathrm{mg}, 8.43 \mathrm{mmol})$ in THF $(10 \mathrm{~mL})$. The reaction mixture was heated at $60^{\circ} \mathrm{C}$ for $4 \mathrm{~h}$. The reaction mixture was concentrated in vacuo and the resulting residue was diluted with DCM $(100 \mathrm{~mL})$ and washed with $\mathrm{H}_{2} \mathrm{O}(100 \mathrm{~mL})$. The separated organic layer was passed through a hydrophobic frit and concentrated in vacuo. The resulting residue was purified by silica gel chromatography (0-60\% EtOAc in cyclohexane). The appropriate fractions were combined and solvent evaporated in vacuo to give $\mathbf{3 0}$ (688 mg, $1.90 \mathrm{mmol}, 90 \%$ ) as a orange oil; $v_{\max }$ (thin film) $/ \mathrm{cm}^{-1}: 1500,1310,1250,742 ;{ }^{1} \mathrm{H}$ NMR $\left(400 \mathrm{MHz}, \mathrm{CD}_{3} \mathrm{OD}\right) \delta \mathrm{ppm}$ 7.77-7.74 (m, $\left.1 \mathrm{H}\right), 7.69$ (d, J = 5.9, $1 \mathrm{H}), 7.52-7.47(\mathrm{~m}, 2 \mathrm{H}), 7.41-7.35(\mathrm{~m}, 2 \mathrm{H}), 7.33-7.27(\mathrm{~m}, 1 \mathrm{H}), 6.77(\mathrm{~d}, J=5.9,1 \mathrm{H}), 5.53(\mathrm{~s}, 2 \mathrm{H}), 4.02-3.92(\mathrm{~m}$, $1 \mathrm{H}), 2.98-2.86(\mathrm{~m}, 2 \mathrm{H}), 2.38-2.24(\mathrm{~m}, 8 \mathrm{H}), 2.15-2.03(\mathrm{~m}, 2 \mathrm{H}), 1.74-1.62(\mathrm{~m}, 2 \mathrm{H}) ;{ }^{13} \mathrm{C} \mathrm{NMR}\left(101 \mathrm{MHz}, \mathrm{CD}_{3} \mathrm{OD}\right)$ $\delta$ ppm 161.4, 155.3, 140.2, 139.1, 137.6, 131.0, 129.7, 129.6, 128.9, 128.7, 128.6, 109.4, 69.4, 55.6, 48.0, 46.3, 32.9, 16.7; HRMS (M + H) ${ }^{+}$calculated for $\mathrm{C}_{22} \mathrm{H}_{27} \mathrm{~N}_{4} \mathrm{O}$ 363.2179; found 363.2190; LCMS (formic acid): $\mathrm{R}_{\mathrm{t}}=0.56 \mathrm{~min}$ (100\%), LRMS $(\mathrm{M}+\mathrm{H})^{+}$calculated for $\mathrm{C}_{22} \mathrm{H}_{27} \mathrm{~N}_{4} \mathrm{O} 363.2$; found 363.1 .

\section{2-(Benzyloxy)-5-bromo-3-methyl-N-(1-methylpiperidin-4-yl)-1,7-naphthyridin-8-amine (31)}<smiles>Cc1cc2c(Br)cnc(NC3CCN(C)CC3)c2nc1OCc1ccccc1</smiles>

NBS (194 mg, $1.10 \mathrm{mmol}$ ) was added to a solution of 30 (395 mg, $1.10 \mathrm{mmol}$ ) in THF (5 mL) and the mixture was stirred at $\mathrm{rt}$ for $4 \mathrm{~h}$. The reaction mixture was concentrated in vacuo. The resulting residue was dissolved in DCM $(30 \mathrm{~mL})$ and washed with $\mathrm{H}_{2} \mathrm{O}(50 \mathrm{~mL})$. The organic phase was separated and the aqueous washed with DCM (3 
$\times 50 \mathrm{~mL}$ ). The combined organic layers were passed through a hydrophobic frit and concentrated in vacuo. The resulting residue was purified by silica gel chromatography (0-100\% EtOH and EtOAc). The appropriate fractions were combined and solvent evaporated in vacuo to give $31(234 \mathrm{mg}, 0.53 \mathrm{mmol}, 49 \%)$ as an orange oil. ${ }^{1} \mathrm{H}$ NMR $\left(400 \mathrm{MHz}, \mathrm{CDCl}_{3}\right) \delta \mathrm{ppm} 7.99(\mathrm{~s}, 1 \mathrm{H}), 7.95(\mathrm{~d}, J=1.0,1 \mathrm{H}), 7.52-7.48(\mathrm{~m}, 2 \mathrm{H}), 7.46-7.39(\mathrm{~m}, 2 \mathrm{H}), 7.37-7.31(\mathrm{~m}$, $1 \mathrm{H}), 6.20(\mathrm{~d}, J=8.1,1 \mathrm{H}), 5.52(\mathrm{~s}, 2 \mathrm{H}), 4.19-4.07(\mathrm{~m}, 1 \mathrm{H}), 3.20-3.09(\mathrm{~m}, 2 \mathrm{H}), 2.54-2.47(\mathrm{~m}, 5 \mathrm{H}), 2.44(\mathrm{~d}, J=1.0$, $3 \mathrm{H}), 2.24-2.17(\mathrm{~m}, 2 \mathrm{H}), 1.93-1.83(\mathrm{~m}, 2 \mathrm{H})$; LCMS (formic acid): $\mathrm{R}_{\mathrm{t}}=0.90 \mathrm{~min}(98 \%), \mathrm{LRMS}(\mathrm{M}+\mathrm{H})^{+}$calculated for $\mathrm{C}_{22} \mathrm{H}_{26} \mathrm{~N}_{4} \mathrm{OBr}$ 441.1; found 441.1, 443.1 .

\section{2-(Benzyloxy)-3-methyl-N-(1-methylpiperidin-4-yl)-5-(5-methylpyridin-3-yl)-1,7-naphthyridin-8-amine (32)}<smiles>Cc1cncc(-c2cnc(NC3CCN(C)CC3)c3nc(Cc4ccccc4)c(C)cc23)c1</smiles>

A mixture of 31 (234 mg, $0.53 \mathrm{mmol}$ ), (5-methylpyridin-3-yl)boronic acid (145 mg, $1.06 \mathrm{mmol}), \mathrm{Pd}(\mathrm{OAc})_{2}$ (12 mg, $0.05 \mathrm{mmol})$, cataCXium $A^{\circledR}(19 \mathrm{mg}, 0.05 \mathrm{mmol})$ and $\mathrm{K}_{2} \mathrm{CO}_{3}(147 \mathrm{mg}, 1.06 \mathrm{mmol})$ in 1,4-dioxane $(3 \mathrm{~mL})$ and $\mathrm{H}_{2} \mathrm{O}$ $(1.5 \mathrm{~mL})$ was heated at $100{ }^{\circ} \mathrm{C}$ in a microwave reactor for $1 \mathrm{~h}$. The reaction mixture was allowed to cool to $\mathrm{rt}$, diluted with EtOAc $(20 \mathrm{~mL})$, filtered through Celite ${ }^{\circledR}$ and concentrated in vacuo. The resulting residue was purified by silica gel chromatography $(0-100 \% \mathrm{EtOH}$ and EtOAc). The appropriate fractions were combined and solvent evaporated in vacuo to give $32(116 \mathrm{mg}, 0.26 \mathrm{mmol}, 48 \%)$ as a yellow solid; ${ }^{1} \mathrm{H} \mathrm{NMR}\left(400 \mathrm{MHz}, \mathrm{CD}_{3} \mathrm{OD}\right)$ $\delta$ ppm $8.41(\mathrm{~s}, 1 \mathrm{H}), 8.37(\mathrm{~s}, 1 \mathrm{H}), 7.73-7.69(\mathrm{~m}, 2 \mathrm{H}), 7.68-7.65(\mathrm{~m}, 1 \mathrm{H}), 7.53-7.48(\mathrm{~m}, 2 \mathrm{H}), 7.42-7.34(\mathrm{~m}, 2 \mathrm{H})$, 7.33-7.27 (m, 1H), $5.57(\mathrm{~s}, 2 \mathrm{H}), 4.07-3.95(\mathrm{~m}, 1 \mathrm{H}), 2.96-2.88(\mathrm{~m}, 2 \mathrm{H}), 2.44(\mathrm{~s}, 3 \mathrm{H}), 2.36-2.23(\mathrm{~m}, 8 \mathrm{H}), 2.16-2.08$ $(\mathrm{m}, 2 \mathrm{H}), 1.79-1.66(\mathrm{~m}, 2 \mathrm{H})$; LCMS (formic acid): $\mathrm{R}_{\mathrm{t}}=0.62 \mathrm{~min}(96 \%)$, LRMS $(\mathrm{M}+\mathrm{H})^{+}$calculated for $\mathrm{C}_{28} \mathrm{H}_{32} \mathrm{~N}_{5} \mathrm{O}$ 454.3; found 454.2.

3-Methyl-8-((1-methylpiperidin-4-yl)amino)-5-(5-methylpyridin-3-yl)-1,7-naphthyridin-2(1H)-one (9)<smiles>Cc1cncc(-c2cnc(NC3CCN(C)CC3)c3[nH]c(=O)c(C)cc23)c1</smiles>

32 (116 mg, $0.26 \mathrm{mmol}$ ) was dissolved in TFA ( $3 \mathrm{~mL}, 38.90 \mathrm{mmol})$ and left to stir at $80^{\circ} \mathrm{C}$ for $3 \mathrm{~h}$. The volatile components were removed in vacuo. Toluene $(5 \mathrm{~mL})$ was added and the solvent evaporated in vacuo $(\times 3)$. The resulting residue was dissolved in $\mathrm{MeOH}(10 \mathrm{~mL})$ and passed through a preconditioned $(\mathrm{MeOH}, 10 \mathrm{~mL})$ amino propyl column $(5 \mathrm{~g})$. The appropriate fractions were combined and solvent evaporated in vacuo. The resulting residue was purified by MDAP (high $\mathrm{pH}$ ). The appropriate fractions were combined and solvent evaporated in vacuo to give 9 (65 mg, $0.18 \mathrm{mmol}, 70 \%$ ) as a yellow solid; m.p. $262-265^{\circ} \mathrm{C}$ (decomp.); $v_{\max }(\mathrm{solid}) / \mathrm{cm}^{-1}: 3392$, 2926, 1660 (C=O), 1695, 1445, 860, 723; ${ }^{1} \mathrm{H}$ NMR (400 MHz, DMSO-d 6 ) $\delta$ ppm 11.47 (br.s, $\left.1 \mathrm{H}\right), 8.44$ (d, $J=1.7$, $1 \mathrm{H}), 8.36(\mathrm{~d}, J=1.7,1 \mathrm{H}), 7.71(\mathrm{~s}, 1 \mathrm{H}), 7.62(\mathrm{~s}, 1 \mathrm{H}), 7.51(\mathrm{~d}, J=1.2,1 \mathrm{H}), 6.84(\mathrm{~d}, J=6.6,1 \mathrm{H}), 4.00-3.91(\mathrm{~m}, 1 \mathrm{H})$, 2.80-2.74 (m, 2H), $2.37(\mathrm{~s}, 3 \mathrm{H}), 2.18(\mathrm{~s}, 3 \mathrm{H}), 2.07(\mathrm{~s}, 3 \mathrm{H}), 2.05-1.94(\mathrm{~m}, 4 \mathrm{H}), 1.59-1.44(\mathrm{~m}, 2 \mathrm{H}) ;{ }^{13} \mathrm{C} \mathrm{NMR}$ (101 MHz, DMSO-d $\left.\mathrm{d}_{6}\right)$ 161.1, 148.7, 147.3, 139.3, 137.7, 133.0, 132.9, 132.0, 121.1, 120.6, 118.1, 54.5, 47.6, 46.2, $31.8,18.0,16.9$; N.B. $2 \mathrm{C}$ signals not visible in spectrum; HRMS $(\mathrm{M}+\mathrm{H})^{+}$calculated for $\mathrm{C}_{21} \mathrm{H}_{26} \mathrm{~N}_{5} \mathrm{O} 364.2138$; found 364.2132; LCMS (formic acid): $\mathrm{R}_{t}=0.35 \mathrm{~min}(100 \%)$, LRMS $(M+\mathrm{H})^{+}$calculated for $\mathrm{C}_{21} \mathrm{H}_{26} \mathrm{~N}_{5} \mathrm{O} 364.2$; found 364.1.

\section{2-(Benzyloxy)-3-methyl-1,7-naphthyridin-8(7H)-one (33)}<smiles>Cc1cc2cc[nH]c(=O)c2nc1OCc1ccccc1</smiles>

$\mathrm{H}_{2} \mathrm{O}(0.25 \mathrm{~mL}, 14.05 \mathrm{mmol})$ was added to a mixture of 2-(benzyloxy)-8-chloro-3-methyl-1,7-naphthyridine (25) ${ }^{2}$ $(2.00 \mathrm{~g}, 7.02 \mathrm{mmol}), \mathrm{Pd}_{2}(\mathrm{dba})_{3}(0.32 \mathrm{~g}, 0.35 \mathrm{mmol})$, BrettPhos $(0.19 \mathrm{~g}, 0.35 \mathrm{mmol})$, and $\mathrm{NaO} \mathrm{Bu}^{\mathrm{B}}(2.70 \mathrm{~g}$, $28.10 \mathrm{mmol})$ in THF $(30 \mathrm{~mL})$. The reaction mixture was stirred at $70{ }^{\circ} \mathrm{C}$ for $2 \mathrm{~h}$. The reaction mixture was concentrated in vacuo and the resulting residue was dissolved in DCM $(50 \mathrm{~mL})$ and washed with $\mathrm{H}_{2} \mathrm{O}(50 \mathrm{~mL})$. The aqueous phase was extracted with DCM $(3 \times 50 \mathrm{~mL})$ and the combined organic layers were passed through 
a hydrophobic frit and concentrated in vacuo. The resulting residue was purified by silica gel chromatography (0-50\% EtOH in EtOAc). The appropriate fractions were combined and solvent evaporated in vacuo to give 33 $(1.71 \mathrm{~g}, 6.42 \mathrm{mmol}, 91 \%)$ as a yellow solid; ${ }^{1} \mathrm{H}$ NMR (400 MHz, DMSO-d 6 ) $\delta$ ppm 11.39 (br.s, 1H), 7.89-7.85 (m, $1 \mathrm{H})$, 7.57-7.52 (m, 2H), 7.42-7.36 (m, 2H), 7.35-7.30 (m, 1H), 7.14-7.09 (m, 1H), $6.44(\mathrm{~d}, J=6.9,1 \mathrm{H}), 5.50(\mathrm{~s}$, $2 \mathrm{H}), 2.31-2.28(\mathrm{~m}, 3 \mathrm{H})$; LCMS (formic acid): $\mathrm{R}_{\mathrm{t}}=0.96 \mathrm{~min}(99 \%)$, LRMS $(\mathrm{M}+\mathrm{H})^{+}$calculated for $\mathrm{C}_{16} \mathrm{H}_{15} \mathrm{~N}_{2} \mathrm{O}_{2} 267.1$; found 267.0 .

\section{2-(Benzyloxy)-5-bromo-3-methyl-1,7-naphthyridin-8(7H)-one (34)}<smiles>Cc1cc2c(Br)c[nH]c(=O)c2nc1OCc1ccccc1</smiles>

NBS (1.77 g, $9.91 \mathrm{mmol})$ was added to a mixture of $33(2.64 \mathrm{~g}, 9.91 \mathrm{mmol})$ in THF $(50 \mathrm{~mL})$. The reaction mixture was left to stir at $\mathrm{rt}$ for $0.5 \mathrm{~h}$. The reaction mixture was concentrated in vacuo and the resulting solid was suspended in $\mathrm{CH}_{2} \mathrm{Cl}_{2}(20 \mathrm{~mL})$, filtered under reduced pressure, washed with $\mathrm{CH}_{2} \mathrm{Cl}_{2}(20 \mathrm{~mL})$ and collected to give 34 (1.97 g, $5.71 \mathrm{mmol}, 58 \%$ ) as an off white solid; m.p. $255-258{ }^{\circ} \mathrm{C}$ (decomp.); $v_{\max }$ (solid)/ $/ \mathrm{cm}^{-1}: 3208(\mathrm{~N}-\mathrm{H}), 1664$ (C=O), 1410, 1080, 728; ${ }^{1} \mathrm{H}$ NMR (400 MHz, DMSO-d 6 ) $\delta$ ppm 11.73 (br.s., $1 \mathrm{H}$ ) 7.91 (d, J = 1.0, 1H) 7.55 (d, $J=7.1$, 2H) $7.48(\mathrm{~s}, 1 \mathrm{H}) 7.36-7.42(\mathrm{~m}, 2 \mathrm{H}) 7.30-7.36(\mathrm{~m}, 1 \mathrm{H}) 5.52(\mathrm{~s}, 2 \mathrm{H}) 2.35(\mathrm{~s}, 3 \mathrm{H}) ;{ }^{13} \mathrm{C}$ NMR $\left(101 \mathrm{MHz}, \mathrm{DMSO}_{-} \mathrm{d}_{6}\right)$ $\delta$ ppm 160.5, 159.2, 137.5, 136.9, 135.9, 128.8, 128.7, 128.3, 128.0, 127.9, 127.8, 95.2, 67.5, 15.9; HRMS (M + H) calculated for $\mathrm{C}_{16} \mathrm{H}_{14} \mathrm{BrN}_{2} \mathrm{O}_{2} 345.0233$; found 345.0244; LCMS (formic acid): $\mathrm{R}_{\mathrm{t}}=1.14 \mathrm{~min}$ (100\%), LRMS (M + $\mathrm{H})^{+}$calculated for $\mathrm{C}_{16} \mathrm{H}_{14} \mathrm{~N}_{2} \mathrm{O}_{2} \mathrm{Br} 345.0$; found 345.1, 347.1.

\section{2-(Benzyloxy)-3-methyl-5-(5-methylpyridin-3-yl)-1,7-naphthyridin-8(7H)-one (35)}<smiles>Cc1cncc(-c2c[nH]c(=O)c3nc(OCc4ccccc4)c(C)cc23)c1</smiles>

A mixture of 34 (1.50 g, $4.35 \mathrm{mmol})$, (5-methylpyridin-3-yl)boronic acid (1.19 g, $8.69 \mathrm{mmol}), \mathrm{Pd}(\mathrm{OAc})_{2}(0.10 \mathrm{~g}$, $0.44 \mathrm{mmol})$, cataCXium $A^{\circledR}(0.16 \mathrm{~g}, 0.44 \mathrm{mmol})$ and $\mathrm{K}_{2} \mathrm{CO}_{3}(1.20 \mathrm{~g}, 8.69 \mathrm{mmol})$ in 1,4-Dioxane $(8 \mathrm{~mL})$ and $\mathrm{H}_{2} \mathrm{O}$ $(4 \mathrm{~mL})$ was heated at $100^{\circ} \mathrm{C}$ in a microwave reactor for $1 \mathrm{~h}$. The reaction mixture was allowed to cool to $\mathrm{rt}$, diluted with EtOAC $(50 \mathrm{~mL})$ and DCM $(50 \mathrm{~mL})$, filtered through Celite ${ }^{\circledR}$ and concentrated in vacuo. The resulting residue was purified by silica gel chromatography (0-50\% $\mathrm{EtOH}$ in EtOAc). The appropriate fractions were combined and solvent evaporated in vacuo to give $35(1.32 \mathrm{~g}, 3.69 \mathrm{mmol}, 85 \%)$ as a white solid; ${ }^{1} \mathrm{H}$ NMR $\left(400 \mathrm{MHz}, \mathrm{DMSO}-\mathrm{d}_{6}\right) \delta \mathrm{ppm} 11.72(\mathrm{~d}, J=4.4,1 \mathrm{H}), 8.46(\mathrm{~d}, J=4.4,1 \mathrm{H}), 8.41(\mathrm{~d}, J=1.6,1 \mathrm{H}), 7.68-7.66(\mathrm{~m}, 1 \mathrm{H})$, 7.65-7.62 (m, 1H), 7.58-7.55 (m, 2H), 7.43-7.37 (m, 2H), 7.36-7.31 (m, 1H), 7.16-7.12 (m, 1H), 5.55 (s, $2 \mathrm{H}), 2.38$ $(\mathrm{s}, 3 \mathrm{H}), 2.27(\mathrm{~s}, 3 \mathrm{H})$; LCMS (formic acid): $\mathrm{R}_{\mathrm{t}}=0.78 \mathrm{~min}(100 \%)$, LRMS $(\mathrm{M}+\mathrm{H})^{+}$calculated for $\mathrm{C}_{22} \mathrm{H}_{20} \mathrm{~N}_{3} \mathrm{O}_{2} 358.2$; found 358.0 .

\section{2-(Benzyloxy)-3-methyl-5-(5-methylpyridin-3-yl)-1,7-naphthyridin-8-yl trifluoromethanesulfonate (36)}<smiles>COc1ncc(-c2cncc(C)c2)c2cc(C)c(Br)nc12</smiles>

To a mixture of $35(1.32 \mathrm{~g}, 3.69 \mathrm{mmol})$ in DCM $(25 \mathrm{~mL})$, pyridine $(0.60 \mathrm{~mL}, 7.39 \mathrm{mmol})$ was added at $0{ }^{\circ} \mathrm{C}$. The reaction mixture was left to stir for $0.5 \mathrm{~h}$. Triflicanhydride $(1.25 \mathrm{~mL}, 7.39 \mathrm{mmol})$ was added drop-wise and the reaction mixture was stirred at $0{ }^{\circ} \mathrm{C}$ for $1 \mathrm{~h}$. The reaction mixture was diluted with $\mathrm{DCM}(50 \mathrm{~mL})$ and washed with $\mathrm{H}_{2} \mathrm{O}(50 \mathrm{~mL})$ and brine $(50 \mathrm{~mL})$. The organic layer was separated, passed through a hydrophobic frit and concentrated in vacuo to give $36\left(1.81 \mathrm{~g}, 3.70 \mathrm{mmol}\right.$, quant.) as a pale yellow solid; m.p. $132-133^{\circ} \mathrm{C} ; \mathrm{v}_{\max }$ (solid)/cm-1: 1424, 1204, 1139 (S=0), 871, 831, 693; ${ }^{1} \mathrm{H} \mathrm{NMR} \mathrm{(400} \mathrm{MHz,} \mathrm{CDCl} 3$ ) $\delta \mathrm{ppm} 8.69(\mathrm{~s}, 1 \mathrm{H}), 8.61(\mathrm{~s}, 1 \mathrm{H})$, $8.13(\mathrm{~s}, 1 \mathrm{H}), 7.83-7.80(\mathrm{~m}, 1 \mathrm{H}), 7.79-7.77(\mathrm{~m}, 1 \mathrm{H}), 7.59-7.55(\mathrm{~m}, 2 \mathrm{H}), 7.45-7.39(\mathrm{~m}, 2 \mathrm{H}), 7.39-7.33(\mathrm{~m}, 1 \mathrm{H}), 5.69$

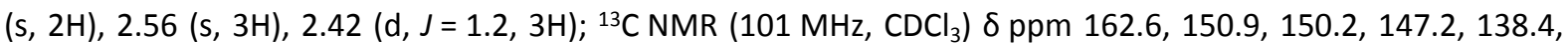
$137.8,136.4,133.7,133.4,132.6,131.3,131.0,130.7,128.5,128.3,128.2,118.7$ (q, J $J_{C-F}=320.0$ ), 69.1, 18.5, 17.1; 
${ }^{19} \mathrm{~F}$ NMR $\left(376 \mathrm{MHz}\right.$, DMSO- $\left.\mathrm{d}_{6}\right) \delta \mathrm{ppm}-74.1$; HRMS $(\mathrm{M}+\mathrm{H})^{+}$calculated for $\mathrm{C}_{23} \mathrm{H}_{19} \mathrm{~F}_{3} \mathrm{~N}_{3} \mathrm{O}_{4} \mathrm{~S}$ 490.1043; found 490.1027; LCMS (formic acid): $R_{t}=1.48$ min (100\%), LRMS $(M+H)^{+}$calculated for $\mathrm{C}_{23} \mathrm{H}_{19} \mathrm{~F}_{3} \mathrm{~N}_{3} \mathrm{O}_{4} \mathrm{~S}$ 490.1; found 490.1.

8-((1-(2-Hydroxyethyl)piperidin-4-yl)amino)-3-methyl-5-(5-methylpyridin-3-yl)-1,7-naphthyridin-2(1H)-one (10)<smiles>Cc1cncc(-c2cnc(NC3CCN(CCO)CC3)c3[nH]c(=O)c(C)cc23)c1</smiles>

Following General Procedure A using 2-(4-aminopiperidin-1-yl)ethanol (88mg, $0.60 \mathrm{mmol})$, gave 10 (24 mg, $0.06 \mathrm{mmol}, 30 \%$ ) as a yellow solid; m.p. $217-220^{\circ} \mathrm{C}$ (decomp.); $v_{\max }\left(\right.$ solid)/cm $\mathrm{cm}^{-1}: 3393(\mathrm{~N}-\mathrm{H}), 1659(\mathrm{C}=0), 1595$, 1450, 720; ${ }^{1} \mathrm{H}$ NMR (400 MHz, DMSO-d $\left.\mathrm{d}_{6}\right) \delta \mathrm{ppm} 8.46-8.42(\mathrm{~m}, 1 \mathrm{H}), 8.37(\mathrm{~d}, J=2.0,1 \mathrm{H}), 7.70(\mathrm{~s}, 1 \mathrm{H}), 7.64-7.60$ $(\mathrm{m}, 1 \mathrm{H}), 7.50(\mathrm{~d}, J=1.2,1 \mathrm{H}), 6.86-6.84(\mathrm{~m}, 1 \mathrm{H}), 4.37-4.28(\mathrm{~m}, 1 \mathrm{H}), 4.04-3.93(\mathrm{~m}, 1 \mathrm{H}), 3.55-3.40(\mathrm{~m}, 3 \mathrm{H}), 2.92-$ $2.85(\mathrm{~m}, 2 \mathrm{H}), 2.44-2.36(\mathrm{~m}, 5 \mathrm{H}), 2.16-2.04(\mathrm{~m}, 5 \mathrm{H}), 2.02-1.94(\mathrm{~m}, 2 \mathrm{H}), 1.58-1.46(\mathrm{~m}, 2 \mathrm{H}) ;{ }^{13} \mathrm{C} \mathrm{NMR}(101 \mathrm{MHz}$, DMSO-d $\left.{ }_{6}\right) \delta$ ppm 162.0, 148.5, 147.1, 145.8, 139.0, 137.4, 134.1, 132.9, 132.8, 131.9, 120.9, 120.6, 117.9, 60.3, 58.7, 52.7, 47.9, 31.7, 17.8, 16.7; HRMS $(M+H)^{+}$calculated for $\mathrm{C}_{22} \mathrm{H}_{28} \mathrm{~N}_{5} \mathrm{O}_{2}$ 394.2238; found 394.2247; LCMS (high pH): $\mathrm{R}_{t}=0.75 \min (87 \%)$, LRMS $(\mathrm{M}+\mathrm{H})^{+}$calculated for $\mathrm{C}_{22} \mathrm{H}_{28} \mathrm{~N}_{5} \mathrm{O}_{2} 394.2$; found 394.2.

tert-Butyl 4-((2-(benzyloxy)-3-methyl-1,7-naphthyridin-8-yl)amino)piperidine-1-carboxylate (37)<smiles>Cc1cc2ccnc(NC3CCN(C(=O)O)CC3)c2nc1OCc1ccccc1</smiles>

tert-Butyl 4-aminopiperidine-1-carboxylate $(1.265 \mathrm{~g}, 6.320 \mathrm{mmol})$ was added to a solution of 2-(benzyloxy)-8chloro-3-methyl-1,7-naphthyridine $(25)^{2}(1.200 \mathrm{~g}, 4.214 \mathrm{mmol})$, sodium tert-butoxide $(1.622 \mathrm{~g}, 16.87 \mathrm{mmol})$, $\mathrm{Pd}_{2}(\mathrm{dba})_{3}(0.216 \mathrm{~g}, 0.236 \mathrm{mmol}$ ) and 2-(dicyclohexylphosphino)3,6-dimethoxy-2',4',6'-triisopropyl-1,1'-biphenyl $(0.225 \mathrm{~g}, 0.419 \mathrm{mmol})$ in THF $(19 \mathrm{~mL})$. The reaction mixture was then stirred at $60^{\circ} \mathrm{C}$ for 4 hours before being allowed to cool to $\mathrm{rt}$ and then concentrated in vacuo. The resultant residue was then diluted with DCM (40 $\mathrm{mL})$ and washed with $\mathrm{H}_{2} \mathrm{O}(40 \mathrm{~mL})$. The separated organic layer was then passed through a hydrophobic frit and concentrated in vacuo. The residue was purified by silica chromatography (0-60\% EtOAc in cyclohexane) and the appropriate fractions combined and concentrated in vacuo yielding 37 (1.360 g, $3.032 \mathrm{mmol}, 72 \%)$ as an orange solid. m.p. $133-134{ }^{\circ} \mathrm{C} ; v_{\max }\left(\right.$ solid)/(cm ${ }^{-1}$ : $3367(\mathrm{~N}-\mathrm{H}), 2939,1682(\mathrm{C}=\mathrm{O}), 1516,1421,1162,734 ;{ }^{1} \mathrm{H}$ NMR (400 $\mathrm{MHz}$, METHANOL- $\left.d_{4}\right) \delta$ ppm 7.78-7.76 (m, $\left.1 \mathrm{H}\right), 7.71(\mathrm{~d}, J=6.0 \mathrm{~Hz}, 1 \mathrm{H})$, 7.53-7.47 (m, $\left.2 \mathrm{H}\right), 7.41-7.34(\mathrm{~m}, 2 \mathrm{H})$, 7.33-7.27 (m, $1 \mathrm{H}), 6.79(\mathrm{~d}, J=6.0 \mathrm{~Hz}, 1 \mathrm{H}), 5.55(\mathrm{~s}, 2 \mathrm{H}), 4.17-4.08(\mathrm{~m}, 1 \mathrm{H}), 4.08-4.00(\mathrm{~m}, 2 \mathrm{H}), 3.12-2.98(\mathrm{~m}, 2 \mathrm{H})$, $2.38(\mathrm{~d}, J=1.0 \mathrm{~Hz}, 3 \mathrm{H}), 2.10-2.01(\mathrm{~m}, 2 \mathrm{H}), 1.58-1.46(\mathrm{~m}, 11 \mathrm{H})$ (N.B. exchangeable proton not visible); LCMS (formic): $\mathrm{R}_{\mathrm{t}}=0.93 \min (100 \%)$, LRMS $(\mathrm{M}+\mathrm{H})^{+}$calculated for $\mathrm{C}_{26} \mathrm{H}_{33} \mathrm{~N}_{4} \mathrm{O}_{3} 449.3$; found 449.5 .

tert-Butyl 4-((2-(benzyloxy)-5-bromo-3-methyl-1,7-naphthyridin-8-yl)amino)piperidine-1-carboxylate (26)<smiles>Cc1cc2c(Br)cnc(NC3CCN(C(=O)O)CC3)c2nc1OCc1ccccc1</smiles>

1-Bromopyrrolidine-2,5-dione $(0.824 \mathrm{~g}, 4.63 \mathrm{mmol})$ was added to a solution of $37(2.066 \mathrm{~g}, 4.606 \mathrm{mmol})$ in chloroform $(52 \mathrm{~mL})$ and stirred at $\mathrm{rt}$ for 1.5 hours before being diluted with $\mathrm{H}_{2} \mathrm{O}(30 \mathrm{~mL})$. The organic phase was then passed through a hydrophobic frit and concentrated in vacuo to yield $26(2.414 \mathrm{~g}, 4.577 \mathrm{mmol}, 99 \%)$ as an orange solid. m.p. $149-152{ }^{\circ} \mathrm{C} ; v_{\max }$ (solid)/cm ${ }^{-1}: 3405(\mathrm{~N}-\mathrm{H}), 2930,2812,1660$ (C=O), 1594, 1519, 1253, 1165, 1127; ${ }^{1} \mathrm{H}$ NMR (400 MHz, CHLOROFORM-d) $\delta$ ppm 8.01 (s, $\left.1 \mathrm{H}\right)$, 7.98-7.95 (m, $\left.1 \mathrm{H}\right), 7.51-7.46(\mathrm{~m}, 2 \mathrm{H}), 7.44-7.38$ $(\mathrm{m}, 2 \mathrm{H}), 7.37-7.32(\mathrm{~m}, 1 \mathrm{H}), 6.19(\mathrm{~d}, \mathrm{~J}=8.1 \mathrm{~Hz}, 1 \mathrm{H}), 5.51(\mathrm{~s}, 2 \mathrm{H}), 4.28-4.16(\mathrm{~m}, 1 \mathrm{H}), 4.14-3.99(\mathrm{~m}, 2 \mathrm{H}), 3.12-3.00$ $(\mathrm{m}, 2 \mathrm{H}), 2.45$ (d, J=1.0 Hz, $3 \mathrm{H}), 2.17-2.07(\mathrm{~m}, 2 \mathrm{H}), 1.57-1.47(\mathrm{~m}, 11 \mathrm{H}) ;{ }^{13} \mathrm{C}$ NMR (101 MHz, CHLOROFORM-d) $\delta$ ppm 160.3, 154.8, 153.2, 141.2, 137.1, 135.8, 130.1, 128.6, 127.9, 127.8, 127.4, 127.2, 103.2, 79.5, 68.4, 47.5, 42.7, 32.3, 28.5, 16.6; HRMS (M + H) calculated for $\mathrm{C}_{26} \mathrm{H}_{32} \mathrm{BrN}_{4} \mathrm{O}_{3}$ 527.1658; found 527.1655; LCMS (formic): $\mathrm{R}_{t}$ $=1.66 \min (97 \%)$, LRMS $(\mathrm{M}+\mathrm{H})^{+}$calculated for $\mathrm{C}_{26} \mathrm{H}_{32} \mathrm{BrN}_{4} \mathrm{O}_{3}$ 527.2; found 527.0, 528.9. 
<smiles>Cc1cc2c(Br)cnc(NC3CCNCC3)c2[nH]c1=O</smiles>

$26(9.18 \mathrm{~g}, 17.4 \mathrm{mmol})$ was dissolved in TFA $(60 \mathrm{~mL})$ at $\mathrm{rt}$. The solution was then heated to reflux and stirred for 18 hours. The volatile components were removed in vacuo. To the residue was added toluene (15 $\mathrm{mL})$ and the mixture concentrated in vacuo ( $\times 3)$. The resultant solid was dissolved in $\mathrm{MeOH}(50 \mathrm{~mL})$ and passed through a preconditioned (100 mL MeOH) aminopropyl column (70 g) and eluted with $\mathrm{MeOH}(500 \mathrm{~mL})$. The desired fractions were combined and concentrated in vacuo yielding 38 (5.56 g, $16.5 \mathrm{mmol}, 95 \%)$ as an orange solid. m.p. 241-244 ${ }^{\circ} \mathrm{C} ; v_{\max }$ (solid)/cm ${ }^{-1}$ : $3473(\mathrm{~N}-\mathrm{H}), 3377(\mathrm{~N}-\mathrm{H}), 2845,1672$ (C=O), 1596, 1434, 1131, 800; ${ }^{1} \mathrm{H}$ NMR $\left(400 \mathrm{MHz}, \mathrm{DMSO}-d_{6}\right) \delta \mathrm{ppm} 7.92(\mathrm{~s}, 1 \mathrm{H}), 7.82-7.77(\mathrm{~m}, 1 \mathrm{H}), 6.95(\mathrm{~d}, \mathrm{~J}=6.4 \mathrm{~Hz}, 1 \mathrm{H}), 4.24-4.12(\mathrm{~m}, 1 \mathrm{H}), 3.43-3.27$ $(\mathrm{m}, 2 \mathrm{H}), 3.17(\mathrm{~s}, 1 \mathrm{H}), 3.12-3.00(\mathrm{~m}, 2 \mathrm{H}), 2.24-2.08(\mathrm{~m}, 5 \mathrm{H}), 1.75-1.61(\mathrm{~m}, 2 \mathrm{H})$ (N.B. exchangeable lactam proton not visible); LCMS (formic): $\mathrm{Rt}=0.53 \mathrm{~min}(96 \%)$, LRMS $(\mathrm{M}+\mathrm{H})^{+}$calculated for $\mathrm{C}_{14} \mathrm{H}_{18} \mathrm{BrN}_{4} \mathrm{O} 337.1$; found 337.1, 339.1 .

tert-Butyl (2-(4-((5-bromo-3-methyl-2-oxo-1,2-dihydro-1,7-naphthyridin-8-yl)amino)piperidin-1yl)ethyl)carbamate (39)<smiles>Cc1cc2c(Br)cnc(NC3CCN(CCNC(C)(C)C)CC3)c2[nH]c1=O</smiles>

A mixture of 38 (94 mg, $0.59 \mathrm{mmol}$ ) and tert-butyl (2-oxoethyl)carbamate ( $219 \mathrm{mg}, 0.65 \mathrm{mmol})$ in $\mathrm{MeOH}(5 \mathrm{~mL})$ and $\mathrm{AcOH}(0.5 \mathrm{~mL})$ was heated at $50{ }^{\circ} \mathrm{C}$ for $3 \mathrm{~h}$. Picoline borane complex ( $55 \mathrm{mg}, 0.59 \mathrm{mmol}$ ) was added and the reaction mixture was heated at $50{ }^{\circ} \mathrm{C}$ for a further $18 \mathrm{~h}$. The reaction mixture was concentrated in vacuo and the resulting residue diluted with sat. aq. $\mathrm{NaHCO}_{3}(20 \mathrm{~mL})$ and $\mathrm{DCM}(20 \mathrm{~mL})$. The organic layer was separated and the aqueous extracted with DCM $(3 \times 20 \mathrm{~mL})$. The combined organic layers were passed through a hydrophobic frit and concentrated in vacuo. The resulting residue was purified by silica gel chromatography $(0-50 \%$ EtOH in EtOAc). The appropriate fractions were combined and solvent evaporated in vacuo to give 39 (123 mg, $0.26 \mathrm{mmol}, 43 \%)$ as a yellow solid; ${ }^{1} \mathrm{H}$ NMR (400 MHz, DMSO-d 6 ) $\delta$ ppm 11.59 (br.s, $\left.1 \mathrm{H}\right), 7.90(\mathrm{~s}, 1 \mathrm{H}), 7.79(\mathrm{~s}, 1 \mathrm{H})$, 6.86-6.79 (m, 1H), $6.65(\mathrm{t}, J=5.1,1 \mathrm{H}), 3.91-3.82(\mathrm{~m}, 1 \mathrm{H}), 3.06-3.00(\mathrm{~m}, 2 \mathrm{H}), 2.88-2.80(\mathrm{~m}, 2 \mathrm{H}), 2.36-2.29(\mathrm{~m}$, $2 \mathrm{H}), 2.17(\mathrm{~s}, 3 \mathrm{H}), 2.10-2.02(\mathrm{~m}, 2 \mathrm{H}), 1.97-1.90(\mathrm{~m}, 2 \mathrm{H}), 1.49-1.42(\mathrm{~m}, 2 \mathrm{H}), 1.38(\mathrm{~s}, 9 \mathrm{H})$; LCMS (formic acid): $\mathrm{R}_{\mathrm{t}}=0.73 \mathrm{~min}(100 \%)$, LRMS $(\mathrm{M}+\mathrm{H})^{+}$calculated for $\mathrm{C}_{21} \mathrm{H}_{31} \mathrm{BrN}_{5} \mathrm{O}_{3} 480.2$; found 480.2, 482.2.

tert-Butyl (2-(4-((3-methyl-5-(5-methylpyridin-3-yl)-2-oxo-1,2-dihydro-1,7-naphthyridin-8yl)amino)piperidin-1-yl)ethyl)carbamate (40)<smiles>Cc1cncc(-c2cnc(NC3CCN(CCNC(=O)OCc4ccccc4)CC3)c3[nH]c(=O)c(C)cc23)c1</smiles>

A mixture of 39 (123 mg, $0.26 \mathrm{mmol}$ ), (5-methylpyridin-3-yl)boronic acid (70 mg, $0.51 \mathrm{mmol}), \mathrm{Pd}(\mathrm{OAc})_{2}(6 \mathrm{mg}$, $0.03 \mathrm{mmol})$, cataCXium $A^{\circledR}(9 \mathrm{mg}, 0.03 \mathrm{mmol})$ and $\mathrm{K}_{2} \mathrm{CO}_{3}(71 \mathrm{mg}, 0.51 \mathrm{mmol})$ in 1,4-dioxane $(3 \mathrm{~mL})$ and $\mathrm{H}_{2} \mathrm{O}$ $(1.5 \mathrm{~mL})$ was heated at $100{ }^{\circ} \mathrm{C}$ in a microwave reactor for $1 \mathrm{~h}$. The reaction mixture was allowed to cool to $\mathrm{rt}$, diluted with EtOAc $(20 \mathrm{~mL})$, filtered through Celite ${ }^{\circledR}$ and concentrated in vacuo. The resulting residue was purified by silica gel chromatography $(0-50 \% \mathrm{EtOH}$ in EtOAc). The appropriate fractions were combined and sovent evaporated in vacuo to give $40(88 \mathrm{mg}, 0.18 \mathrm{mmol}, 70 \%)$ as a yellow solid; ${ }^{1} \mathrm{H} \mathrm{NMR}\left(400 \mathrm{MHz}^{\mathrm{C}} \mathrm{CDCl}_{3}\right)$ $\delta$ ppm 13.37 (br.s, 1H), 8.51 (d, $J=1.6,1 \mathrm{H}), 8.47$ (d, $J=1.6,1 \mathrm{H}), 7.87(\mathrm{~s}, 1 \mathrm{H}), 7.69(\mathrm{~d}, J=1.0,1 \mathrm{H}), 7.54-7.50(\mathrm{~m}$, $1 \mathrm{H}), 6.75(\mathrm{~d}, J=6.1,1 \mathrm{H}), 5.13-4.99(\mathrm{~m}, 1 \mathrm{H}), 4.30-4.16(\mathrm{~m}, 1 \mathrm{H}), 3.30-3.21(\mathrm{~m}, 2 \mathrm{H}), 3.04-2.92(\mathrm{~m}, 2 \mathrm{H}), 2.57-2.48$ $(\mathrm{m}, 2 \mathrm{H}), 2.45(\mathrm{~s}, 3 \mathrm{H}), 2.34(\mathrm{~s}, 3 \mathrm{H}), 2.31-2.18(\mathrm{~m}, 4 \mathrm{H}), 1.87-1.75(\mathrm{~m}, 2 \mathrm{H}), 1.46(\mathrm{~s}, 9 \mathrm{H})$; LCMS (formic acid): $\mathrm{R}_{\mathrm{t}}=0.51 \mathrm{~min}(98 \%)$, LRMS $(\mathrm{M}+\mathrm{H})^{+}$calculated for $\mathrm{C}_{27} \mathrm{H}_{37} \mathrm{~N}_{6} \mathrm{O}_{3} 493.3$; found 493.3. 
<smiles>Cc1cncc(-c2cnc(NC3CCN(CCN)CC3)c3[nH]c(=O)c(C)cc23)c1</smiles>

40 (116 mg, $0.24 \mathrm{mmol}$ ) was dissolved in $4 \mathrm{M} \mathrm{HCl}$ in 1,4-dioxane ( $3 \mathrm{~mL}, 12.00 \mathrm{mmol}$ ) and left to stir at rt for $18 \mathrm{~h}$. The reaction mixture was concentrated in vacuo and the resulting residue was purified by MDAP (high pH). The appropriate fractions were combined and solvent evaporated in vacuo to give $\mathbf{1 1}$ (36 mg, $0.09 \mathrm{mmol}, 39 \%)$ as a yellow solid; ${ }^{1} \mathrm{H}$ NMR $\left(400 \mathrm{MHz}, \mathrm{DMSO}-\mathrm{d}_{6}\right) \delta \mathrm{ppm} 8.44(\mathrm{~d}, J=1.8,1 \mathrm{H}), 8.37(\mathrm{~d}, J=1.8,1 \mathrm{H}), 7.70(\mathrm{~s}, 1 \mathrm{H}), 7.64-$ $7.60(\mathrm{~m}, 1 \mathrm{H}), 7.51(\mathrm{~d}, J=1.2,1 \mathrm{H}), 6.88(\mathrm{~d}, J=6.8,1 \mathrm{H}), 5.47(\mathrm{br} . \mathrm{s}, 3 \mathrm{H}), 4.04-3.94(\mathrm{~m}, 1 \mathrm{H}), 2.90-2.80(\mathrm{~m}, 2 \mathrm{H}), 2.70-$ $2.63(\mathrm{~m}, 2 \mathrm{H}), 2.37(\mathrm{~s}, 3 \mathrm{H}), 2.36-2.31(\mathrm{~m}, 2 \mathrm{H}), 2.11-1.96(\mathrm{~m}, 7 \mathrm{H}), 1.58-1.46(\mathrm{~m}, 2 \mathrm{H}) ; \mathrm{LCMS}\left(\right.$ high pH): $\mathrm{R}_{\mathrm{t}}=0.77 \mathrm{~min}$ (92\%), LRMS $(\mathrm{M}+\mathrm{H})^{+}$calculated for $\mathrm{C}_{22} \mathrm{H}_{29} \mathrm{~N}_{6} \mathrm{O} 393.2$; found 393.4.

\section{tert-Butyl (3-oxopropyl)carbamate (41)}

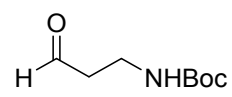

Dess Martin periodinane $(944 \mathrm{mg}, 2.23 \mathrm{mmol}$ ) was added to a solution of tert-butyl (3-hydroxypropyl)carbamate $(0.29 \mathrm{~mL}, 1.71 \mathrm{mmol})$ in $\mathrm{DCM}(9 \mathrm{~mL})$ at $0{ }^{\circ} \mathrm{C}$. The reaction mixture was allowed to warm to rt and stirred for $18 \mathrm{~h}$. The reaction mixture was quenched with $20 \%$ aq. $\mathrm{Na}_{2} \mathrm{~S}_{2} \mathrm{O}_{3}(20 \mathrm{~mL})$ and sat. aq. $\mathrm{NaHCO}_{3}(20 \mathrm{~mL})$ and diluted with $\mathrm{Et}_{2} \mathrm{O}(30 \mathrm{~mL})$. The organic layer was separated and washed with $20 \%$ aq. $\mathrm{Na}_{2} \mathrm{~S}_{2} \mathrm{O}_{3}(20 \mathrm{~mL})$, sat. aq. $\mathrm{NaHCO}_{3}$ $(20 \mathrm{~mL})$ and brine $(20 \mathrm{~mL})$. The organic layer was passed through a hydrophobic frit and concentrated in vacuo to give 41 (316 mg, $1.82 \mathrm{mmol}$, quant.) as a colourless oil; ${ }^{1} \mathrm{H} \mathrm{NMR} \mathrm{(400} \mathrm{MHz,} \mathrm{CDCl} 3$ ) $\delta \mathrm{ppm} 9.82(\mathrm{~s}, 1 \mathrm{H}), 4.92$ $(1 \mathrm{H}$, br. s), $3.47-3.40(\mathrm{~m}, 2 \mathrm{H}) 2.12(\mathrm{t}, J=5.7,2 \mathrm{H}), 1.44(\mathrm{~s}, 9 \mathrm{H})$.

tert-Butyl (3-(4-((5-bromo-3-methyl-2-oxo-1,2-dihydro-1,7-naphthyridin-8-yl)amino)piperidin-1yl)propyl)carbamate (42)<smiles>Cc1cc2c(Br)cnc(NC3CCN(CCCNC(C)(C)C)CC3)c2[nH]c1=O</smiles>

A mixture of 38 (474 mg, $2.74 \mathrm{mmol})$ and 41 (1.11 g, $3.28 \mathrm{mmol})$ in $\mathrm{MeOH}(6 \mathrm{~mL})$ and AcOH $(0.6 \mathrm{~mL})$ was heated at $50^{\circ} \mathrm{C}$ for $3 \mathrm{~h}$. Picoline borane complex $(254 \mathrm{mg}, 2.74 \mathrm{mmol})$ was added and the reaction mixture was heated at $50^{\circ} \mathrm{C}$ for a further $18 \mathrm{~h}$. The reaction mixture was concentrated in vacuo and the resulting residue diluted with sat. aq. $\mathrm{NaHCO}_{3}(20 \mathrm{~mL})$ and DCM $(20 \mathrm{~mL})$. The organic layer was separated and the aqueous extracted with DCM $(3 \times 20 \mathrm{~mL})$. The combined organic layers were passed through a hydrophobic frit and concentrated in vacuo. The resulting residue was purified by silica gel chromatography $(0-100 \% \mathrm{EtOH}$ in EtOAc). The appropriate fractions were combined and solvent evaporated in vacuo to give 42 (850 mg, $1.72 \mathrm{mmol}, 63 \%)$ as a yellow solid; ${ }^{1} \mathrm{H}$ NMR (400 MHz, DMSO-d ${ }_{6}$ ) $\delta$ ppm 11.60 (br.s, 1H), 7.91 (s, 1H), 7.80 (d, J = 1.0, 1H), 6.85-6.75 (m, 2H), 3.93$3.82(\mathrm{~m}, 1 \mathrm{H}), 2.95(\mathrm{q}, J=6.7,2 \mathrm{H}), 2.89-2.80(\mathrm{~m}, 2 \mathrm{H}), 2.32-2.24(\mathrm{~m}, 2 \mathrm{H}), 2.18(\mathrm{~d}, J=1.0,3 \mathrm{H}), 2.05-1.92(\mathrm{~m}, 4 \mathrm{H})$, 1.58-1.48 (m, 4H), $1.38(\mathrm{~s}, 9 \mathrm{H})$; LCMS (formic acid): $\mathrm{R}_{\mathrm{t}}=0.75 \mathrm{~min}(100 \%)$, LRMS $(\mathrm{M}+\mathrm{H})^{+}$calculated for $\mathrm{C}_{22} \mathrm{H}_{33} \mathrm{BrN}_{5} \mathrm{O}_{3}$ 494.2; found 494.1, 496.1 .

tert-Butyl (3-(4-((3-methyl-5-(5-methylpyridin-3-yl)-2-oxo-1,2-dihydro-1,7-naphthyridin-8yl)amino)piperidin-1-yl)propyl)carbamate (43)<smiles>Cc1cncc(-c2cnc(NC3CCN(CCCNC(C)(C)C)CC3)c3[nH]c(=O)c(C)cc23)c1</smiles>

A mixture of 42 (120 mg, $0.24 \mathrm{mmol})$, (5-methylpyridin-3-yl)boronic acid (67 mg, $0.49 \mathrm{mmol}), \mathrm{Pd}(\mathrm{OAc})_{2}(8 \mathrm{mg}$, $0.04 \mathrm{mmol})$, cataCXium $A^{\circledR}(13 \mathrm{mg}, 0.04 \mathrm{mmol})$ and $\mathrm{K}_{2} \mathrm{CO}_{3}(81 \mathrm{mg}, 0.58 \mathrm{mmol})$ in 1,4-Dioxane $(2 \mathrm{~mL})$ and $\mathrm{H}_{2} \mathrm{O}$ $(1 \mathrm{~mL})$ was heated at $100{ }^{\circ} \mathrm{C}$ in a microwave reactor for $1 \mathrm{~h}$. The reaction mixture was allowed to cool to $\mathrm{rt}$, 
diluted with EtOAc $(20 \mathrm{~mL})$, filtered through Celite ${ }^{\circledR}$ and concentrated in vacuo. The resulting residue was purified by silica gel chromatography (0-100\% EtOH in EtOAc). The appropriate fractions were combined and solvent evaporated in vacuo to give $43(70 \mathrm{mg}, 0.14 \mathrm{mmol}, 57 \%)$ as a yellow solid; ${ }^{1} \mathrm{H} \mathrm{NMR}\left(400 \mathrm{MHz}, \mathrm{CD}_{3} \mathrm{OD}\right)$ $\delta$ ppm $8.45(\mathrm{~s}, 1 \mathrm{H}), 8.37(\mathrm{~d}, J=1.7,1 \mathrm{H}), 7.73(\mathrm{~s}, 2 \mathrm{H}), 7.62(\mathrm{~s}, 1 \mathrm{H}), 4.14-4.04(\mathrm{~m}, 1 \mathrm{H}), 3.11(\mathrm{t}, J=6.7,2 \mathrm{H}), 3.08-$ $3.01(\mathrm{~m}, 2 \mathrm{H}), 2.51-2.45(\mathrm{~m}, 5 \mathrm{H}), 2.29-2.14(\mathrm{~m}, 7 \mathrm{H}), 1.79-1.65(\mathrm{~m}, 4 \mathrm{H}), 1.46(\mathrm{~s}, 9 \mathrm{H})$; LCMS (formic acid): $\mathrm{R}_{\mathrm{t}}=0.51 \mathrm{~min}(100 \%)$, LRMS $(\mathrm{M}+\mathrm{H})^{+}$calculated for $\mathrm{C}_{28} \mathrm{H}_{39} \mathrm{~N}_{6} \mathrm{O}_{3} 507.3$; found 507.3.

\section{8-((1-(3-Aminopropyl)piperidin-4-yl)amino)-3-methyl-5-(5-methylpyridin-3-yl)-1,7-naphthyridin-2(1H)-one} (12)<smiles>Cc1cncc(-c2cnc(NC3CCN(CCCN)CC3)c3[nH]c(=O)c(C)cc23)c1</smiles>

43 (70 mg, $0.14 \mathrm{mmol}$ ) was stirred in $4 \mathrm{M} \mathrm{HCl}$ in 1,4-dioxane ( $5 \mathrm{~mL}, 20.00 \mathrm{mmol}$ ) for $18 \mathrm{~h}$. The reaction mixture was concentrated in vacuo and the resulting solid suspended in $\mathrm{Et}_{2} \mathrm{O}(10 \mathrm{~mL})$, filtered under reduced pressure, washed with $\mathrm{Et}_{2} \mathrm{O}(10 \mathrm{~mL})$ and collected. The resulting solid purified by MDAP (high $\mathrm{pH}$ ). The appropriate fractions were combined and evaporated in vacuo to give 12 (43 mg, $0.11 \mathrm{mmol}, 77 \%$ ) as a yellow solid; ${ }^{1} \mathrm{H}$ NMR

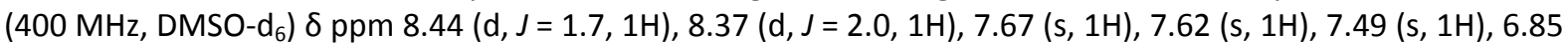
$(\mathrm{d}, J=6.6,1 \mathrm{H}), 4.02-3.94(\mathrm{~m}, 1 \mathrm{H}), 2.90-2.84(\mathrm{~m}, 2 \mathrm{H}), 2.61-2.54(\mathrm{~m}, 2 \mathrm{H}), 2.38(\mathrm{~s}, 3 \mathrm{H}), 2.35-2.30(\mathrm{~m}, 2 \mathrm{H}), 2.07(\mathrm{~d}$, $J=1.0,3 \mathrm{H}), 2.05-1.97(\mathrm{~m}, 4 \mathrm{H}), 1.56-1.47(\mathrm{~m}, 4 \mathrm{H})$; LCMS (high pH): $\mathrm{R}_{\mathrm{t}}=0.79 \mathrm{~min}(98 \%), \mathrm{LRMS}(\mathrm{M}+\mathrm{H})^{+}$calculated for $\mathrm{C}_{23} \mathrm{H}_{31} \mathrm{~N}_{6} \mathrm{O}$ 407.2; found 407.5.

tert-Butyl (3-(4-((3-methyl-2-oxo-5-(m-tolyl)-1,2-dihydro-1,7-naphthyridin-8-yl)amino)piperidin-1yl)propyl)carbamate (44)<smiles>Cc1cccc(-c2cnc(NC3CCN(CCCNC(C)(C)C)CC3)c3[nH]c(=O)c(C)cc23)c1</smiles>

A mixture of 42 (300 mg, $0.61 \mathrm{mmol})$, (3-(hydroxymethyl)phenyl)boronic acid (184 mg, $1.21 \mathrm{mmol}), \mathrm{Pd}(\mathrm{OAc})_{2}$ (20 mg, $0.09 \mathrm{mmol})$, cataCXium $\mathrm{A}^{\circledR}(33 \mathrm{mg}, 0.09 \mathrm{mmol})$ and $\mathrm{K}_{2} \mathrm{CO}_{3}(201 \mathrm{mg}, 1.46 \mathrm{mmol})$ in 1,4-dioxane $(3 \mathrm{~mL})$ and $\mathrm{H}_{2} \mathrm{O}(1.5 \mathrm{~mL})$ was heated at $100{ }^{\circ} \mathrm{C}$ in a microwave reactor for $1 \mathrm{~h}$. The reaction mixture was allowed to cool to $\mathrm{rt}$, diluted with EtOAc $(20 \mathrm{~mL})$, filtered through Celite ${ }^{\circledR}$ and concentrated in vacuo. The resulting residue was purified by silica gel chromatography (0-100\% EtOH in EtOAc). The appropriate fractions were combined and solvent evaporated in vacuo to give $44(69 \mathrm{mg}, 0.14 \mathrm{mmol}, 68 \%)$ as a yellow solid; ${ }^{1} \mathrm{H}$ NMR $\left(400 \mathrm{MHz}, \mathrm{CD}_{3} \mathrm{OD}\right)$ $\delta$ ppm 7.71-7.68 (m, 2H), 7.40-7.34 (m, 1H), $7.25(\mathrm{~d}, J=7.6,1 \mathrm{H}), 7.19(\mathrm{~s}, 1 \mathrm{H}), 7.15(\mathrm{~d}, J=7.6,1 \mathrm{H}), 4.10-4.01(\mathrm{~m}$, $1 \mathrm{H}), 3.15-3.02(\mathrm{~m}, 4 \mathrm{H}), 2.51-2.45(\mathrm{~m}, 2 \mathrm{H}), 2.43(\mathrm{~s}, 3 \mathrm{H}), 2.34-2.21(\mathrm{~m}, 2 \mathrm{H}), 2.20-2.13(\mathrm{~m}, 5 \mathrm{H}), 1.79-1.60(\mathrm{~m}, 4 \mathrm{H})$, $1.46(\mathrm{~s}, 9 \mathrm{H})$; LCMS (formic acid): $\mathrm{R}_{t}=0.82 \mathrm{~min}(100 \%)$, LRMS $(\mathrm{M}+\mathrm{H})^{+}$calculated for $\mathrm{C}_{29} \mathrm{H}_{40} \mathrm{~N}_{5} \mathrm{O}_{3}$ 506.3; found 506.3 .

8-((1-(3-Aminopropyl)piperidin-4-yl)amino)-3-methyl-5-(m-tolyl)-1,7-naphthyridin-2(1H)-one (13)<smiles>Cc1cccc(-c2cnc(NC3CCN(CCCN)CC3)c3[nH]c(=O)c(C)cc23)c1</smiles>

$44(69 \mathrm{mg}, 0.14 \mathrm{mmol}$ ) was stirred in $4 \mathrm{M} \mathrm{HCl}$ in 1,4-dioxane $(3 \mathrm{~mL}, 12.00 \mathrm{mmol})$ for $18 \mathrm{~h}$ at rt. The reaction mixture was concentrated in vacuo and the resulting solid suspended in $\mathrm{Et}_{2} \mathrm{O}(10 \mathrm{~mL})$, and concentrated in vacuo. The resulting solid was purified by MDAP (formic acid). The appropriate fractions were combined and solvent evaporated in vacuo. The resulting solid was dissolved in $\mathrm{MeOH}(10 \mathrm{~mL})$ and passed through a preconditioned $(\mathrm{MeOH}, 10 \mathrm{~mL})$ amino propyl column $(10 \mathrm{~g})$, which was then washed with $\mathrm{MeOH}(20 \mathrm{~mL})$. The filtrate was concentrated in vacuo to give $13(30 \mathrm{mg}, 0.07 \mathrm{mmol}, 54 \%)$ as a yellow solid; m.p. $125-126^{\circ} \mathrm{C} ; v_{\max }(\mathrm{solid}) / \mathrm{cm}^{-1}$ : $2922(\mathrm{~N}-\mathrm{H}), 1662$ (C=O), 1594, 1444, 791; ${ }^{1} \mathrm{H}$ NMR (400 MHz, DMSO-d $\left.\mathrm{d}_{6}\right) \delta \mathrm{ppm} 7.66(\mathrm{~s}, 1 \mathrm{H}), 7.53(\mathrm{~d}, J=1.2,1 \mathrm{H}$ ), 
7.38-7.33 (m, 1H), $7.20(\mathrm{~d}, J=7.6,1 \mathrm{H}), 7.17-7.11(\mathrm{~m}, 2 \mathrm{H}), 6.80(\mathrm{~d}, J=6.6,1 \mathrm{H}), 4.02-3.92(\mathrm{~m}, 2 \mathrm{H}), 2.88-2.85(\mathrm{~m}$, $2 \mathrm{H}), 2.73-2.60(\mathrm{~m}, 2 \mathrm{H}), 2.37(\mathrm{~s}, 3 \mathrm{H}), 2.32(\mathrm{t}, J=7.1,2 \mathrm{H}), 2.06(\mathrm{~d}, J=1.2,3 \mathrm{H}), 2.05-2.03(\mathrm{~m}, 1 \mathrm{H}), 2.02-1.95(\mathrm{~m}$, 5H), 1.59-1.43 (m, 4H); ${ }^{13} \mathrm{C}$ NMR (101 MHz, DMSO-d 6 ) $\delta$ ppm 162.1, 145.5, 138.4, 137.7, 136.6, 133.6, 133.1, $130.3,128.4,127.7,126.9,121.5,120.9,120.7,55.7,52.3,47.9,31.8,21.0,16.8 ;$ N. B. 2C signals hidden under solvent peak; HRMS $(\mathrm{M}+\mathrm{H})^{+}$calculated for $\mathrm{C}_{24} \mathrm{H}_{32} \mathrm{~N}_{5} \mathrm{O}$ 406.2601; found 406.2605; LCMS (formic acid): $\mathrm{R}_{\mathrm{t}}=0.54 \min (98 \%)$, LRMS $(\mathrm{M}+\mathrm{H})^{+}$calculated for $\mathrm{C}_{24} \mathrm{H}_{32} \mathrm{~N}_{5} \mathrm{O}$ 406.3; found 406.1.

\section{tert-Butyl (3-(4-((5-(cyclohex-1-en-1-yl)-3-methyl-2-oxo-1,2-dihydro-1,7-naphthyridin-8-yl)amino)piperidin-} 1-yl)propyl)carbamate (45)<smiles>Cc1cc2c(C3=CCCCC3)cnc(NC3CCN(CCCNC(=O)O)CC3)c2[nH]c1=O</smiles>

A mixture of 42 (0.17 mL, $0.79 \mathrm{mmol})$, 2-(cyclohex-1-en-1-yl)-4,4,5,5-tetramethyl-1,3,2-dioxaborolane (0.17 mL, $0.80 \mathrm{mmol}), \mathrm{Pd}(\mathrm{OAc})_{2}(14 \mathrm{mg}, 0.06 \mathrm{mmol})$, cataCXium $\mathrm{A}^{\circledR}(22 \mathrm{mg}, 0.06 \mathrm{mmol})$ and $\mathrm{K}_{2} \mathrm{CO}_{3}(168 \mathrm{mg}, 1.21 \mathrm{mmol})$ in 1,4-dioxane $(2 \mathrm{~mL})$ and $\mathrm{H}_{2} \mathrm{O}(1 \mathrm{~mL})$ was heated at $100^{\circ} \mathrm{C}$ in a microwave reactor for $1 \mathrm{~h}$. The reaction mixture was allowed to cool to rt, diluted with EtOAc $(20 \mathrm{~mL})$, filtered through Celite ${ }^{\circledR}$ and concentrated in vacuo. The resulting solid was suspended in DCM $(20 \mathrm{~mL})$, filtered under reduced pressure, rinsed with DCM $(20 \mathrm{~mL})$ and $\mathrm{H}_{2} \mathrm{O}(20 \mathrm{~mL})$. The solid was collected to give 45 (185 mg, $\left.0.37 \mathrm{mmol}, 62 \%\right)$ as a yellow solid; ${ }^{1} \mathrm{H} \mathrm{NMR} \mathrm{(400} \mathrm{MHz,}$ DMSO-d 6 ) $\delta$ ppm 11.35 (br.s, $1 \mathrm{H}), 7.57(\mathrm{~s}, 1 \mathrm{H}), 7.49(\mathrm{~s}, 1 \mathrm{H}), 6.79-6.72(\mathrm{~m}, 1 \mathrm{H}), 6.59(\mathrm{~d}, J=6.6,1 \mathrm{H}), 3.95-3.84(\mathrm{~m}$, $1 \mathrm{H}), 2.98-2.90(\mathrm{~m}, 2 \mathrm{H}), 2.85-2.78(\mathrm{~m}, 2 \mathrm{H}), 2.29-2.23(\mathrm{~m}, 2 \mathrm{H}), 2.21-2.14(\mathrm{~m}, 4 \mathrm{H}), 2.11(\mathrm{~s}, 3 \mathrm{H}), 2.04-1.91(\mathrm{~m}, 4 \mathrm{H})$, 1.77-1.63 (m, 4H), 1.57-1.49 (m, 2H), 1.48-1.42 (m, 2H), $1.38(\mathrm{~s}, 9 \mathrm{H})$; LCMS (formic acid): $\mathrm{R}_{\mathrm{t}}=0.78 \mathrm{~min}(95 \%)$, LRMS $(\mathrm{M}+\mathrm{H})^{+}$calculated for $\mathrm{C}_{28} \mathrm{H}_{42} \mathrm{~N}_{5} \mathrm{O}_{3} 496.3$; found 496.3 .

\section{8-((1-(3-Aminopropyl)piperidin-4-yl)amino)-5-cyclohexyl-3-methyl-1,7-naphthyridin-2(1H)-one (14)<smiles>Cc1cc2c(C3CCCCC3)cnc(NC3CCN(CCCN)CC3)c2[nH]c1=O</smiles>

A solution of 45 (145 mg, $0.29 \mathrm{mmol})$ in $\mathrm{EtOH}(20 \mathrm{~mL})$ was hydrogenated in the $\mathrm{H}$-Cube using a $10 \% \mathrm{Pd} / \mathrm{C}$ cat cart $\left(50{ }^{\circ} \mathrm{C}, 40\right.$ barr pressure) for $3 \mathrm{~h}$. The reaction mixture was concentrated in vacuo to give a pale-yellow solid. This material was dissolved in $4 \mathrm{M} \mathrm{HCl}$ in 1,4-dioxane $(3 \mathrm{~mL}, 12.00 \mathrm{mmol}$ ) and left to stir at $\mathrm{rt}$ for $2 \mathrm{~h}$. The reaction mixture was concentrated in vacuo and the resulting solid was purified by MDAP (high $\mathrm{pH}$ ). The appropriate fractions were combined and solvent evaporated in vacuo to give 14 (13 mg, $0.03 \mathrm{mmol}, 11 \%$ over two steps) as a yellow solid; ${ }^{1} \mathrm{H} N M R\left(400 \mathrm{MHz}, \mathrm{DMSO}-\mathrm{d}_{6}\right) \delta \mathrm{ppm} 7.88(\mathrm{~s}, 1 \mathrm{H}), 7.64(\mathrm{~s}, 1 \mathrm{H}), 6.49(\mathrm{~d}, J=6.6,1 \mathrm{H}), 4.61$ (br.s, $\left.2 \mathrm{H}\right)$, 3.93-3.82 (m, 1H), 2.91-2.80 (m, 4H), 2.59-2.53 (m, 2H), 2.35-2.27 (m, 2H), $2.15(\mathrm{~s}, 3 \mathrm{H}), 2.02-1.91(\mathrm{~m}, 4 \mathrm{H})$, 1.82-1.75 (m, 5H), 1.54-1.38 (m, 8H); LCMS (high $\mathrm{pH}): \mathrm{R}_{\mathrm{t}}=0.49 \mathrm{~min}(98 \%)$, LRMS $(\mathrm{M}+\mathrm{H})^{+}$calculated for $\mathrm{C}_{23} \mathrm{H}_{36} \mathrm{~N}_{5} \mathrm{O} 398.3$; found 398.4.

tert-Butyl (3-(4-((5-(3,6-dihydro-2H-pyran-4-yl)-3-methyl-2-oxo-1,2-dihydro-1,7-naphthyridin-8yl)amino)piperidin-1-yl)propyl)carbamate (46)<smiles>Cc1cc2c(C3=CCOCC3)cnc(NC3CCN(CCCNC(C)(C)C)CC3)c2[nH]c1=O</smiles>

A mixture of 42 (220 mg, $0.45 \mathrm{mmol}$ ), 2-(3,6-dihydro-2H-pyran-4-yl)-4,4,5,5-tetramethyl-1,3,2-dioxaborolane $(122 \mathrm{mg}, 0.58 \mathrm{~mol}), \mathrm{Pd}(\mathrm{OAc})_{2}(10 \mathrm{mg}, 0.04 \mathrm{mmol})$, cataCXium $\mathrm{A}^{\circledR}(16 \mathrm{mg}, 0.04 \mathrm{mmol})$ and $\mathrm{K}_{2} \mathrm{CO}_{3}(123 \mathrm{mg}$, $0.89 \mathrm{mmol})$ in 1,4-dioxane $(2 \mathrm{~mL})$ and $\mathrm{H}_{2} \mathrm{O}(1 \mathrm{~mL})$ was heated at $100{ }^{\circ} \mathrm{C}$ in a microwave reactor for $1 \mathrm{~h}$. The reaction mixture was allowed to cool to rt, diluted with EtOAc $(20 \mathrm{~mL})$, filtered through Celite ${ }^{\circledR}$ and concentrated in vacuo. The resulting solid was purified by silica gel chromatography (0-50\% EtOH in EtOAc). The appropriate fractions were combined and solvent evaporated in vacuo to give 46 (107 mg, $0.22 \mathrm{mmol}, 48 \%$ ) as a yellow solid; 
${ }^{1} \mathrm{H}$ NMR $\left(400 \mathrm{MHz}, \mathrm{CD}_{3} \mathrm{OD}\right) \delta \mathrm{ppm} 7.81(\mathrm{~d}, J=1.0,1 \mathrm{H}), 7.63(\mathrm{~s}, 1 \mathrm{H}), 5.81-5.87(\mathrm{~m}, 1 \mathrm{H}), 4.34-4.29(\mathrm{~m}, 2 \mathrm{H}), 4.10-$ $4.03(\mathrm{~m}, 1 \mathrm{H}), 3.99-3.95(\mathrm{~m}, 2 \mathrm{H}), 3.13-3.09(\mathrm{~m}, 4 \mathrm{H}), 2.65-2.60(\mathrm{~m}, 2 \mathrm{H}), 2.42-2.38(\mathrm{~m}, 3 \mathrm{H}), 2.23(\mathrm{~d}, J=1.0,3 \mathrm{H})$, 2.23-2.21 (m, 3H), 1.80-1.72 (m, 4H), $1.45(\mathrm{~s}, 9 \mathrm{H})$; LCMS (formic acid): $\mathrm{R}_{\mathrm{t}}=0.58 \mathrm{~min}(81 \%)$, LRMS (M + $\mathrm{H})^{+}$calculated for $\mathrm{C}_{27} \mathrm{H}_{40} \mathrm{~N}_{5} \mathrm{O}_{4} 498.3$; found 498.3 .

8-((1-(3-Aminopropyl)piperidin-4-yl)amino)-3-methyl-5-(tetrahydro-2H-pyran-4-yl)-1,7-naphthyridin-2(1H)one (15)<smiles>Cc1cc2c(C3CCOCC3)cnc(NC3CCN(CCCN)CC3)c2[nH]c1=O</smiles>

A solution of 46 (77 mg, $0.16 \mathrm{mmol})$ in $\mathrm{EtOH}(20 \mathrm{~mL})$ was hydrogenated in the H-Cube using a $10 \% \mathrm{Pd} / \mathrm{C}$ cat cart $\left(50{ }^{\circ} \mathrm{C}, 40\right.$ barr pressure) for $3 \mathrm{~h}$. The reaction mixture was concentrated in vacuo to give a yellow solid. The solid was dissolved in $4 \mathrm{M} \mathrm{HCl}$ in 1,4-dioxane $(3 \mathrm{~mL}, 12.00 \mathrm{mmol}$ ) and left to stir at rt for $2 \mathrm{~h}$. The reaction mixture was concentrated in vacuo and the resulting solid was purified by MDAP (high $\mathrm{pH}$ ). The appropriate fractions were combined and solvent evaporated in vacuo to give 15 (18 mg, $0.05 \mathrm{mmol}, 30 \%)$ as a yellow solid; ${ }^{1} \mathrm{H}$ NMR (400 MHz, CD $\mathrm{CD}_{3} \mathrm{O}$ ppm $7.97(\mathrm{~s}, 1 \mathrm{H}), 7.62(\mathrm{~s}, 1 \mathrm{H}), 4.08-4.02(\mathrm{~m}, 2 \mathrm{H}), 4.00-3.90(\mathrm{~m}, 1 \mathrm{H}), 3.70-3.61(\mathrm{~m}, 2 \mathrm{H})$, $3.25-3.15(\mathrm{~m}, 1 \mathrm{H}), 3.02-2.96(\mathrm{~m}, 2 \mathrm{H}), 2.76-2.68(\mathrm{~m}, 2 \mathrm{H}), 2.48-2.42(\mathrm{~m}, 2 \mathrm{H}), 2.27(\mathrm{~s}, 3 \mathrm{H}), 2.24-2.16(\mathrm{~m}, 2 \mathrm{H}), 2.14-$ $2.07(\mathrm{~m}, 2 \mathrm{H}), 1.85-1.77(\mathrm{~m}, 4 \mathrm{H}), 1.76-1.69(\mathrm{~m}, 2 \mathrm{H}), 1.66-1.59(\mathrm{~m}, 2 \mathrm{H}) ; \mathrm{LCMS}($ high $\mathrm{pH}): \mathrm{R}_{\mathrm{t}}=0.71 \mathrm{~min}(100 \%)$, LRMS $(\mathrm{M}+\mathrm{H})^{+}$calculated for $\mathrm{C}_{22} \mathrm{H}_{34} \mathrm{~N}_{5} \mathrm{O}_{2} 400.3$; found 400.4 .

8-((1-(3-Aminopropyl)piperidin-4-yl)amino)-5-(3,6-dihydro-2H-pyran-4-yl)-3-methyl-1,7-naphthyridin-2(1H)one (16)<smiles>Cc1cc2c(C3=CCOCC3)cnc(NC3CCN(CCCN)CC3)c2[nH]c1=O</smiles>

46 (30 mg, $0.060 \mathrm{mmol}$ ) was dissolved in $4 \mathrm{M} \mathrm{HCl}$ in 1,4-dioxane ( $3 \mathrm{~mL}, 12.00 \mathrm{mmol}$ ) and left to stir at $\mathrm{rt}$ for $2 \mathrm{~h}$. The reaction mixture was concentrated in vacuo and the resulting solid was purified by MDAP (high pH). The appropriate fractions were combined and solvent evaporated in vacuo to give 16 (13 mg, $0.03 \mathrm{mmol}, 54 \%)$ as a yellow solid; m.p. $217-20^{\circ} \mathrm{C} ; v_{\max }\left(\right.$ solid)/cm ${ }^{-1}$ : $3387(\mathrm{~N}-\mathrm{H}), 2927,1655(\mathrm{C}=\mathrm{O}), 1583,1450,1121,850 ;{ }^{1} \mathrm{H} \mathrm{NMR}$ $\left(400 \mathrm{MHz}, \mathrm{DMSO}-\mathrm{d}_{6}\right) \delta \mathrm{ppm} 7.68(\mathrm{~d}, J=1.0,1 \mathrm{H}), 7.59(\mathrm{~s}, 1 \mathrm{H}), 6.66(\mathrm{~d}, J=6.8,1 \mathrm{H}), 5.73-5.69(\mathrm{~m}, 1 \mathrm{H}), 4.71$ (br.s, $3 \mathrm{H}), 4.25-4.20(\mathrm{~m}, 2 \mathrm{H}), 3.97-3.88(\mathrm{~m}, 1 \mathrm{H}), 3.87-3.82(\mathrm{~m}, 2 \mathrm{H}), 2.88-2.80(\mathrm{~m}, 2 \mathrm{H}), 2.60-2.53(\mathrm{~m}, 2 \mathrm{H}), 2.35-2.37$ $(\mathrm{m}, 4 \mathrm{H}), 2.13(\mathrm{~d}, J=1.0,3 \mathrm{H}), 2.04-1.92(\mathrm{~m}, 4 \mathrm{H}), 1.56-1.40(\mathrm{~m}, 4 \mathrm{H}) ;{ }^{13} \mathrm{C} \mathrm{NMR}\left(400 \mathrm{MHz}, \mathrm{DMSO}-\mathrm{d}_{6}\right) \delta \mathrm{ppm} \mathrm{162.2,}$ $145.3,136.9,133.4,133.2,131.2,126.5,122.1,120.8,79.1,64.8,63.6,55.8,52.3,47.8,31.8,30.4$, 16.8; N.B. $1 C$ signal hidden under solvent peak; HRMS $(\mathrm{M}+\mathrm{H})^{+}$calculated for $\mathrm{C}_{22} \mathrm{H}_{32} \mathrm{~N}_{5} \mathrm{O}_{2}$ 398.2551; found 398.2563; LCMS (formic acid): $\mathrm{R}_{t}=0.35 \mathrm{~min}(100 \%)$, LRMS $(\mathrm{M}+\mathrm{H})^{+}$calculated for $\mathrm{C}_{22} \mathrm{H}_{32} \mathrm{~N}_{5} \mathrm{O}_{2} 398.2$; found 398.3.

tert-Butyl 4-((2-(benzyloxy)-5-(3,6-dihydro-2H-pyran-4-yl)-3-methyl-1,7-naphthyridin-8-yl)amino)piperidine1-carboxylate (47)<smiles>Cc1cc2c(C3=CCOCC3)cnc(NC3CCN(C(C)(C)C)CC3)c2nc1OCc1ccccc1</smiles>

2-(3,6-Dihydro-2H-pyran-4-yl)-4,4,5,5-tetramethyl-1,3,2-dioxaborolane (0.593 g, $2.82 \mathrm{mmol})$ was added at rt to a stirred mixture of 26 (1.163 g, $2.205 \mathrm{mmol})$, potassium carbonate $(0.609 \mathrm{~g}, 4.41 \mathrm{mmol}), \mathrm{Pd}(\mathrm{OAc})_{2}(0.044 \mathrm{~g}, 0.20$ $\mathrm{mmol})$, and butyldi-1-adamantylphosphine $(0.070 \mathrm{~g}, 0.20 \mathrm{mmol})$ in 1,4-dioxane $(9.80 \mathrm{~mL})$ and $\mathrm{H}_{2} \mathrm{O}(4.90 \mathrm{~mL})$. The resultant reaction mixture was then heated at $100{ }^{\circ} \mathrm{C}$ for 1 hour in a microwave reactor. This was repeated a further three times across three different vessels. The third repeat required a further addition of 2-(3,6-dihydro$2 \mathrm{H}$-pyran-4-yl)-4,4,5,5-tetramethyl-1,3,2-dioxaborolane $(0.710 \mathrm{~g}, 3.38 \mathrm{mmol})$ and was heated to $100{ }^{\circ} \mathrm{C}$ for a further $30 \mathrm{~min}$ in a microwave reactor. The four reaction mixtures were allowed to cool to rt before being 
combined and diluted with EtOAc $(80 \mathrm{~mL})$. The combined mixture was filtered through Celite ${ }^{\circledR}$ and concentrated in vacuo before being purified by silica chromatography (0-50\% EtOAc in cyclohexane). The relevant fractions were combined and concentrated in vacuo to yield $47(4.42 \mathrm{~g}, 8.33 \mathrm{mmol}, 86 \%)$ as an orange solid. m.p. 163-169 ${ }^{\circ} \mathrm{C} ; \mathrm{v}_{\max }(\mathrm{solid}) / \mathrm{cm}^{-1}$ : $3385(\mathrm{~N}-\mathrm{H}), 2926,2849,1683(\mathrm{C}=0), 1517,1422,1151,701 ;{ }^{1} \mathrm{H} \mathrm{NMR}(400 \mathrm{MHz}$, CHLOROFORM-d) $\delta$ ppm 7.89-7.87 (m, $1 \mathrm{H}), 7.78(\mathrm{~s}, 1 \mathrm{H})$, 7.56-7.50 (m, $2 \mathrm{H})$, 7.47-7.40 (m, $2 \mathrm{H}), 7.38(\mathrm{~m}, 1 \mathrm{H})$, $6.24(\mathrm{~d}, J=8.3 \mathrm{~Hz}, 1 \mathrm{H}), 5.84-5.80(\mathrm{~m}, 1 \mathrm{H}), 5.55(\mathrm{~s}, 2 \mathrm{H}), 4.41$ (app. q, J=2.8 Hz, $2 \mathrm{H}), 4.35-4.23(\mathrm{~m}, 1 \mathrm{H}), 4.16-4.06$ $(\mathrm{m}, 2 \mathrm{H}), 4.02(\mathrm{t}, J=5.4 \mathrm{~Hz}, 2 \mathrm{H}), 3.16-3.04(\mathrm{~m}, 2 \mathrm{H}), 2.52-2.46(\mathrm{~m}, 2 \mathrm{H}), 2.44(\mathrm{~d}, J=1.0 \mathrm{~Hz}, 3 \mathrm{H}), 2.21-2.13(\mathrm{~m}, 2 \mathrm{H})$, 1.60-1.52 (m, $11 \mathrm{H})$; HRMS $(\mathrm{M}+\mathrm{H})^{+}$calculated for $\mathrm{C}_{31} \mathrm{H}_{39} \mathrm{~N}_{4} \mathrm{O}_{4}$ 531.2971; found 531.2978; LCMS (formic): $\mathrm{Rt}=$ $1.00 \min (98 \%)$, LRMS $(\mathrm{M}+\mathrm{H})^{+}$calculated for $\mathrm{C}_{31} \mathrm{H}_{39} \mathrm{~N}_{4} \mathrm{O}_{4} 531.3$; found 531.5.

\section{5-(3,6-Dihydro-2H-pyran-4-yl)-3-methyl-8-(piperidin-4-ylamino)-1,7-naphthyridin-2(1H)-one (27)}<smiles>COCCC1=CCOCC1</smiles>

$47(0.878 \mathrm{~g}, 1.66 \mathrm{mmol})$ was dissolved in TFA $(7 \mathrm{~mL})$ and stirred at reflux for 3 hours. The volatile components were removed in vacuo. To the resultant residue was added toluene $(15 \mathrm{~mL})$ and concentrated in vacuo $(\times 3)$. The resulting residue was diluted with $\mathrm{MeOH}(20 \mathrm{~mL})$ and passed through a preconditioned $(100 \mathrm{~mL} \mathrm{MeOH})$ aminopropyl column (70 g). The column was washed with $\mathrm{MeOH}(150 \mathrm{~mL})$ and the desired fractions combined and concentrated in vacuo yielding $27(0.536 \mathrm{~g}, 1.57 \mathrm{mmol}, 95 \%)$ as a yellow solid. m.p. $252-256{ }^{\circ} \mathrm{C} ; \mathrm{v}_{\max }$ (solid)/cm ${ }^{-1}$ : 3395 (N-H), 2925, 1658 (C=O), 1593, 1524, 1450, 1127, 845; ${ }^{1} \mathrm{H}$ NMR (400 MHz, CHLOROFORM-d) $\delta$ ppm 7.86-7.83 (m, $1 \mathrm{H}), 7.79(\mathrm{~s}, 1 \mathrm{H}), 6.59(\mathrm{~d}, J=6.8 \mathrm{~Hz}, 1 \mathrm{H}), 5.80-5.65(\mathrm{~m}, 1 \mathrm{H}), 4.43-4.36(\mathrm{~m}, 2 \mathrm{H}), 4.33-4.21(\mathrm{~m}$, $1 \mathrm{H}), 4.01(\mathrm{t}, J=5.3 \mathrm{~Hz}, 2 \mathrm{H}), 3.27-3.16(\mathrm{~m}, 2 \mathrm{H}), 2.92-2.81(\mathrm{~m}, 2 \mathrm{H}), 2.49-2.42(\mathrm{~m}, 2 \mathrm{H}), 2.37(\mathrm{~d}, J=1.0 \mathrm{~Hz}, 3 \mathrm{H}), 2.27-$ $2.18(\mathrm{~m}, 2 \mathrm{H}), 1.62$ (qd, J=11.8, $3.9 \mathrm{~Hz}, 2 \mathrm{H}$ ) (N.B. exchangeable lactam and piperidine amine protons not visible); ${ }^{13} \mathrm{C}$ NMR (101 MHz, CHLOROFORM-d) $\delta$ ppm 164.4, 146.0, 138.5, 135.7, 132.9, 131.6, 127.0, 122.5, 122.4, 120.3, 65.7, 64.5, 48.8, 45.9, 34.1, 31.1, 17.6; HRMS (M + H)+ calculated for $\mathrm{C}_{19} \mathrm{H}_{25} \mathrm{~N}_{4} \mathrm{O}_{2}$, 341.1978; found 341.1976; LCMS (formic): $\mathrm{R}_{t}=0.39 \min (96 \%)$, LRMS $(\mathrm{M}+\mathrm{H})^{+}$calculated for $\mathrm{C}_{19} \mathrm{H}_{25} \mathrm{~N}_{4} \mathrm{O}_{2}$ 341.2; found 341.0.

3-(4-((5-(3,6-Dihydro-2H-pyran-4-yl)-3-methyl-2-oxo-1,2-dihydro-1,7-naphthyridin-8-yl)amino)piperidin-1yl)propanamide (17)<smiles>Cc1cc2c(C3=CCOCC3)cnc(NC3CCN(CCC(N)=O)CC3)c2[nH]c1=O</smiles>

Acrylamide $(0.017 \mathrm{~g}, 0.24 \mathrm{mmol})$ was added at rt to a stirred solution of $27(0.081 \mathrm{~g}, 0.24 \mathrm{mmol})$ and dolomite $(0.022 \mathrm{~g}, 0.12 \mathrm{mmol})$ in $\mathrm{H}_{2} \mathrm{O}(2 \mathrm{~mL})$. The reaction was stirred vigorously at $\mathrm{rt}$ for 96 hours. Further acrylamide $(0.068 \mathrm{~g}, 0.95 \mathrm{mmol})$ was added and the reaction stirred vigorously for 5 hours. The reaction mixture was allowed to settle, and the solution decanted away from the dolomite and concentrated in vacuo. The resultant solid was dissolved in 1:1 MeOH:DMSO and purified by MDAP (high $\mathrm{pH}$ ). The relevant fractions were combined and concentrated in vacuo yielding $17(22 \mathrm{mg}, 0.053 \mathrm{mmol}, 23 \%)$ as a yellow solid. m.p. $241-246{ }^{\circ} \mathrm{C} ; v_{\max }(\mathrm{solid}) / \mathrm{cm}^{-}$ 1: 3398 (N-H), 2940, 1660 (C=O), 1594, 1455, 1123, 843; ${ }^{1} \mathrm{H}$ NMR (400 MHz, DMSO- $d_{6}, 393 \mathrm{~K}$ ) $\delta$ ppm 7.68-7.66 $(\mathrm{m}, 1 \mathrm{H}), 7.60(\mathrm{~s}, 1 \mathrm{H}), 6.76-6.49(\mathrm{~m}, 2 \mathrm{H}), 6.47-6.39(\mathrm{~m}, 1 \mathrm{H}), 5.77-5.72(\mathrm{~m}, 1 \mathrm{H}), 4.26$ (app. q, J=2.8 Hz, $2 \mathrm{H}), 4.08-$ $3.95(\mathrm{~m}, 1 \mathrm{H}), 3.89$ (t, J=5.4 Hz, $2 \mathrm{H}), 2.62(\mathrm{t}, J=7.1 \mathrm{~Hz}, 2 \mathrm{H}), 2.40-2.32(\mathrm{~m}, 2 \mathrm{H}), 2.27$ (t, J=7.1 Hz, $2 \mathrm{H}), 2.25-2.14$ $(\mathrm{m}, 5 \mathrm{H}), 2.05-1.95(\mathrm{~m}, 2 \mathrm{H}), 1.63-1.51(\mathrm{~m}, 2 \mathrm{H})$ (N.B. exchangeable lactam proton not visible and signal obscured by $\mathrm{H}_{2} \mathrm{O}$ peak but visible on $\mathrm{rt}^{1} \mathrm{H}$ NMR spectrum at $\left.2.89-2.80 \mathrm{ppm}(\mathrm{m}, 2 \mathrm{H})\right)$; HRMS $(\mathrm{M}+\mathrm{H})^{+}$calculated for $\mathrm{C}_{22} \mathrm{H}_{30} \mathrm{~N}_{5} \mathrm{O}_{3}$ 412.2349; found 412.2352; LCMS (high $\mathrm{pH}$ ): $\mathrm{R}_{\mathrm{t}}=0.71 \mathrm{~min}(100 \%)$, LRMS $(\mathrm{M}+\mathrm{H})^{+}$calculated for $\mathrm{C}_{22} \mathrm{H}_{30} \mathrm{~N}_{5} \mathrm{O}_{3} 411.2$; found 412.1 .

tert-Butyl (3-(4-((5-(5-(hydroxymethyl)pyridin-3-yl)-3-methyl-2-oxo-1,2-dihydro-1,7-naphthyridin-8yl)amino)piperidin-1-yl)propyl)carbamate (48) 
<smiles>Cc1cc(-c2cnc(NC3CCN(CCCNC(C)(C)C)CC3)c3[nH]c(=O)c(C)cc23)ccn1</smiles>

A mixture of 42 (300 mg, $0.61 \mathrm{mmol}),(5-($ hydroxymethyl)pyridin-3-yl)boronic acid (184 mg, $1.21 \mathrm{mmol})$, $\mathrm{Pd}(\mathrm{OAc})_{2}(20 \mathrm{mg}, 0.09 \mathrm{mmol})$, butyldi-1-adamantylphosphine $(32 \mathrm{mg}, 0.09 \mathrm{mmol}$ ) and potassium carbonate (201 $\mathrm{mg}, 1.46 \mathrm{mmol})$ in 1,4-dioxane $(3 \mathrm{~mL})$ and $\mathrm{H}_{2} \mathrm{O}(1.5 \mathrm{~mL})$ was heated at $100^{\circ} \mathrm{C}$ in a microwave reactor for 1 hour. The reaction mixture was allowed to cool to rt, diluted with EtOAc $(20 \mathrm{~mL})$, filtered through Celite ${ }^{\circledR}$ and concentrated in vacuo. The resulting residue was purified by silica gel chromatography (0-100\% EtOH in EtOAc). The appropriate fractions were combined and concentrated in vacuo to give $\mathbf{4 8}$ (305 mg, $0.59 \mathrm{mmol}, 96 \%)$ as a yellow solid. ${ }^{1} \mathrm{H}$ NMR $\left(400 \mathrm{MHz}, \mathrm{CD}_{3} \mathrm{OD}\right) \delta \mathrm{ppm} 7.73(\mathrm{~s}, 1 \mathrm{H}), 7.71(\mathrm{~s}, 1 \mathrm{H}), 7.50-7.26(\mathrm{~m}, 4 \mathrm{H}), 4.70(\mathrm{~s}, 2 \mathrm{H}), 4.15-$ $4.03(\mathrm{~m}, 1 \mathrm{H}), 3.15-3.07(\mathrm{~m}, 4 \mathrm{H}), 2.59-2.50(\mathrm{~m}, 2 \mathrm{H}), 2.42-2.31(\mathrm{~m}, 2 \mathrm{H}), 2.23-2.14(\mathrm{~m}, 5 \mathrm{H}), 1.81-1.68(\mathrm{~m}, 4 \mathrm{H})$, $1.46(\mathrm{~s}, 9 \mathrm{H})$ N.B. Lactam and hydroxy proton not visible; LCMS (formic): $\mathrm{R}_{\mathrm{t}}=0.61 \mathrm{~min}(96 \%)$, LRMS (M + $\mathrm{H})^{+}$calculated for $\mathrm{C}_{28} \mathrm{H}_{39} \mathrm{~N}_{6} \mathrm{O}_{4} 523.3$; found 523.3

8-((1-(3-Aminopropyl)piperidin-4-yl)amino)-5-(3-(hydroxymethyl)phenyl)-3-methyl-1,7-naphthyridin-2(1H)one (18)<smiles>Cc1cc2c(-c3cncc(CO)c3)cnc(NC3CCN(CCCN)CC3)c2[nH]c1=O</smiles>

$48(50 \mathrm{mg}, 0.10 \mathrm{mmol})$ was stirred in $4 \mathrm{M} \mathrm{HCl}$ in 1,4-dioxane $(2 \mathrm{~mL}, 8.00 \mathrm{mmol})$ for 18 hours at rt. The reaction mixture was concentrated in vacuo and the resulting solid suspended in $\mathrm{Et}_{2} \mathrm{O}(10 \mathrm{~mL})$. The solvent was removed using a pipette and the remaining solid concentrated in vacuo. The resulting solid was purified by MDAP (formic). The appropriate fractions were combined and concentrated in vacuo. The resulting residue was dissolved in $\mathrm{MeOH}(10 \mathrm{~mL})$ and passed through a preconditioned $(10 \mathrm{~mL} \mathrm{MeOH})$ aminopropyl column $(5 \mathrm{~g})$, which was then washed with $\mathrm{MeOH}(20 \mathrm{~mL})$. The filtrate was concentrated in vacuo to give $18(9 \mathrm{mg}, 0.02 \mathrm{mmol}, 22 \%)$ as a yellow solid. ${ }^{1} \mathrm{H}$ NMR $\left(400 \mathrm{MHz}\right.$, METHANOL- $\left.d_{4}\right) \delta \mathrm{ppm} 8.57(\mathrm{~d}, J=1.7 \mathrm{~Hz}, 1 \mathrm{H}), 8.49(\mathrm{~d}, J=1.7 \mathrm{~Hz}, 1 \mathrm{H}), 7.90-7.86$ $(\mathrm{m}, 1 \mathrm{H}), 7.63(\mathrm{~s}, 1 \mathrm{H}), 7.58(\mathrm{~s}, 1 \mathrm{H}), 4.77(\mathrm{~s}, 2 \mathrm{H}), 4.10-3.99(\mathrm{~m}, 1 \mathrm{H}), 3.08-2.98(\mathrm{~m}, 2 \mathrm{H}), 2.79(\mathrm{t}, J=7.0 \mathrm{~Hz}, 2 \mathrm{H})$, $2.50(\mathrm{t}, \mathrm{J}=7.5 \mathrm{~Hz}, 2 \mathrm{H}), 2.30-2.11(\mathrm{~m}, 7 \mathrm{H}), 1.81-1.62(\mathrm{~m}, 4 \mathrm{H}) \mathrm{N}$.B. Exchangeable protons not visible; LCMS (formic): $\mathrm{R}_{\mathrm{t}}=0.37 \mathrm{~min}(100 \%)$, LRMS $(\mathrm{M}+\mathrm{H})^{+}$calculated for $\mathrm{C}_{23} \mathrm{H}_{31} \mathrm{~N}_{6} \mathrm{O}_{2} 423.2$; found 423.4 .

Rac tert-butyl (3-(4-((5-bromo-3-methyl-2-oxo-1,2-dihydro-1,7-naphthyridin-8-yl)amino)piperidin-1-yl)-2fluoro-3-oxopropyl)carbamate (49)<smiles>Cc1cc2c(Br)cnc(NC3CCN(C(=O)C(F)CNC(=O)O)CC3)c2[nH]c1=O</smiles>

$N$-Ethyl- $N$-isopropylpropan-2-amine $(0.155 \mathrm{~mL}, 0.890 \mathrm{mmol})$ was added to a stirred mixture of $38(100 \mathrm{mg}, 0.297$ $\mathrm{mmol})$, HATU (135 mg, $0.356 \mathrm{mmol}$ ) and 3-((tert-butoxycarbonyl)amino)-2-fluoropropanoate (153 mg, 0.741 $\mathrm{mmol}$ ) in DMF (2.5 mL). The resultant solution was stirred at $\mathrm{rt}$ for $15 \mathrm{~min}$ before being purified by MDAP (high $\mathrm{pH})$. The desired fractions were combined and concentrated in vacuo yielding $49(67 \mathrm{mg}, 0.13 \mathrm{mmol}, 43 \%)$ as an orange solid. m.p. $258-262{ }^{\circ} \mathrm{C} ; v_{\max }\left(\right.$ solid)/cm-1: $3379(\mathrm{~N}-\mathrm{H}), 2923,1661$ (C=O), 1601 (C=O), 1162; ${ }^{1} \mathrm{H}$ NMR (400 MHz, DMSO- $\left.d_{6}, 393 \mathrm{~K}\right) \delta$ ppm 11.19 (br. s, $\left.1 \mathrm{H}\right), 7.91(\mathrm{~s}, 1 \mathrm{H}), 7.82-7.77(\mathrm{~m}, 1 \mathrm{H}), 6.68(\mathrm{~d}, J=6.1 \mathrm{~Hz}, 1 \mathrm{H}), 6.46-6.37$ $(\mathrm{m}, 1 \mathrm{H}), 5.35$ (ddd, J=48.7, 7.2, 4.0 Hz, $1 \mathrm{H}), 4.31-4.20(\mathrm{~m}, 1 \mathrm{H}), 4.12-4.00(\mathrm{~m}, 2 \mathrm{H}), 3.53-3.32(\mathrm{~m}, 2 \mathrm{H}), 3.27-3.15$ $(\mathrm{m}, 2 \mathrm{H}), 2.22(\mathrm{~d}, J=1.2 \mathrm{~Hz}, 3 \mathrm{H}), 2.13-2.05(\mathrm{~m}, 2 \mathrm{H}), 1.61-1.49(\mathrm{~m}, 2 \mathrm{H}), 1.43(\mathrm{~s}, 9 \mathrm{H}) ; \mathrm{HRMS}(\mathrm{M}+\mathrm{H})^{+}$calculated for $\mathrm{C}_{22} \mathrm{H}_{30} \mathrm{BrFN}_{5} \mathrm{O}_{4}$ 526.1387; found 526.1449; LCMS (high pH): $\mathrm{R}_{\mathrm{t}}=1.04 \mathrm{~min}(89 \%), \mathrm{LRMS}(\mathrm{M}+\mathrm{H})^{+}$calculated for $\mathrm{C}_{22} \mathrm{H}_{30} \mathrm{BrFN}_{5} \mathrm{O}_{4}$ 526.1; found 525.9, 527.9

Rac-tert-butyl (3-(4-((5-bromo-3-methyl-2-oxo-1,2-dihydro-1,7-naphthyridin-8-yl)amino)piperidin-1-yl)-2fluoropropyl)carbamate (50) 


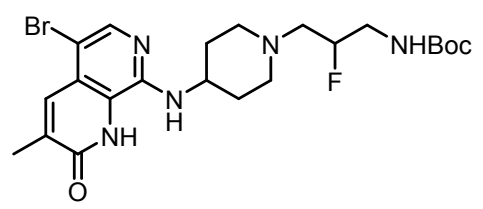

Under an inert atmosphere of nitrogen, 49 (564 mg, $1.07 \mathrm{mmol}$ ) was dissolved in anhydrous THF (40 mL) at rt. The stirred solution was then cooled to $0{ }^{\circ} \mathrm{C}$ before $2 \mathrm{M} \mathrm{LiAlH}$ in THF solution $(2.68 \mathrm{~mL}, 5.36 \mathrm{mmol}$ ) was added dropwise. The reaction mixture was stirred for a further $30 \mathrm{~min}$ at $0^{\circ} \mathrm{C}$. EtOAc $(40 \mathrm{~mL})$ was added slowly under nitrogen at $0^{\circ} \mathrm{C}$ with vigorous stirring. Saturated aq. Rochelle's salt solution $(40 \mathrm{~mL})$ was then added slowly under nitrogen at $0{ }^{\circ} \mathrm{C}$ with vigorous stirring. The resultant solution was stirred for 63 hours until two distinct layers were visible. The organic layer was separated and the aqueous layer extracted with EtOAc $(2 \times 40 \mathrm{~mL})$. The combined organic layers were concentrated in vacuo producing a yellow solid which was purified by silica chromatography $(0-30 \% \mathrm{EtOH}$ in EtOAc). The desired fractions were combined and concentrated in vacuo yielding 50 (151 mg, $0.295 \mathrm{mmol}, 28 \%$ ) as a yellow solid. ${ }^{1} \mathrm{H} \mathrm{NMR}$ (400 MHz, DMSO- $d_{6}, 393 \mathrm{~K}$ ) $\delta$ ppm 11.20 (br. $\mathrm{s}, 1 \mathrm{H}), 7.89(\mathrm{~s}, 1 \mathrm{H}), 7.80-7.78(\mathrm{~m}, 1 \mathrm{H}), 6.64-6.56(\mathrm{~m}, 1 \mathrm{H}), 6.39-6.32(\mathrm{~m}, 1 \mathrm{H})$, 4.78-4.56 (m, $1 \mathrm{H}), 4.04-3.92(\mathrm{~m}$, $1 \mathrm{H}), 3.36-3.15(\mathrm{~m}, 2 \mathrm{H}), 2.92-2.87(\mathrm{~m}, 2 \mathrm{H}), 2.65-2.56(\mathrm{~m}, 2 \mathrm{H}), 2.35-2.26(\mathrm{~m}, 2 \mathrm{H}), 2.22(\mathrm{~d}, J=1.3 \mathrm{~Hz}, 3 \mathrm{H}), 2.04-$ $1.96(\mathrm{~m}, 2 \mathrm{H}), 1.65-1.54(\mathrm{~m}, 2 \mathrm{H}), 1.43(\mathrm{~s}, 9 \mathrm{H})$; LCMS (high pH): $\mathrm{R}_{\mathrm{t}}=1.14 \mathrm{~min}(100 \%), \mathrm{LRMS}(\mathrm{M}+\mathrm{H})^{+}$calculated for $\mathrm{C}_{22} \mathrm{H}_{32} \mathrm{BrFN}_{5} \mathrm{O}_{3} 512.2$; found 512.1, 514.1

Rac-tert-butyl (3-(4-((5-(3,6-dihydro-2H-pyran-4-yl)-3-methyl-2-oxo-1,2-dihydro-1,7-naphthyridin-8yl)amino)piperidin-1-yl)-2-fluoropropyl)carbamate (51)<smiles>Cc1cc2c(C3=CCOCC3)cnc(NC3CCN(CC(F)CNC(C)(C)C)CC3)c2[nH]c1=O</smiles>

2-(3,6-Dihydro-2H-pyran-4-yl)-4,4,5,5-tetramethyl-1,3,2-dioxaborolane (79 $\mathrm{mg}, 0.38 \mathrm{mmol}$ ) was added at $\mathrm{rt}$ to a stirred mixture of 50 (150 mg, $0.29 \mathrm{mmol})$, potassium carbonate $(81 \mathrm{mg}, 0.59 \mathrm{mmol}), \mathrm{Pd}(\mathrm{OAc})_{2}(8 \mathrm{mg}, 0.03 \mathrm{mmol})$ and butyldi-1-adamantylphosphine $(12 \mathrm{mg}, 0.034 \mathrm{mmol})$ in 1,4-dioxane $(2 \mathrm{~mL})$ and $\mathrm{H}_{2} \mathrm{O}(1 \mathrm{~mL})$. The resultant reaction mixture was then heated at $100{ }^{\circ} \mathrm{C}$ for 1 hour in a microwave reactor then allowed to cool down to $\mathrm{rt}$ over 13 hours. The reaction mixture was diluted with EtOAc $(20 \mathrm{~mL})$ and filtered through Celite ${ }^{\circledR}$. The solution was concentrated in vacuo before being purified by silica chromatography (0-30\% EtOH in EtOAc). The relevant fractions were combined and concentrated in vacuo to yield $\mathbf{5 1}(75 \mathrm{mg}, 0.15 \mathrm{mmol}, 50 \%)$ as a yellow solid. ${ }^{1} \mathrm{H}$ NMR (400 MHz, DMSO- $\left.d_{6}, 393 \mathrm{~K}\right) \delta$ ppm 10.95 (br. s, $\left.1 \mathrm{H}\right), 7.68(\mathrm{~s}, 1 \mathrm{H}), 7.62(\mathrm{~s}, 1 \mathrm{H}), 6.42(\mathrm{~d}, J=6.8 \mathrm{~Hz}, 1 \mathrm{H}), 6.39-$ $6.32(\mathrm{~m}, 1 \mathrm{H}), 5.76-5.72(\mathrm{~m}, 1 \mathrm{H}), 4.77-4.58(\mathrm{~m}, 1 \mathrm{H}), 4.26$ (app. q, J=2.8 Hz, $2 \mathrm{H}), 4.06-3.97$ (m, $1 \mathrm{H}), 3.89$ (t, J=5.4 $\mathrm{Hz}, 2 \mathrm{H}), 3.32-3.19(\mathrm{~m}, 2 \mathrm{H}), 2.94-2.86(\mathrm{~m}, 2 \mathrm{H}), 2.65-2.56(\mathrm{~m}, 2 \mathrm{H}), 2.40-2.25(\mathrm{~m}, 4 \mathrm{H}), 2.17(\mathrm{~d}, J=1.0 \mathrm{~Hz}, 3 \mathrm{H})$, 2.04-1.96 (m, $2 \mathrm{H}), 1.65-1.53(\mathrm{~m}, 2 \mathrm{H}), 1.43(\mathrm{~s}, 9 \mathrm{H})$; HRMS $(\mathrm{M}+\mathrm{H})^{+}$calculated for $\mathrm{C}_{27} \mathrm{H}_{39} \mathrm{FN}_{5} \mathrm{O}_{4} 516.2986$; found 516.2987; LCMS (high pH): $\mathrm{R}_{t}=1.02 \mathrm{~min}(84 \%)$, LRMS $(\mathrm{M}+\mathrm{H})^{+}$calculated for $\mathrm{C}_{27} \mathrm{H}_{39} \mathrm{FN}_{5} \mathrm{O}_{4} 516.3$; found 516.2.

Rac 8-((1-(3-amino-2-fluoropropyl)piperidin-4-yl)amino)-5-(3,6-dihydro-2H-pyran-4-yl)-3-methyl-1,7naphthyridin-2(1H)-one (19)<smiles>Cc1cc2c(C3=CCOCC3)cnc(NC3CCN(CC(F)CN)CC3)c2[nH]c1=O</smiles>

52 (69 $\mathrm{mg}, 0.13 \mathrm{mmol}$ ) was dissolved in $4 \mathrm{M} \mathrm{HCl}$ in 1,4-dioxane $(7 \mathrm{~mL})$ at $\mathrm{rt}$. The resultant solution was stirred at rt for 2 hours before being concentrated in vacuo. The resultant solid was dissolved in 1:1 MeOH:DMSO and purified by MDAP (high $\mathrm{pH}$ ). The desired fractions were combined and concentrated in vacuo to yield 19 (29 mg, $0.070 \mathrm{mmol}, 52 \%$ ) as a yellow solid. m.p. $225-227^{\circ} \mathrm{C} ; \mathrm{v}_{\max }$ (solid)/cm $\mathrm{cm}^{-1}: 3390(\mathrm{~N}-\mathrm{H}), 2940,1683(\mathrm{C}=0), 1519,1418$, 1363, 1155, 736, 698; ${ }^{1} \mathrm{H}$ NMR (400 MHz, DMSO- $\left.d_{6}, 393 \mathrm{~K}\right) \delta \mathrm{ppm} 7.70-7.67(\mathrm{~m}, 1 \mathrm{H}), 7.62(\mathrm{~s}, 1 \mathrm{H}), 6.42(\mathrm{~d}, J=6.5$ $\mathrm{Hz}, 1 \mathrm{H}$ ), 5.77-5.72 (m, $1 \mathrm{H}$ ), 4.57 (dquin., J=49.4, 5.4 Hz, 1 H), 4.26 (app. q, J=2.7 Hz, $2 \mathrm{H}$ ), 4.08-3.95 (m, $1 \mathrm{H}$ ), 3.89 $(\mathrm{t}, J=5.4 \mathrm{~Hz}, 2 \mathrm{H}), 2.95-2.87(\mathrm{~m}, 2 \mathrm{H}), 2.86-2.76(\mathrm{~m}, 2 \mathrm{H}), 2.66-2.56(\mathrm{~m}, 2 \mathrm{H}), 2.39-2.25(\mathrm{~m}, 4 \mathrm{H}), 2.17(\mathrm{~d}, J=1.3 \mathrm{~Hz}$, $3 \mathrm{H}), 2.05-1.94(\mathrm{~m}, 2 \mathrm{H}), 1.65-1.52$ (m, $2 \mathrm{H}$ ) (N.B. exchangeable lactam and primary amine protons not visible); 
${ }^{19} \mathrm{~F}$ NMR $\left(376 \mathrm{MHz}\right.$, DMSO- $\left.d_{6}\right) \delta \mathrm{ppm}-184.64(\mathrm{~s}, 1 \mathrm{~F})$; HRMS $(\mathrm{M}+\mathrm{H}){ }^{+}$calculated for $\mathrm{C}_{22} \mathrm{H}_{31} \mathrm{FN}_{5} \mathrm{O}_{2} 416.2462$; found 416.2458; LCMS (high pH): $\mathrm{R}_{t}=0.75 \mathrm{~min}(100 \%)$, $\mathrm{LRMS}(\mathrm{M}+\mathrm{H})^{+}$calculated for $\mathrm{C}_{22} \mathrm{H}_{31} \mathrm{FN}_{5} \mathrm{O}_{2}$ 416.2; found 416.2.

tert-Butyl (3-(4-((5-bromo-3-methyl-2-oxo-1,2-dihydro-1,7-naphthyridin-8-yl)amino)piperidin-1-yl)-2,2difluoro-3-oxopropyl)carbamate (52)<smiles>Cc1cc2c(Br)cnc(NC3CCN(C(=O)C(F)(F)CNC(=O)O)CC3)c2[nH]c1=O</smiles>

38 (1141 mg, $3.383 \mathrm{mmol}$ ) was added at rt to a stirred solution of 3-((tert-butoxycarbonyl)amino)-2,2difluoropropanoic acid (750 mg, $3.33 \mathrm{mmol}$ ), HATU (3.799 g, $9.991 \mathrm{mmol}$ ) and $N$-ethyl- $N$-isopropylpropan-2amine $(2.61 \mathrm{~mL}, 15.0 \mathrm{mmol})$ in DMF $(17 \mathrm{~mL})$. The resultant solution was stirred at $\mathrm{rt}$ for 3 hours before being diluted with EtOAc $(40 \mathrm{~mL})$ and washed with $\mathrm{H}_{2} \mathrm{O}(40 \mathrm{~mL})$. A precipitate formed and was collected under reduced pressure yielding 52 (648 mg, $1.19 \mathrm{mmol}, 36 \%$ ) as a yellow solid. $v_{\max }(\mathrm{solid}) / \mathrm{cm}^{-1}: 3390(\mathrm{~N}-\mathrm{H}), 2930,1681$ (C=O), 1519, 1418, 1364, 1161, 699; ${ }^{1} \mathrm{H}$ NMR (400 MHz, DMSO-d, $\left.393 \mathrm{~K}\right) \delta$ ppm 11.18 (br. s, $1 \mathrm{H}$ ), 7.92 (s, $1 \mathrm{H}$ ), 7.82$7.79(\mathrm{~m}, 1 \mathrm{H}), 6.73-6.64(\mathrm{~m}, 1 \mathrm{H}), 6.56-6.44(\mathrm{~m}, 1 \mathrm{H}), 4.35-4.24(\mathrm{~m}, 1 \mathrm{H}), 4.20-4.09(\mathrm{~m}, 2 \mathrm{H}), 3.72(\mathrm{td}, J=15.4,6.4$ $\mathrm{Hz}, 2 \mathrm{H}), 3.39-3.26(\mathrm{~m}, 2 \mathrm{H}), 2.23(\mathrm{~d}, \mathrm{~J}=1.3 \mathrm{~Hz}, 3 \mathrm{H}), 2.18-2.07(\mathrm{~m}, 2 \mathrm{H}), 1.64-1.52(\mathrm{~m}, 2 \mathrm{H}), 1.44(\mathrm{~s}, 9 \mathrm{H}) ;$ LCMS (high pH): $\mathrm{R}_{\mathrm{t}}=1.15 \mathrm{~min}(100 \%), \operatorname{LRMS}(\mathrm{M}+\mathrm{H})^{+}$calculated for $\mathrm{C}_{22} \mathrm{H}_{29} \mathrm{BrF}_{2} \mathrm{~N}_{5} \mathrm{O}_{4}$ 544.1; found 544.0, 546.0.

8-((1-(3-Amino-2,2-difluoropropyl)piperidin-4-yl)amino)-5-bromo-3-methyl-1,7-naphthyridin-2(1H)-one (53)<smiles>Cc1cc2c(Br)cnc(NC3CCN(CC(F)(F)CN)CC3)c2[nH]c1=O</smiles>

52 (530 mg, $0.97 \mathrm{mmol}$ ) was dissolved in THF $(10 \mathrm{~mL})$ at $\mathrm{rt}$ under a nitrogen atmosphere. $1 \mathrm{M} \mathrm{BH}_{3} \cdot \mathrm{THF}$ complex in THF solution ( $49 \mathrm{~mL}, 49 \mathrm{mmol}$ ) was then added under nitrogen and stirred at rt for 2 hours. To the solution was added $\mathrm{MeOH}(1 \mathrm{~mL})$ dropwise at $\mathrm{rt}$ under nitrogen (solution effervesced and generated an exotherm). The solution was stirred for 1.5 hours before being concentrated in vacuo producing a yellow solid. The resultant solid was dissolved in $\mathrm{MeOH}(20 \mathrm{~mL})$ and diluted with aq. $1 \mathrm{M} \mathrm{HCl}$ solution $(20 \mathrm{~mL})$ before being heated to $80^{\circ} \mathrm{C}$ for $45 \mathrm{~min}$. The solution was neutralised with saturated aq. $\mathrm{NaHCO}_{3}$ solution and extracted with $\mathrm{DCM}(40 \mathrm{~mL})$. The organic layer was separated and the aqueous layer extracted further with DCM $(3 \times 20 \mathrm{~mL})$. The organic fractions were combined, washed with brine $(40 \mathrm{~mL})$ and concentrated in vacuo generating $53(370 \mathrm{mg}, 0.86$ mmol, 88\%) as a yellow solid. m.p. 204-209 ${ }^{\circ} \mathrm{C} ; \mathrm{v}_{\max }$ (solid)/cm ${ }^{-1}: 3395$ (N-H), 2935, 1658 (C=O), 1524, 1444, 1044, 857; ${ }^{1} \mathrm{H}$ NMR $\left(400 \mathrm{MHz}\right.$, DMSO- $\left.d_{6}, 393 \mathrm{~K}\right) \delta \mathrm{ppm} 7.91(\mathrm{~s}, 1 \mathrm{H}), 7.83-7.79(\mathrm{~m}, 1 \mathrm{H}), 6.83(\mathrm{~d}, J=6.6 \mathrm{~Hz}, 1 \mathrm{H}), 3.94-$ $3.83(\mathrm{~m}, 1 \mathrm{H}), 3.00-2.89(\mathrm{~m}, 4 \mathrm{H}), 2.80(\mathrm{t}, \mathrm{J}=14.4 \mathrm{~Hz}, 2 \mathrm{H}), 2.38-2.30(\mathrm{~m}, 2 \mathrm{H}), 2.19(\mathrm{~d}, \mathrm{~J}=1.2 \mathrm{~Hz}, 3 \mathrm{H}), 2.00-1.90(\mathrm{~m}$, $2 \mathrm{H}), 1.56-1.45\left(\mathrm{~m}, 2 \mathrm{H}\right.$ ) (N.B. exchangeable lactam and primary amine protons not visible); HRMS $(\mathrm{M}+\mathrm{H})^{+}$ calculated for $\mathrm{C}_{17} \mathrm{H}_{23} \mathrm{BrF}_{2} \mathrm{~N}_{5} \mathrm{O}$ 430.1054; found 430.1053; LCMS (high pH): $\mathrm{R}_{\mathrm{t}}=0.92 \mathrm{~min}$ (91\%), LRMS (M + $\mathrm{H})^{+}$calculated for $\mathrm{C}_{17} \mathrm{H}_{23} \mathrm{BrF}_{2} \mathrm{~N}_{5} \mathrm{O} 430.1$; found 430.1, 432.1 .

8-((1-(3-Amino-2,2-difluoropropyl)piperidin-4-yl)amino)-5-(3,6-dihydro-2H-pyran-4-yl)-3-methyl-1,7naphthyridin-2(1H)-one (20)<smiles>Cc1cc2c(C3=CCOCC3)cnc(NC3CCN(CC(F)(F)CN)CC3)c2[nH]c1=O</smiles>

2-(3,6-Dihydro-2H-pyran-4-yl)-4,4,5,5-tetramethyl-1,3,2-dioxaborolane (209 mg, $0.997 \mathrm{mmol}$ ) was added at rt to a stirred mixture of $53(335 \mathrm{mg}, 0.779 \mathrm{mmol})$, potassium carbonate $(215 \mathrm{mg}, 1.56 \mathrm{mmol}), \mathrm{Pd}(\mathrm{OAc})_{2}(18 \mathrm{mg}$, $0.078 \mathrm{mmol}$ ) and butyldi-1-adamantylphosphine (33 mg, $0.091 \mathrm{mmol})$ in 1,4-dioxane $(7 \mathrm{~mL})$ and $\mathrm{H}_{2} \mathrm{O}(3.5 \mathrm{~mL})$. The resultant reaction mixture was then heated at $100^{\circ} \mathrm{C}$ for 1 hour in a microwave reactor. The reaction mixture was allowed to cool to rt before being diluted with EtOAc $(20 \mathrm{~mL})$ and filtered through Celite ${ }^{\circledR}$. The resultant solution was concentrated in vacuo and dissolved in 1:1 MeOH:EtOAc $(0.8 \mathrm{~mL})$ and DCM $(0.2 \mathrm{~mL})$ before being purified by MDAP (high $\mathrm{pH}$ ). The desired fractions were combined and concentrated in vacuo yielding 20 (61 mg, $0.14 \mathrm{mmol}, 18 \%$ ) as a yellow solid. m.p. $220-223^{\circ} \mathrm{C} ; \mathrm{v}_{\max }(\mathrm{solid}) / \mathrm{cm}^{-1}: 3395(\mathrm{~N}-\mathrm{H}), 2925,1657(\mathrm{C}=0), 1593,1452$, 
1121, 842; ${ }^{1} \mathrm{H}$ NMR (400 MHz, DMSO- $\left.d_{6}\right) \delta$ ppm 7.71-7.69 (m, $\left.1 \mathrm{H}\right), 7.61(\mathrm{~s}, 1 \mathrm{H}), 6.66(\mathrm{~d}, J=6.5 \mathrm{~Hz}, 1 \mathrm{H}), 5.75-5.70$ $(\mathrm{m}, 1 \mathrm{H}), 4.26-4.22(\mathrm{~m}, 2 \mathrm{H}), 3.99-3.89(\mathrm{~m}, 1 \mathrm{H}), 3.86(\mathrm{t}, \mathrm{J}=5.3 \mathrm{~Hz}, 2 \mathrm{H}), 2.98-2.88(\mathrm{~m}, 4 \mathrm{H}), 2.79(\mathrm{t}, J=14.4 \mathrm{~Hz} 2 \mathrm{H})$, 2.35-2.27 (m, $4 \mathrm{H}), 2.14(\mathrm{~d}, J=1.0 \mathrm{~Hz}, 3 \mathrm{H}), 1.99-1.91(\mathrm{~m}, 2 \mathrm{H}), 1.55-1.44(\mathrm{~m}, 2 \mathrm{H})$ (N.B. exchangeable lactam and primary amine protons not visible); ${ }^{19} \mathrm{~F}$ NMR (376 MHz, DMSO- $\left.d_{6}\right) \delta \mathrm{ppm}-105.01(\mathrm{~s}, 1 \mathrm{~F}) ; \mathrm{HRMS}(\mathrm{M}+\mathrm{H})^{+}$ calculated for $\mathrm{C}_{22} \mathrm{H}_{30} \mathrm{~F}_{2} \mathrm{~N}_{5} \mathrm{O}_{2}$ 434.2368; found 434.2363; LCMS (high pH): $\mathrm{R}_{\mathrm{t}}=0.84 \mathrm{~min}$ (98\%), LRMS (M + $\mathrm{H})^{+}$calculated for $\mathrm{C}_{22} \mathrm{H}_{30} \mathrm{~F}_{2} \mathrm{~N}_{5} \mathrm{O}_{2}$ 434.2; found 434.1.

tert-Butyl

(3-(4-((5-(3,6-dihydro-2H-pyran-4-yl)-3-methyl-2-oxo-1,2-dihydro-1,7-naphthyridin-8yl)amino)piperidin-1-yl)-3-oxopropyl)carbamate (54)<smiles>CCCCNCCC(=O)N1CCC(Nc2ncc(C3=CCOCC3)c3[nH]c(=O)c(C)cc23)CC1</smiles>

HATU (378 mg, $0.993 \mathrm{mmol})$ and $N$-ethyl- $N$-isopropylpropan-2-amine $(0.259 \mathrm{~mL}, 1.49 \mathrm{mmol})$ were added at rt to a stirred solution of 27 (169 $\mathrm{mg}, 0.496 \mathrm{mmol})$ in DMF $(3 \mathrm{~mL})$. The reaction mixture was stirred at rt for 5 hours before being diluted with $\mathrm{H}_{2} \mathrm{O}(10 \mathrm{~mL})$ and extracted with EtOAc $(4 \times 10 \mathrm{~mL})$. The combined organic fractions were washed with brine $(10 \mathrm{~mL})$, passed through a hydrophobic frit and concentrated in vacuo. The resultant solid was dissolved in 1:1 MeOH:DMSO and purified by MDAP (formic). The desired fractions were combined and concentrated in vacuo yielding $54(104 \mathrm{mg}, 0.203 \mathrm{mmol}, 41 \%)$ as a cream solid. ${ }^{1} \mathrm{H}$ NMR (400 MHz, DMSO$\left.d_{6}, 393 \mathrm{~K}\right) \delta$ ppm 11.06 (br. s, $\left.1 \mathrm{H}\right), 7.71-7.67(\mathrm{~m}, 1 \mathrm{H}), 7.64(\mathrm{~s}, 1 \mathrm{H}), 6.53-6.40(\mathrm{~m}, 1 \mathrm{H}), 6.19-5.95(\mathrm{~m}, 1 \mathrm{H}), 5.78-$ $5.70(\mathrm{~m}, 1 \mathrm{H}), 4.27$ (app. q, J=2.8 Hz, $2 \mathrm{H}), 4.10-3.95(\mathrm{~m}, 1 \mathrm{H}), 3.89$ (t, J=5.4 Hz, $2 \mathrm{H}), 3.30-3.06(\mathrm{~m}, 4 \mathrm{H}), 2.56-2.51$ $(\mathrm{m}, 2 \mathrm{H}), 2.43-2.30(\mathrm{~m}, 2 \mathrm{H}), 2.17(\mathrm{~d}, \mathrm{~J}=1.0 \mathrm{~Hz}, 3 \mathrm{H}), 2.11-1.99(\mathrm{~m}, 2 \mathrm{H}), 1.56-1.34(\mathrm{~m}, 11 \mathrm{H})$ (N.B. signal obscured by $\mathrm{H}_{2} \mathrm{O}$ peak); LCMS (formic): $\mathrm{R}_{t}=0.69 \mathrm{~min}(100 \%)$, LRMS $(\mathrm{M}+\mathrm{H})^{+}$calculated for $\mathrm{C}_{27} \mathrm{H}_{38} \mathrm{~N}_{5} \mathrm{O}_{5} 512.3$; found 512.2.

\section{8-((1-(3-Aminopropanoyl)piperidin-4-yl)amino)-5-(3,6-dihydro-2H-pyran-4-yl)-3-methyl-1,7-naphthyridin-} 2(1H)-one, hydrochloride (21)<smiles>Cc1cc2c(C3=CCOCC3)cnc(NC3CCN(C(=O)CCN)CC3)c2[nH]c1=O</smiles>

54 (93 $\mathrm{mg}, 0.18 \mathrm{mmol}$ ) was dissolved in $4 \mathrm{M} \mathrm{HCl}$ in 1,4-dioxane $(2 \mathrm{~mL}$ ) at $\mathrm{rt}$. The resultant solution was stirred at $\mathrm{rt}$ for 2 hours before being concentrated in vacuo producing a yellow solid. The resultant solid was washed with $\mathrm{Et}_{2} \mathrm{O}$ and dried under reduced pressure yielding $21(20 \mathrm{mg}, 0.05 \mathrm{mmol}, 25 \%)$ as a cream solid. ${ }^{1} \mathrm{H} \mathrm{NMR}$ uninterpretable due to salt nature. LCMS (formic): $R_{t}=0.37 \mathrm{~min}(100 \%)[\mathrm{M}+\mathrm{H}]^{+}=412$. Characterization for free base compound: $v_{\max }$ (solid)/cm-1: $3390(\mathrm{~N}-\mathrm{H}), 2935,1680(\mathrm{C}=\mathrm{O}), 1621,1513,1417,1364,1126,761 ;{ }^{1} \mathrm{H} \mathrm{NMR}$ (400 MHz, DMSO- $\left.d_{6}, 393 \mathrm{~K}\right) \delta$ ppm 7.71-7.67 (m, $\left.1 \mathrm{H}\right), 7.64(\mathrm{~s}, 1 \mathrm{H}), 6.51-6.44(\mathrm{~m}, 1 \mathrm{H}), 5.77-5.73(\mathrm{~m}, 1 \mathrm{H}), 4.33-$ $4.23(\mathrm{~m}, 3 \mathrm{H}), 4.12-4.01(\mathrm{~m}, 2 \mathrm{H}), 3.89(\mathrm{t}, J=5.4 \mathrm{~Hz}, 2 \mathrm{H}), 3.19-3.08(\mathrm{~m}, 2 \mathrm{H}), 2.45(\mathrm{t}, J=6.5 \mathrm{~Hz}, 2 \mathrm{H}), 2.38-2.32(\mathrm{~m}$, $2 \mathrm{H}), 2.17(\mathrm{~d}, \mathrm{~J}=1.0 \mathrm{~Hz}, 3 \mathrm{H}), 2.09-2.00(\mathrm{~m}, 2 \mathrm{H}), 1.54-1.42(\mathrm{~m}, 2 \mathrm{H})$ (N.B. exchangeable lactam and primary amine protons not visible and signal obscured by $\mathrm{H}_{2} \mathrm{O}$ peak but visible on $\mathrm{rt}^{1} \mathrm{H}$ NMR spectrum at 2.78-2.73 ppm (m, 2 $\mathrm{H})$ ); $\mathrm{HRMS}(\mathrm{M}+\mathrm{H})^{+}$calculated for $\mathrm{C}_{22} \mathrm{H}_{30} \mathrm{~N}_{5} \mathrm{O}_{3}$ 412.2349; found 412.2341; LCMS (high pH): $\mathrm{R}_{t}=0.68 \mathrm{~min}(95 \%)$, LRMS $(\mathrm{M}+\mathrm{H})^{+}$calculated for $\mathrm{C}_{22} \mathrm{H}_{30} \mathrm{~N}_{5} \mathrm{O}_{3} 412.2$; found 412.5 .

Rac tert-butyl (3-(4-((5-(3,6-dihydro-2H-pyran-4-yl)-3-methyl-2-oxo-1,2-dihydro-1,7-naphthyridin-8yl)amino)piperidin-1-yl)-2-fluoro-3-oxopropyl)carbamate (55)<smiles>Cc1cc2c(C3=CCOCC3)cnc(NC3CCN(C(=O)C(F)CNC(=O)OCc4ccccc4)CC3)c2[nH]c1=O</smiles>

$N$-Ethyl- $N$-isopropylpropan-2-amine $(0.154 \mathrm{~mL}, 0.881 \mathrm{mmol})$ was added to a stirred mixture of $27(0.100 \mathrm{~g}, 0.294$ $\mathrm{mmol})$, HATU (134 mg, $0.352 \mathrm{mmol}$ ) and 3-((tert-butoxycarbonyl)amino)-2-fluoropropanoate (151 mg, 0.734 $\mathrm{mmol})$ in DMF $(2.5 \mathrm{~mL})$ at $\mathrm{rt}$. The resultant solution was stirred at $\mathrm{rt}$ for 15 minutes before being purified by 
MDAP (high pH). The desired fractions were combined yielding 55 (115 mg, $0.217 \mathrm{mmol}, 74 \%$ ) as an orange solid. m.p. $183-185^{\circ} \mathrm{C} ; v_{\max }\left(\right.$ solid)/cm ${ }^{-1}: 3385(\mathrm{~N}-\mathrm{H}), 2927,1651$ (C=O), 1448, 1128, 722; ${ }^{\mathrm{H}} \mathrm{NMR}\left(400 \mathrm{MHz}, \mathrm{DMSO}-d_{6}\right.$, 393 K) $\delta$ ppm 7.71-7.67 (m, 1 H), 7.64 (s, 1 H), 6.38 (br. s, 1 H), 5.79-5.73 (m, 1 H), 5.35 (ddd, J=48.9, 7.1, 4.2 Hz, $1 \mathrm{H})$, 4.34-4.24 (m, $3 \mathrm{H}), 4.12-4.00(\mathrm{~m}, 2 \mathrm{H}), 3.89(\mathrm{t}, \mathrm{J}=5.4 \mathrm{~Hz}, 2 \mathrm{H}), 3.55-3.33(\mathrm{~m}, 2 \mathrm{H}), 3.28-3.16(\mathrm{~m}, 2 \mathrm{H}), 2.40-$ $2.32(\mathrm{~m}, 2 \mathrm{H}), 2.17(\mathrm{~d}, J=1.0 \mathrm{~Hz}, 3 \mathrm{H}), 2.14-2.05(\mathrm{~m}, 2 \mathrm{H}), 1.62-1.50(\mathrm{~m}, 2 \mathrm{H}), 1.43(\mathrm{~s}, 9 \mathrm{H})$ (N.B. exchangeable lactam and amine proton not visible); $\mathrm{HRMS}(\mathrm{M}+\mathrm{H})^{+}$calculated for $\mathrm{C}_{27} \mathrm{H}_{37} \mathrm{FN}_{5} \mathrm{O}_{5}$ 530.2779; found 530.2780; LCMS (high $\mathrm{pH}$ ): $\mathrm{R}_{\mathrm{t}}=0.97 \mathrm{~min}(96 \%)$, $\operatorname{LRMS}(\mathrm{M}+\mathrm{H})^{+}$calculated for $\mathrm{C}_{27} \mathrm{H}_{37} \mathrm{FN}_{5} \mathrm{O}_{5}$ 530.3; found 530.2.

Rac 8-((1-(3-amino-2-fluoropropanoyl)piperidin-4-yl)amino)-5-(3,6-dihydro-2H-pyran-4-yl)-3-methyl-1,7naphthyridin-2(1H)-one (22)<smiles>Cc1cc2c(C3=CCOCC3)cnc(NC3CCN(C(=O)C(F)CN)CC3)c2[nH]c1=O</smiles>

55 ( $85 \mathrm{mg}, 0.16 \mathrm{mmol}$ ) was dissolved in $4 \mathrm{M} \mathrm{HCl}$ in 1,4-dioxane $(2 \mathrm{~mL})$ and stirred at $\mathrm{rt}$ for 2 hours. The reaction mixture was concentrated in vacuo before being dissolved in 1:1 MeOH:DMSO and purified by MDAP (high pH). The desired fractions were combined and reduced under a positive pressure of nitrogen yielding 22 (30 mg, $0.070 \mathrm{mmol}, 44 \%)$ as a yellow solid. $\mathrm{V}_{\max }\left(\right.$ solid)/ $\mathrm{cm}^{-1}: 3381(\mathrm{~N}-\mathrm{H}), 2924,1655(\mathrm{C}=0), 1591,1448,1128,843 ;{ }^{1} \mathrm{H}$ NMR $\left(400 \mathrm{MHz}\right.$, DMSO-d $\left.d_{6}, 393 \mathrm{~K}\right) \delta$ ppm $7.69(\mathrm{~s}, 1 \mathrm{H}), 7.64(\mathrm{~s}, 1 \mathrm{H}), 6.50(\mathrm{~d}, \mathrm{~J}=5.4 \mathrm{~Hz}, 1 \mathrm{H}), 5.77-5.71(\mathrm{~m}, 1 \mathrm{H})$, 5.30-5.12 (m, $1 \mathrm{H}), 4.37-4.23(\mathrm{~m}, 3 \mathrm{H}), 4.15-4.01(\mathrm{~m}, 2 \mathrm{H}), 3.89(\mathrm{t}, \mathrm{J}=5.4 \mathrm{~Hz}, 2 \mathrm{H}), 3.26-3.15(\mathrm{~m}, 2 \mathrm{H}), 3.05-2.95(\mathrm{~m}$, $2 \mathrm{H}), 2.39-2.32(\mathrm{~m}, 2 \mathrm{H}), 2.17(\mathrm{~s}, 3 \mathrm{H}), 2.12-2.04(\mathrm{~m}, 2 \mathrm{H}), 1.59-1.47(\mathrm{~m}, 2 \mathrm{H})$ (N.B. exchangeable lactam and primary amine protons not visible); HRMS $(\mathrm{M}+\mathrm{H})^{+}$calculated for $\mathrm{C}_{22} \mathrm{H}_{29} \mathrm{FN}_{5} \mathrm{O}_{3} 430.2254$; found 430.2253; LCMS (high $\mathrm{pH}$ ): $\mathrm{R}_{\mathrm{t}}=0.70 \mathrm{~min}(97 \%)$, $\mathrm{LRMS}(\mathrm{M}+\mathrm{H})^{+}$calculated for $\mathrm{C}_{22} \mathrm{H}_{29} \mathrm{FN}_{5} \mathrm{O}_{3} 430.2$; found 430.1 .

tert-Butyl (3-(4-((5-(3,6-dihydro-2H-pyran-4-yl)-3-methyl-2-oxo-1,2-dihydro-1,7-naphthyridin-8yl)amino)piperidin-1-yl)-2,2-difluoro-3-oxopropyl)carbamate (56)<smiles>CCCCNCC(F)(F)C(=O)N1CCC(Nc2ncc(C3=CCOCC3)c3[nH]c(=O)c(C)cc23)CC1</smiles>

HATU (894 mg, $2.35 \mathrm{mmol}$ ) and $N$-ethyl- $N$-isopropylpropan-2-amine $(0.819 \mathrm{~mL}, 4.70 \mathrm{mmol})$ were added at rt to a stirred solution of 3-((tert-butoxycarbonyl)amino)-2,2-difluoropropanoic acid (318 mg, $1.41 \mathrm{mmol})$ in DMF (7 $\mathrm{mL}$ ). After 30 minutes $27(0.400 \mathrm{~g}, 1.18 \mathrm{mmol})$ was added at rt to the resultant stirred solution and the reaction mixture stirred for 5 hours. The reaction mixture was then diluted with $\mathrm{H}_{2} \mathrm{O}(10 \mathrm{~mL})$ and extracted with EtOAc $(4 \times 10 \mathrm{~mL})$. The combined organic fractions were washed with brine $(10 \mathrm{~mL})$, passed through a hydrophobic frit and concentrated in vacuo. The resultant solid was dissolved in 1:1 MeOH:DMSO and purified by MDAP (formic). The desired fractions were combined and concentrated in vacuo yielding 56 (168 mg, $0.307 \mathrm{mmol}, 26 \%)$ as a cream solid. ${ }^{1} \mathrm{H}$ NMR $\left(400 \mathrm{MHz}\right.$, DMSO- $\left.d_{6}, 393 \mathrm{~K}\right) \delta \mathrm{ppm}$ 7.71-7.68 (m, $\left.1 \mathrm{H}\right), 7.65-7.61(\mathrm{~m}, 1 \mathrm{H}), 6.53-6.44(\mathrm{~m}, 2$ H), 5.76 (br. s, 1 H), 4.40-4.30 (m, 1 H), 4.27 (app. q, J=2.4 Hz, 2 H), 4.17-4.11 (m, 2 H), 3.89 (t, J=5.4 Hz, 2 H), 3.72 (td, J=15.4, 6.4 Hz, $2 \mathrm{H}), 3.40-3.26(\mathrm{~m}, 2 \mathrm{H}), 2.38-2.32(\mathrm{~m}, 2 \mathrm{H}), 2.17(\mathrm{~d}, J=1.0 \mathrm{~Hz}, 3 \mathrm{H}), 2.16-2.08(\mathrm{~m}, 2 \mathrm{H}), 1.66-$ $1.52(\mathrm{~m}, 2 \mathrm{H}), 1.45-1.42$ (m, $9 \mathrm{H}$ ) (N.B. exchangeable lactam proton not visible); LCMS (formic): $R_{t}=0.81 \mathrm{~min}$ (100\%), LRMS $(\mathrm{M}+\mathrm{H})^{+}$calculated for $\mathrm{C}_{27} \mathrm{H}_{36} \mathrm{~F}_{2} \mathrm{~N}_{5} \mathrm{O}_{5} 548.3$; found 548.4.

8-((1-(3-Amino-2,2-difluoropropanoyl)piperidin-4-yl)amino)-5-(3,6-dihydro-2H-pyran-4-yl)-3-methyl-1,7naphthyridin-2(1H)-one, hydrochloride (23)<smiles>Cc1cc2c(C3=CCOCC3)cnc(NC3CCN(C(=O)C(F)(F)CN)CC3)c2[nH]c1=O</smiles>

A mixture of 56 (129 mg, $0.236 \mathrm{mmol})$ in $4 \mathrm{M} \mathrm{HCl}$ in 1,4-dioxane $(7 \mathrm{~mL})$ was stirred for 2 hours at rt before being concentrated in vacuo. The resultant solid was dissolved in 1:1 MeOH:DMSO and purified by MDAP (high pH) to 
yield 23 (42 mg, $0.094 \mathrm{mmol}, 40 \%$ ) as a yellow solid. m.p. 263-266 ${ }^{\circ} \mathrm{C} ; \mathrm{v}_{\max }($ solid)/(m-1.: $3390(\mathrm{~N}-\mathrm{H}), 2935,1658$ (C=O), 1622, 1449, 1121, 844; ${ }^{1} \mathrm{H}$ NMR (400 MHz, CHLOROFORM- $d$ ) $\delta$ ppm 13.19 (br. s, $\left.1 \mathrm{H}\right), 7.86-7.83$ (m, $1 \mathrm{H}$ ), $7.79(\mathrm{~s}, 1 \mathrm{H}), 6.67(\mathrm{~d}, J=7.1 \mathrm{~Hz}, 1 \mathrm{H}), 5.83-5.75(\mathrm{~m}, 1 \mathrm{H}), 4.61-4.46(\mathrm{~m}, 2 \mathrm{H}), 4.44-4.35(\mathrm{~m}, 3 \mathrm{H}), 4.01(\mathrm{t}, J=5.4 \mathrm{~Hz}, 2$ $\mathrm{H}), 3.44-2.94(\mathrm{~m}, 4 \mathrm{H}), 2.50-2.40(\mathrm{~m}, 2 \mathrm{H}), 2.37-2.24(\mathrm{~m}, 5 \mathrm{H}), 1.91-1.61(\mathrm{~m}, 2 \mathrm{H})$ (N.B. exchangeable primary amine protons not visible); ${ }^{13} \mathrm{C}$ NMR (101 MHz, CHLOROFORM- $d$ ) $\delta$ ppm 164.4, 145.7, 138.6, 135.9, 133.0, 131.4, $127.4,123.0,122.6,120.3,119.6,65.7,64.4,47.8,46.0,42.5,33.0,32.2,31.0,17.6 ;{ }^{19} \mathrm{~F} \mathrm{NMR}$ (376 MHz, DMSO$\left.d_{6}\right) \delta$ ppm -105.49 (br. s, $2 \mathrm{~F}$ ); HRMS (M + HM + H)+ calculated for $\mathrm{C}_{22} \mathrm{H}_{28} \mathrm{~F}_{2} \mathrm{~N}_{5} \mathrm{O}_{3}$ 448.2160; found 448.2162; LCMS (high pH): $\mathrm{R}_{\mathrm{t}}=0.79 \mathrm{~min}(100 \%)$, LRMS $(\mathrm{M}+\mathrm{H})^{+}$calculated for $\mathrm{C}_{22} \mathrm{H}_{28} \mathrm{~F}_{2} \mathrm{~N}_{5} \mathrm{O}_{3} 448.2$; found 448.3 .

\section{Rac methyl 2-(bis(2,2,2-trifluoroethoxy)phosphoryl)hex-5-enoate (57)}

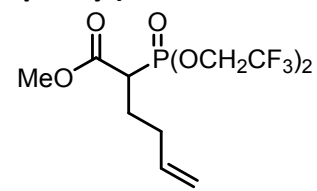

To a stirred solution of methyl 2-(bis(2,2,2-trifluoroethoxy)phosphoryl)acetate (1.33 $\mathrm{mL}, 6.29 \mathrm{mmol}$ ) in DMSO $(10 \mathrm{~mL})$ was added sodium hydride in oil $60 \mathrm{wt} \%(0.166 \mathrm{~g}, 6.92 \mathrm{mmol})$. The resultant reaction mixture was stirred at $\mathrm{rt}$ for $20 \mathrm{~min}$ before 4-bromobut-1-ene $(0.83 \mathrm{~mL}, 8.2 \mathrm{mmol})$ was added dropwise at $\mathrm{rt}$. The resultant solution was stirred at rt for 21 hours. A further portion of 4-bromobut-1-ene $(0.32 \mathrm{~mL}, 3.1 \mathrm{mmol})$ was added and the solution stirred for 1 hour at rt. The solution was then diluted with saturated aq. $\mathrm{NH}_{4} \mathrm{Cl}$ solution $(50 \mathrm{~mL})$ and EtOAc $(50 \mathrm{~mL})$. The aqueous layer was separated and extracted with EtOAc $(2 \times 50 \mathrm{~mL})$. The combined organic fractions were passed through a hydrophobic frit and concentrated in vacuo. The resultant orange oil was purified by silica chromatography (0-100\% EtOAc in cyclohexane). The desired fractions were combined and concentrated in vacuo yielding $57(509 \mathrm{mg}, 1.37 \mathrm{mmol}, 22 \%)$ as a colourless oil. ${ }^{1} \mathrm{H} \mathrm{NMR} \mathrm{(400} \mathrm{MHz}$, CHLOROFORM- $d$ ) $\delta$ ppm 5.75 (ddt, J=17.6, 9.8, 6.6, $6.6 \mathrm{~Hz}, 1 \mathrm{H}), 5.11-5.08(\mathrm{~m}, 1 \mathrm{H}), 5.08-5.05(\mathrm{~m}, 1 \mathrm{H}), 4.51-4.36$ $(\mathrm{m}, 4 \mathrm{H}), 3.80(\mathrm{~s}, 3 \mathrm{H}), 3.23-3.13(\mathrm{~m}, 1 \mathrm{H}), 2.28-1.93(\mathrm{~m}, 4 \mathrm{H})$.

\section{3-(But-3-en-1-yl)-8-chloro-1,7-naphthyridin-2(1H)-one (58)}<smiles>C=CCCc1cc2ccnc(Cl)c2[nH]c1=O</smiles>

To a solution of 57 ( $509 \mathrm{mg}, 1.37 \mathrm{mmol})$ in THF (15 mL) was added 18-crown-6 (772 mg, $2.92 \mathrm{mmol})$. The resulting solution was cooled to $-78{ }^{\circ} \mathrm{C}$ and potassium bis(trimethylsilyl)amide (291 mg, $1.461 \mathrm{mmol}$ ) added in portions. The resultant mixture was allowed to warm to $-45{ }^{\circ} \mathrm{C}$ and stirred for 1.5 hours. tert-butyl (2-chloro-4formylpyridin-3-yl)carbamate ${ }^{2}(0.250 \mathrm{~g}, 0.974 \mathrm{mmol})$ in THF $(2.26 \mathrm{~mL})$ was then added to the solution at $-78^{\circ} \mathrm{C}$ and the resultant solution stirred at $-78^{\circ} \mathrm{C}$ for 1.5 hours. To the stirred solution at $-78{ }^{\circ} \mathrm{C}$ was added saturated aq. $\mathrm{NH}_{4} \mathrm{Cl}$ solution $(15 \mathrm{~mL})$ and $\mathrm{Et}_{2} \mathrm{O}(15 \mathrm{~mL})$ and the solution allowed to warm to $\mathrm{rt}$. The layers were separated and the aqueous extracted further with $\mathrm{Et}_{2} \mathrm{O}(10 \mathrm{~mL})$. The organic layers were combined, washed with brine (10 $\mathrm{mL}$ ) and passed through a hydrophobic frit before being concentrated in vacuo. The resultant residue was dissolved in 1,4-dioxane $(10 \mathrm{~mL})$. To the solution was added $4 \mathrm{M} \mathrm{HCl}$ in 1,4-dioxane $(20 \mathrm{~mL})$ drop-wise at rt. The resultant solution was stirred at $r$ for 19 hours before being concentrated in vacuo. The resultant residue was dissolved in minimal DCM and purified by silica chromatography (0-40\% EtOAc in cyclohexane). The desired fractions were combined and concentrated in vacuo yielding 58 (91 mg, $0.39 \mathrm{mmol}, 40 \%)$. m.p. $114-116^{\circ} \mathrm{C} ; \mathrm{v}_{\max }$ (solid)/cm-1: 3169 (N-H), 3079, 2916, 1653 (C=O), 1470, 929; ${ }^{1} \mathrm{H}$ NMR (400 MHz, CHLOROFORM-d) $\delta$ ppm 9.19 (br. s, $1 \mathrm{H}), 8.19$ (d, J=5.1 Hz, $1 \mathrm{H}), 7.57-7.52(\mathrm{~m}, 1 \mathrm{H}), 7.36$ (d, J=5.1 Hz, $1 \mathrm{H}$ ), 5.87 (ddt, J=16.9, 10.3, 6.6, 6.6 Hz, $1 \mathrm{H})$, 5.14-5.07 (m, $1 \mathrm{H})$, 5.07-5.02 (m, $1 \mathrm{H}), 2.86-2.75(\mathrm{~m}, 2 \mathrm{H}), 2.52-2.43(\mathrm{~m}, 2 \mathrm{H}) ;{ }^{13} \mathrm{C} \mathrm{NMR}(101 \mathrm{MHz}$, CHLOROFORM-d) $\delta$ ppm 161.5, 141.3, 141.1, 137.1, 137.0, 134.0, 129.9, 126.5, 119.9, 115.9, 31.8, 30.0; HRMS $(\mathrm{M}+\mathrm{H})^{+}$calculated for $\mathrm{C}_{12} \mathrm{H}_{11} \mathrm{CIN} \mathrm{N}_{2} \mathrm{O} 235.0638$; found 235.0633; LCMS (formic): $\mathrm{R}_{\mathrm{t}}=0.86 \mathrm{~min}(100 \%), \mathrm{LRMS}(\mathrm{M}+$ $\mathrm{H})^{+}$calculated for $\mathrm{C}_{12} \mathrm{H}_{12} \mathrm{ClN}_{2} \mathrm{O} 235.1$; found 235.2.

2-(Benzyloxy)-3-(but-3-en-1-yl)-8-chloro-1,7-naphthyridine (59)<smiles>C=CCCc1cc2ccnc(Cl)c2nc1OCc1ccccc1</smiles> 
To a solution of 58 (1024 mg, $4.363 \mathrm{mmol})$ in DMF (10 mL) was added potassium carbonate $(0.724 \mathrm{~g}, 5.24 \mathrm{mmol})$. The resulting suspension was stirred at $\mathrm{rt}$ for $20 \mathrm{~min}$ before being treated with benzyl bromide $(0.57 \mathrm{~mL}, 4.8$ $\mathrm{mmol})$. The suspension was then stirred at $\mathrm{rt}$ for 2 hours. The solution was diluted with $\mathrm{H}_{2} \mathrm{O}(15 \mathrm{~mL})$ and EtOAc $(15 \mathrm{~mL})$. The organic layer was separated, washed with saturated aq. $\mathrm{LiCl}$ solution $(5 \mathrm{~mL})$, brine $(5 \mathrm{~mL})$, and passed through a hydrophobic frit before being concentrated in vacuo. The resultant residue was purified by silica chromatography (0-30\% EtOAc in cyclohexane). The desired fractions were combined and concentrated in vacuo yielding 59 (1.226 g, $3.775 \mathrm{mmol}, 87 \%)$ as a white solid. m.p. 86-87 ${ }^{\circ} \mathrm{C} ; v_{\max }$ (solid)/cm ${ }^{-1}: 2951,1412,1264$, 698; ${ }^{1} \mathrm{H}$ NMR (400 MHz, CHLOROFORM-d) $\delta$ ppm 8.24 (d, J=5.4 Hz, $\left.1 \mathrm{H}\right), 7.78(\mathrm{~s}, 1 \mathrm{H}), 7.66-7.60(\mathrm{~m}, 2 \mathrm{H}), 7.47$ (d, $J=5.4 \mathrm{~Hz}, 1 \mathrm{H}), 7.45-7.39(\mathrm{~m}, 2 \mathrm{H}), 7.38-7.32(\mathrm{~m}, 1 \mathrm{H}), 5.92-5.80(\mathrm{~m}, 1 \mathrm{H}), 5.69(\mathrm{~s}, 2 \mathrm{H}), 5.10-4.98(\mathrm{~m}, 2 \mathrm{H}), 2.91(\mathrm{t}$, $J=7.5 \mathrm{~Hz}, 2 \mathrm{H}), 2.54-2.43$ (m, $2 \mathrm{H}) .{ }^{13} \mathrm{C}$ NMR (101 MHz, CHLOROFORM-d) $\delta \mathrm{ppm} \mathrm{161.6,} \mathrm{150.4,} \mathrm{140.6,} \mathrm{137.6,} \mathrm{137.1,}$ $136.8,135.3,132.3,130.7,128.7,128.4,128.1,119.4,115.8,68.5,32.5,29.8 ;$ HRMS (M + H)+ calculated for $\mathrm{C}_{19} \mathrm{H}_{18} \mathrm{CIN}_{2} \mathrm{O} 325.1108$; found 325.1105; LCMS (formic acid): $\mathrm{R}_{\mathrm{t}}=1.50 \mathrm{~min}(100 \%), \mathrm{LRMS}(\mathrm{M}+\mathrm{H})^{+}$calculated for $\mathrm{C}_{19} \mathrm{H}_{18} \mathrm{CIN}_{2} \mathrm{O} 325.1$; found 325.3 .

tert-Butyl 4-((2-(benzyloxy)-3-(but-3-en-1-yl)-1,7-naphthyridin-8-yl)amino)piperidine-1-carboxylate (60)<smiles>C=CCCc1cc2ccnc(NC3CCN(C(C)(C)C)CC3)c2nc1OCc1ccccc1</smiles>

tert-Butyl 4-aminopiperidine-1-carboxylate $(906 \mathrm{mg}, 4.52 \mathrm{mmol})$ was added to a solution of 59 (1224 mg, 3.768 mmol), sodium tert-butoxide $(1449 \mathrm{mg}, 15.07 \mathrm{mmol}), \mathrm{Pd}_{2}(\mathrm{dba})_{3}(173 \mathrm{mg}, 0.188 \mathrm{mmol})$, 2(dicyclohexylphosphino)3,6-dimethoxy-2',4',6'-triisopropyl-1,1'-biphenyl (202 mg, $0.377 \mathrm{mmol}$ ) in toluene (15 $\mathrm{mL}$ ). The resulting reaction mixture was then stirred at $85^{\circ} \mathrm{C}$ for 1 hour. The resultant reaction mixture was allowed to cool to rt before being diluted with EtOAc $(30 \mathrm{~mL})$ and filtered through Celite ${ }^{\circledR}$. The Celite ${ }^{\circledR}$ was washed with EtOAc $(10 \mathrm{~mL})$ and the combined washings concentrated in vacuo producing an orange oil. The resultant oil was partitioned between DCM $(30 \mathrm{~mL})$ and $\mathrm{H}_{2} \mathrm{O}(30 \mathrm{~mL})$. The organic layer was separated and the aqueous layer extracted further with DCM $(3 \times 15 \mathrm{~mL})$. The organic fractions were combined and concentrated in vacuo producing an orange oil. The resultant oil was dissolved in minimal DCM and purified by silica chromatography (0-60\% EtOAc in cyclohexane). The desired fractions were combined and concentrated in vacuo yielding 60 (1.663 g, $3.403 \mathrm{mmol}, 90 \%)$ as an orange oil. ${ }^{1} \mathrm{H}$ NMR (400 MHz, CHLOROFORM-d) $\delta$ ppm 7.90 (d, $J=5.9 \mathrm{~Hz}, 1 \mathrm{H}), 7.65(\mathrm{~s}, 1 \mathrm{H}), 7.50(\mathrm{~d}, J=7.1 \mathrm{~Hz}, 2 \mathrm{H}), 7.44-7.38(\mathrm{~m}, 2 \mathrm{H}), 7.37-7.31(\mathrm{~m}, 1 \mathrm{H}), 6.75(\mathrm{~d}, J=5.9 \mathrm{~Hz}, 1 \mathrm{H})$, $6.20(\mathrm{~d}, J=8.1 \mathrm{~Hz}, 1 \mathrm{H}), 5.88(\mathrm{ddt}, J=17.1,10.3,6.6,6.6 \mathrm{~Hz}, 1 \mathrm{H}), 5.52(\mathrm{~s}, 2 \mathrm{H}), 5.09-4.98(\mathrm{~m}, 2 \mathrm{H}), 4.33-4.22(\mathrm{~m}, 1$ H), 4.16-4.00 (m, 2 H), 3.08 (br. s, 2 H), 2.88 (t, J=7.5 Hz, 2 H), 2.52-2.43 (m, 2 H), 2.19-2.10 (m, 2 H), 1.55-1.49 $(\mathrm{m}, 11 \mathrm{H}) ;{ }^{13} \mathrm{C}$ NMR $(101 \mathrm{MHz}$, CHLOROFORM-d) $\delta \mathrm{ppm}$ 159.5, 154.9, 153.9, 140.4, 137.5, 137.4, 135.8, 130.0, 129.5, 128.6, 128.0, 127.8, 127.4, 115.5, 108.1, 79.5, 68.0, 47.3, 32.8, 32.5, 29.9, 28.5, 26.9; HRMS (M + H)+ calculated for $\mathrm{C}_{29} \mathrm{H}_{36} \mathrm{~N}_{4} \mathrm{O}_{3}$ 489.2866; found 489.2865; LCMS (formic acid): $\mathrm{R}_{\mathrm{t}}=1.05$ min (100\%), LRMS (M + $\mathrm{H})^{+}$calculated for $\mathrm{C}_{29} \mathrm{H}_{37} \mathrm{~N}_{4} \mathrm{O}_{3} 489.3$; found 489.5 .

tert-Butyl 4-((2-(benzyloxy)-5-bromo-3-(but-3-en-1-yl)-1,7-naphthyridin-8-yl)amino)piperidine-1-carboxylate (61)<smiles>C=CCCc1cc2c(Br)cnc(NC3CCN(C(C)(C)C)CC3)c2nc1OCc1ccccc1</smiles>

$\mathrm{N}$-Bromosuccinimide $(661 \mathrm{mg}, 3.71 \mathrm{mmol}$ ) was added at rt to a stirred solution of 60 (1650 $\mathrm{mg}, 3.38 \mathrm{mmol})$ in chloroform ( $27 \mathrm{~mL})$. The resultant solution was then stirred at rt for 15 min before being diluted with $\mathrm{H}_{2} \mathrm{O}(0.5$ $\mathrm{mL}$ ). The organic phase was then passed through a hydrophobic frit and concentrated in vacuo to yield 61(1.833 g, $3.230 \mathrm{mmol}, 96 \%)$ as a yellow solid. m.p. $130-135^{\circ} \mathrm{C} ; v_{\max }\left(\right.$ solid)/cm ${ }^{-1}: 3412(\mathrm{~N}-\mathrm{H}), 2944,1688(\mathrm{C}=\mathrm{O}), 1523$, $1419,1155,701 ;{ }^{1} \mathrm{H}$ NMR $(400 \mathrm{MHz}, \mathrm{CHLOROFORM}-d) \delta \mathrm{ppm} 8.02(\mathrm{~s}, 1 \mathrm{H}), 7.96(\mathrm{~s}, 1 \mathrm{H}), 7.51-7.46(\mathrm{~m}, 2 \mathrm{H}), 7.44-$ $7.38(\mathrm{~m}, 2 \mathrm{H}), 7.38-7.32(\mathrm{~m}, 1 \mathrm{H}), 6.18(\mathrm{~d}, J=8.1 \mathrm{~Hz}, 1 \mathrm{H}), 5.95-5.83(\mathrm{~m}, 1 \mathrm{H}), 5.53(\mathrm{~s}, 2 \mathrm{H}), 5.11-5.01(\mathrm{~m}, 2 \mathrm{H}), 4.27-$ $4.17(\mathrm{~m}, 1 \mathrm{H}), 4.15-4.01(\mathrm{~m}, 2 \mathrm{H}), 3.12-3.01(\mathrm{~m}, 2 \mathrm{H}), 2.92(\mathrm{t}, \mathrm{J}=7.6 \mathrm{~Hz}, 2 \mathrm{H}), 2.54-2.46(\mathrm{~m}, 2 \mathrm{H}), 2.17-2.08$ (m, 2 $\mathrm{H}), 1.56-1.48(\mathrm{~m}, 11 \mathrm{H}) ;{ }^{13} \mathrm{C}$ NMR (101 MHz, CHLOROFORM-d) $\delta \mathrm{ppm} 160.0,154.8,153.2,141.3,137.3,137.1$, 135.4, 131.1, 130.1, 128.6, 127.9, 127.4, 127.2, 115.7, 103.3, 79.5, 68.4, 47.5, 32.8, 32.3, 29.9, 28.5 (N.B. one carbon signal missing); HRMS (M+H) ${ }^{+}$calculated for $\mathrm{C}_{29} \mathrm{H}_{35} \mathrm{BrN}_{4} \mathrm{O}_{3} 567.1971$; found 567.1973; LCMS (formic): $\mathrm{R}_{t}$ $=1.59 \mathrm{~min}(96 \%)$, LRMS $(\mathrm{M}+\mathrm{H})^{+}$calculated for $\mathrm{C}_{29} \mathrm{H}_{36} \mathrm{BrN}_{4} \mathrm{O}_{3}$ 567.2; found 567.3, 569.3. 
tert-Butyl 4-((2-(benzyloxy)-3-(but-3-en-1-yl)-5-(3,6-dihydro-2H-pyran-4-yl)-1,7-naphthyridin-8yl)amino)piperidine-1-carboxylate (62)<smiles>C=CCCc1cc2c(C3=CCOCC3)cnc(NC3CCN(C(=O)OC(C)(C)C)CC3)c2nc1OCc1ccccc1</smiles>

2-(3,6-Dihydro-2H-pyran-4-yl)-4,4,5,5-tetramethyl-1,3,2-dioxaborolane (256 mg, $1.22 \mathrm{mmol}$ ) was added at rt to a stirred mixture of $61(541 \mathrm{mg}, 0.953 \mathrm{mmol})$, potassium carbonate $(263 \mathrm{mg}, 1.91 \mathrm{mmol}), \mathrm{Pd}(\mathrm{OAc})_{2}(11 \mathrm{mg}, 0.048$ $\mathrm{mmol})$ and butyldi-1-adamantylphosphine $(17 \mathrm{mg}, 0.048 \mathrm{mmol})$ in 1,4-dioxane $(5.5 \mathrm{~mL})$ and $\mathrm{H}_{2} \mathrm{O}(2.75 \mathrm{~mL})$. The resultant reaction mixture was then heated at $100{ }^{\circ} \mathrm{C}$ for $45 \mathrm{~min}$ in a microwave reactor. The reaction mixture was allowed to cool to rt before being diluted with EtOAc $(10 \mathrm{~mL})$ and passed through Celite ${ }^{\circledR}$. The resultant solution was concentrated in vacuo. The resultant residue was dissolved in EtOAc $(20 \mathrm{~mL})$ and washed with $\mathrm{H}_{2} \mathrm{O}$ $(20 \mathrm{~mL})$. The layers were separated, and the aqueous layer extracted further with EtOAc $(20 \mathrm{~mL})$. The organic layers were combined, washed with brine $(15 \mathrm{~mL})$, passed through a hydrophobic frit and concentrated in vacuo. The resultant residue was dissolved in minimal DCM and purified by MDAP (high $\mathrm{pH}$ ). The desired fractions were combined and concentrated in vacuo yielding $62(354 \mathrm{mg}, 0.620 \mathrm{mmol}, 65 \%)$ as a pale-yellow solid. m.p. 84-87

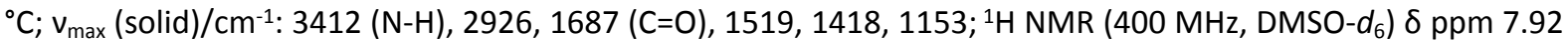
(s, $1 \mathrm{H}), 7.68(\mathrm{~s}, 1 \mathrm{H}), 7.54(\mathrm{~d}, J=7.1 \mathrm{~Hz}, 2 \mathrm{H}), 7.42-7.36(\mathrm{~m}, 2 \mathrm{H}), 7.35-7.28(\mathrm{~m}, 1 \mathrm{H}), 6.64(\mathrm{~d}, J=8.3 \mathrm{~Hz}, 1 \mathrm{H}), 5.85$ (ddt, J=17.0, 10.3, 6.5, $6.5 \mathrm{~Hz}, 1 \mathrm{H}), 5.78-5.74(\mathrm{~m}, 1 \mathrm{H}), 5.61(\mathrm{~s}, 2 \mathrm{H}), 5.03-4.93(\mathrm{~m}, 2 \mathrm{H}), 4.29-4.15(\mathrm{~m}, 3 \mathrm{H}), 4.02-$ $3.91(\mathrm{~m}, 2 \mathrm{H}), 3.87(\mathrm{t}, J=5.4 \mathrm{~Hz}, 2 \mathrm{H}), 3.04-2.88(\mathrm{~m}, 2 \mathrm{H}), 2.84(\mathrm{t}, J=7.5 \mathrm{~Hz}, 2 \mathrm{H}), 2.44-2.32(\mathrm{~m}, 4 \mathrm{H}), 1.97-1.87(\mathrm{~m}$, $2 \mathrm{H}), 1.60-1.47(\mathrm{~m}, 2 \mathrm{H}), 1.43(\mathrm{~s}, 9 \mathrm{H}) ;{ }^{13} \mathrm{C}$ NMR $\left(101 \mathrm{MHz}\right.$, DMSO- $\left.d_{6}\right) \delta \mathrm{ppm} 159.2,154.3,153.2,138.6,138.2$, $138.1,134.6,131.9,129.6,128.8,128.2,128.1,126.5,126.1,121.7,116.0,79.0,68.1,65.4,64.2,55.4,47.4,32.9$, 32.1, 30.6, 29.5, 28.6 (N.B. one $\mathrm{sp}^{2}$ carbon signal missing); HRMS (M + H) calculated for $\mathrm{C}_{34} \mathrm{H}_{43} \mathrm{~N}_{4} \mathrm{O}_{4} 571.3284$; found 571.3287; LCMS (formic): $R_{t}=1.11$ min (100\%), LRMS (M + H)+ calculated for $\mathrm{C}_{34} \mathrm{H}_{43} \mathrm{~N}_{4} \mathrm{O}_{4} 571.3$; found 571.5 .

3-(But-3-en-1-yl)-5-(3,6-dihydro-2H-pyran-4-yl)-8-(piperidin-4-ylamino)-1,7-naphthyridin-2(1H)-one (63)<smiles>C=CCCc1cc2c(C3=CCOCC3)cnc(NC3CCNCC3)c2[nH]c1=O</smiles>

$62(931 \mathrm{mg}, 1.63 \mathrm{mmol})$ was dissolved in TFA $(10 \mathrm{~mL})$ at $\mathrm{rt}$. The resultant solution was then heated to reflux and stirred for 1 hour before being allowed to cool down to rt. Volatile components were then removed in vacuo. Toluene was added to the resulting residue and evaporated off in vacuo $(3 \times 10 \mathrm{~mL})$. The resultant residue was dissolved in minimal $\mathrm{MeOH}$ and passed through a preconditioned aminopropyl column $(25 \mathrm{~mL})$ and washed with $\mathrm{MeOH}(50 \mathrm{~mL})$. The desired fractions were combined and concentrated in vacuo. The resultant residue was dissolved in 1:1 MeOH:DCM and purified by MDAP (high $\mathrm{pH}$ ). The desired fractions were combined and concentrated in vacuo yielding $63(219 \mathrm{mg}, 0.576 \mathrm{mmol}, 35 \%)$ as a yellow solid. m.p. $207-210^{\circ} \mathrm{C} ; \mathrm{v}_{\max }(\mathrm{solid}) / \mathrm{cm}^{-}$ ${ }^{1}: 3390(\mathrm{~N}-\mathrm{H}), 2921,1653$ (C=O), 1592, 1440, 1127, 903; ${ }^{1} \mathrm{H}$ NMR (400 MHz, DMSO- $\left.d_{6}\right) \delta \mathrm{ppm} 7.63(\mathrm{~s}, 1 \mathrm{H}), 7.60$ $(\mathrm{s}, 1 \mathrm{H}), 6.69(\mathrm{~d}, J=6.8 \mathrm{~Hz}, 1 \mathrm{H}), 5.84(\mathrm{ddt}, J=17.0,10.4,6.5,6.5 \mathrm{~Hz}, 1 \mathrm{H}), 5.74-5.68(\mathrm{~m}, 1 \mathrm{H}), 5.08-4.94(\mathrm{~m}, 2 \mathrm{H})$, $4.23(\mathrm{~d}, \mathrm{~J}=2.5 \mathrm{~Hz}, 2 \mathrm{H}), 4.08-3.94(\mathrm{~m}, 1 \mathrm{H}), 3.85(\mathrm{t}, J=5.3 \mathrm{~Hz}, 2 \mathrm{H}), 3.06-2.87(\mathrm{~m}, 2 \mathrm{H}), 2.63(\mathrm{t}, J=7.4 \mathrm{~Hz}, 2 \mathrm{H}), 2.38-$ $2.25(\mathrm{~m}, 4 \mathrm{H}), 2.00-1.81(\mathrm{~m}, 2 \mathrm{H}), 1.41-1.23(\mathrm{~m}, 2 \mathrm{H})$ (N.B. one signal obscured by solvent peak, exchangeable lactam and amine protons not visible); ${ }^{13} \mathrm{C}$ NMR (101 MHz, DMSO- $\left.d_{6}\right) \delta$ ppm 162.1, 145.5, 138.4, 137.6, 136.9, $133.6,131.6,127.1,122.6,121.2,120.9,115.8,65.3,64.1,48.7,45.5,33.6,32.2,30.8,29.7$; HRMS $(\mathrm{M}+\mathrm{H})^{+}$ calculated for $\mathrm{C}_{22} \mathrm{H}_{29} \mathrm{~N}_{4} \mathrm{O}_{2}$ 381.2291; found 381.2296; LCMS (high pH): $\mathrm{R}_{\mathrm{t}}=0.96 \mathrm{~min}(100 \%)$, LRMS (M + $\mathrm{H})^{+}$calculated for $\mathrm{C}_{22} \mathrm{H}_{29} \mathrm{~N}_{4} \mathrm{O}_{2} 381.2$; found 381.4 .

8-((1-(3-Amino-2,2-difluoropropanoyl)piperidin-4-yl)amino)-3-(but-3-en-1-yl)-5-(3,6-dihydro-2H-pyran-4-yl)1,7-naphthyridin-2(1H)-one (24) 
<smiles>C=CCCc1cc2c(C3=CCOCC3)cnc(NC3CCN(C(=O)C(F)(F)CN)CC3)c2[nH]c1=O</smiles>

HATU $(300 \mathrm{mg}, 0.788 \mathrm{mmol})$ and DIPEA $(0.229 \mathrm{~mL}, 1.31 \mathrm{mmol})$ were added at rt to a stirred solution of 3-((tertbutoxycarbonyl)amino)-2,2-difluoropropanoic acid (118 mg, $0.526 \mathrm{mmol}$ ) in DMF (2 mL). After 15 minutes 63 $(0.100 \mathrm{~g}, 0.263 \mathrm{mmol})$ was added at $\mathrm{rt}$ to the stirred solution and the reaction mixture stirred for 5 hours. The reaction mixture was then diluted with $\mathrm{H}_{2} \mathrm{O}(10 \mathrm{~mL})$ and extracted with EtOAc $(4 \times 10 \mathrm{~mL})$. The combined organic fractions were washed with brine $(10 \mathrm{~mL})$ and passed through a hydrophobic frit. The resultant solution was then concentrated in vacuo. The resultant solid was dissolved in 1:1 MeOH:DMSO and purified by MDAP (formic). The desired fractions were combined and concentrated in vacuo yielding a cream solid. The solid was dissolved in $4 \mathrm{M} \mathrm{HCl}$ in 1,4-dioxane $(4 \mathrm{~mL})$ at rt. The resultant solution was stirred at $\mathrm{rt}$ for 30 min before being filtered under reduced pressure. The filtrate was concentrated in vacuo and the resulting residue dissolved in 1:1 MeOH:DMSO and purified by MDAP (high $\mathrm{pH}$ ). The desired fractions were combined and concentrated in vacuo yielding 24 (7 mg, $0.02 \mathrm{mmol}, 5 \%$ over two steps) as a yellow solid. $\left.{ }^{1} \mathrm{H} \mathrm{NMR} \mathrm{(400} \mathrm{MHz,} \mathrm{DMSO-} d_{6}, 393 \mathrm{~K}\right) \delta$ ppm 7.71-7.60 (m, $2 \mathrm{H}), 6.58-6.47(\mathrm{~m}, 1 \mathrm{H}), 5.88$ (ddt, J=16.9, 10.3, 6.6, $6.6 \mathrm{~Hz}, 1 \mathrm{H}), 5.80-5.71(\mathrm{~m}, 1 \mathrm{H}), 5.14-4.95$ $(\mathrm{m}, 2 \mathrm{H}), 4.42-4.31(\mathrm{~m}, 1 \mathrm{H}), 4.31-4.25(\mathrm{~m}, 2 \mathrm{H}), 4.23-4.12(\mathrm{~m}, 2 \mathrm{H}), 3.95-3.86(\mathrm{~m}, 2 \mathrm{H}), 3.40-3.13(\mathrm{~m}, 4 \mathrm{H}), 2.75-$ $2.65(\mathrm{~m}, 2 \mathrm{H}), 2.46-2.31(\mathrm{~m}, 4 \mathrm{H}), 2.19-2.07(\mathrm{~m}, 2 \mathrm{H}), 1.66-1.51(\mathrm{~m}, 2 \mathrm{H})$ (N.B. exchangeable lactam and primary amine protons not visible); ${ }^{13} \mathrm{C}$ NMR (151 MHz, DMSO- $\left.d_{6}\right) \delta \mathrm{ppm} 162.0,161.4,145.2,138.4,137.6,137.3,133.6$, $131.5,127.4,123.2,121.3,120.8,118.4,115.9,65.3,64.1,47.4,45.7,44.4,42.0,40.6,32.2,30.8,29.6 ;{ }^{19} \mathrm{~F} \mathrm{NMR}$ $\left(376 \mathrm{MHz}\right.$, DMSO- $\left.d_{6}\right) \delta \mathrm{ppm}-105.58--105.41(\mathrm{~m}, 2 \mathrm{~F})$; HRMS $(\mathrm{M}+\mathrm{H})^{+}$calculated for $\mathrm{C}_{25} \mathrm{H}_{32} \mathrm{~F}_{2} \mathrm{~N}_{5} \mathrm{O}_{3}$ 488.2473; found 488.2473; LCMS (high pH): $\mathrm{R}_{t}=0.96 \mathrm{~min}(97 \%)$, LRMS $(\mathrm{M}+\mathrm{H})^{+}$calculated for $\mathrm{C}_{25} \mathrm{H}_{31} \mathrm{~F}_{2} \mathrm{~N}_{5} \mathrm{O}_{3} 488.2$; found 488.3 . 


\section{TR-FRET Assays}

The BRD4(1), ATAD2 and TAF1(2) TR-FRET assays have all been described previously. ${ }^{2,3}$

\section{TAF1(2) NanoBRET Assay}

All high throughput data analysis was carried out in IDBS ActivityBase XE.

NanoBRET tracer data binding were fitted using the following four parameter logistic fit was used, eq. (1),

$$
y=\frac{a-d}{1+(x / c)^{b}}+d
$$

where ' $a$ ' is the minimum, ' $b$ ' is the Hill slope, ' $c$ ' is the pIC50 and ' $d$ ' is the maximum. Assay data was normalized to microplate controls using the following equation, eq. (2),

$$
x=\frac{100-(100(a-b))}{c-b}
$$

where ' $a$ ' is the raw compound data, ' $b$ ' is the low control raw data and ' $c$ ' is the high control raw data. Data generated using the NanoBRET tracer assay was normalized using the following equation, eq. (3),

$$
x=\left(\frac{a}{d}\right) * 1000
$$

where ' $x$ ' is milliBRET units (mBu), ' $a$ ' is the acceptor fluorescence at $610 \mathrm{~nm}$ and ' $d$ ' is the donor fluorescence at $480 \mathrm{~nm}$.

Compounds were titrated 1:4 from $10 \mathrm{mM}$ stock solutions in 100\% DMSO, with $40 \mathrm{~nL}$ transferred per well to a white 384-well TC treated microplate (Nunc 164610, Thermo Fisher Scientific, USA) using a Labcyte Echo 555 (Labcyte Inc., USA) all other liquid handling was performed using a Thermo Scientific Multidrop (Thermo Fisher Scientific, USA) unless otherwise stated. HEK293-wt cells were seeded into a Corning 6-well microplate at $8 \mathrm{e} 5$ cells per well and left to attach for $4-6 \mathrm{~h}$ at $37^{\circ} \mathrm{C}, 5 \% \mathrm{CO}_{2}$ prior to transfection. The cells were then transfected with the following transfection mix (per well): $92 \mu \mathrm{L}$ OptimMEM, $0.002 \mu \mathrm{g}$ TAF1A-NanoLuc (obtained from Promega) , $8 \mu$ l FuGENE HD.

Following an overnight incubation at $37{ }^{\circ} \mathrm{C}, 5 \% \mathrm{CO}_{2}$, cells were washed with PBS and then detached by trypsinisation using TrypLE Express. Cells were then centrifuged at 1500 RPM for 5 min, the supernatant discarded, and the cell pellet resuspended in OptiMEM + 4\% US FBS at 2 e 5 cells $/ \mathrm{mL}$. BSP-BODIPY was then added to the cell solution at a Final Assay Concentration (FAC) of $5 \mu \mathrm{M} .40 \mathrm{~nL}$ of the cell suspension was dispensed per well into the pre-stamped compound microplates and then incubated for $4-6 \mathrm{~h}$ at $37{ }^{\circ} \mathrm{C}, 5 \% \mathrm{CO}_{2}$ this timepoint was chosen to give the optimal signal::background (data not shown). NanoLuc substrate solution was prepared by performing 1:100 dilution in OptiMEM. $10 \mu \mathrm{L}$ of this solution was added per well, plates centrifuged at 1000 RPM for $1 \mathrm{~min}$ and shaken at 1000 RPM for 1 min followed immediately by data capture. Data was ratioed (3) and then normalised using equation (2), to 16 high (DMSO) and 16 low (BAY-299, ${ }^{4} 10 \mu \mathrm{M} \mathrm{FAC)} \mathrm{control} \mathrm{wells} \mathrm{on}$ each microplate. $\mathrm{pIC}_{50}$ determination was performed by plotting the ratioed, normalised data against the $\mathrm{BET}$ inhibitor concentration and applying a four-parameter logistic fit as described in equation (1). 


\section{TAF1(2) Compound Docking}

Docking was carried out using Maestro 2018. The crystal structure from the complex with $\mathbf{1 8}$ was used as the starting point (PDB: 7P4S). Refinement was carried out in the structure preparation wizard to carry out $\mathrm{H}$-bond optimisation of the active-site water hydrogens. Docking with Glide was performed using a core constraint ( $0.3 \AA$ RMSD to the naphythyridone-piperidine substructure of 18). An additional location constraint was used to position the basic nitrogen to interact with the sidechain of Asp1539.

\section{Crystallization and Crystallography Materials}

Human TAF1 (1501-1635) at $15.5 \mathrm{mg} / \mathrm{mL}$ was incubated with $>3$ fold molar excess of compound 18 in $10 \mathrm{mM}$ HEPES, pH 7.5, $300 \mathrm{mM} \mathrm{NaCl}, 5 \%$ Glycerol, $2 \%$ DMSO on ice for $15 \mathrm{mis}$, then centrifuged for 15 mins at $4^{\circ} \mathrm{C}, 13 \mathrm{~K}$ rpm. Crystal screening was carried out using diverse commercial screens in sitting drops at $4{ }^{\circ} \mathrm{C}$ using $50 \mathrm{~nL}$ of protein to $150 \mathrm{~nL}$ of precipitant. Crystals grown in a Morpheus ${ }^{5}$ condition consisting of 30\% w/v EDO_P8K, 0.1 M Morpheus buffer 2 and $10 \%$ Morpheus alcohols at $4{ }^{\circ} \mathrm{C}$ were harvested directly from the crystallisation drop and flash frozen in liquid nitrogen with no addition of cryoprotectant. Data from a single crystal at $100 \mathrm{~K}$ was collected at the Genoble Europeon Synchotron Facility (ESRF, ID23-1) and processed using XDS ${ }^{6}$ and aimless ${ }^{7}$ in a $\mathrm{P} 2{ }_{1} 2{ }_{1} 2$ space group to give a 2.17Å dataset. Molecular replacement using Chain A of $3 U V 4$.pdb was performed using Phaser $^{8}$ in the CCP4 suite ${ }^{9}$ to reveal a single protein molecule in the ASU. Manual model building was performed using $\mathrm{COOT}^{10}$ and refined using BUSTER ${ }^{11}$ within the Global Phasing software suite.

Clear difference density for the ligand was found in two sites. Firstly, the ligand was found bound in the acetylated lysine binding site. Additionally, a second ligand molecule could be modelled at the interface between ASUs in the crystal. The molecule was stacked against the aromatic face of W1547 from one protein molecule in one ASU and against another ligand from an adjacent ASU (Figure S2). This ligand/ligand stacking contributes to reduced crystal and diffraction quality giving rise to slightly higher than average Rmerge and Rfree statistics. The statistics for the data collection and refined co-ordinates are given in Table S5. The final crystal structures are deposited in the Protein Data Bank under the accession codes PDB: 7P4S. 
(a) $2 \mathrm{mFo}-\mathrm{DFc}$ (at 0.7sigma) in grey.

$\mathrm{mFo}$-DFc (at \pm 3 sigma) in green $/$ red.

(Generated by Buster report ${ }^{11}$ )

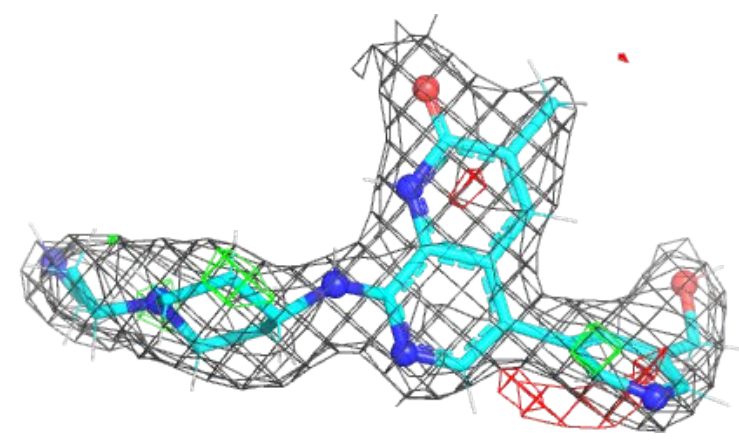

Ligand is well defined by the electron density map (b) $2 \mathrm{mFo}-\mathrm{DFc}$ (at 0.7 sigma) in grey.

$\mathrm{mFo}$-DFc (at \pm 3 sigma) in green $/$ red.

(Generated by Buster report ${ }^{11}$ )

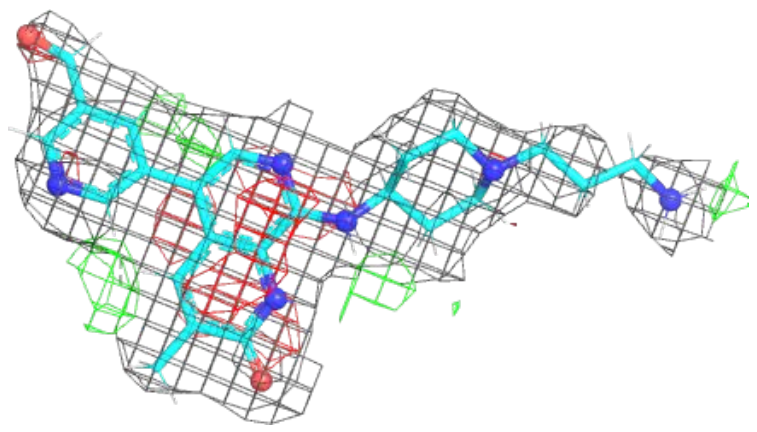

Ligand is well defined by the electron density map

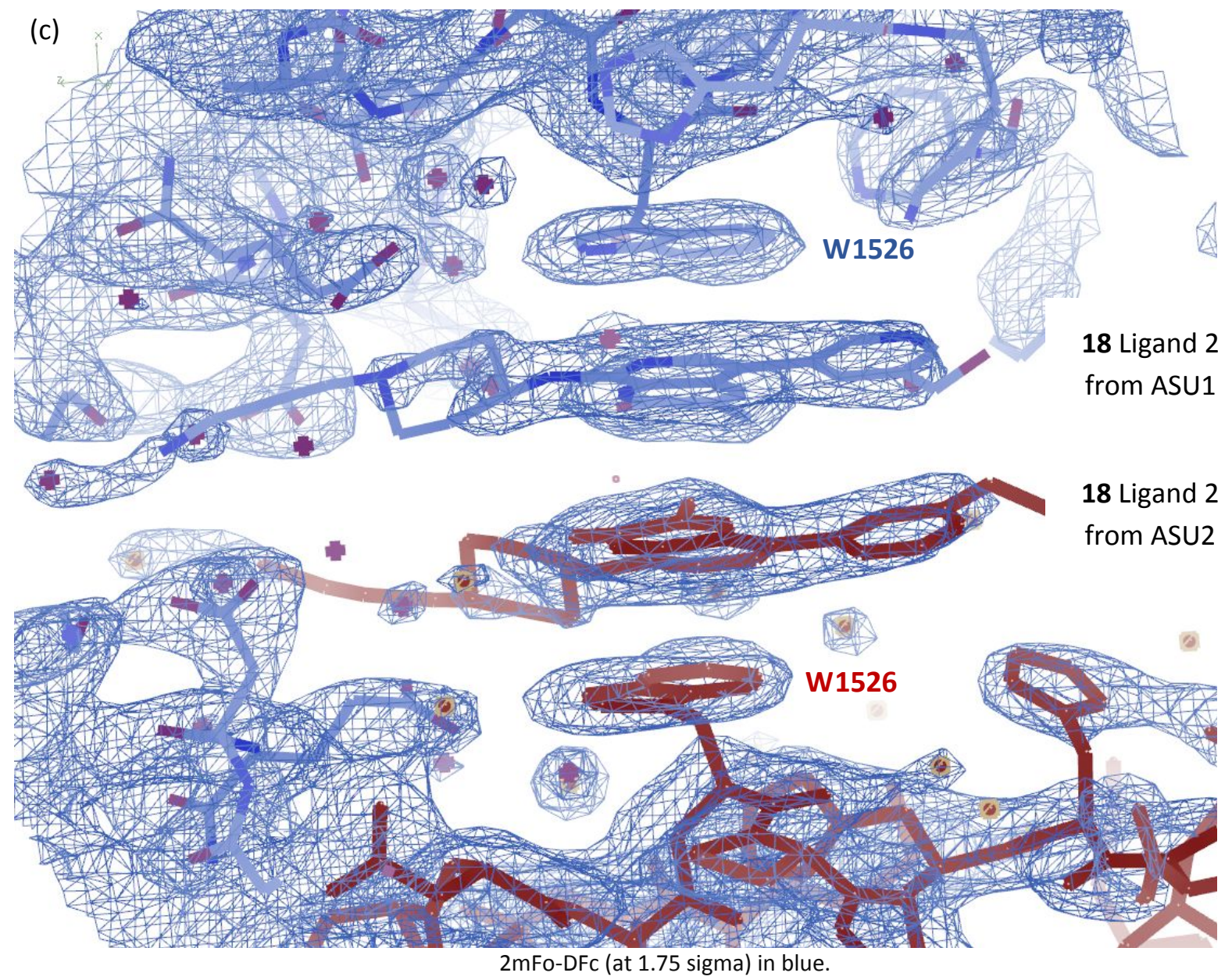

Figure S5. (a) Electron density maps around 18 Ligand 1; (b) Electron density maps around 18 Ligand 2; (c) Electron density maps around $\mathbf{1 8}$ Ligand 2 showing interface between adjacent ASU. 


\begin{tabular}{|c|c|}
\hline (collection on a single crystal) & $\begin{array}{l}\text { X-ray crystal structure of } \mathbf{1 8} \\
\text { bound to human TAF1(2) }\end{array}$ \\
\hline \multicolumn{2}{|l|}{ Data collection } \\
\hline Space group & $\mathrm{P} 2{ }_{1} 2_{1} 2$ \\
\hline \multicolumn{2}{|l|}{ Cell dimensions } \\
\hline$a, b, c(\AA)$ & $54.651,56007,58.308$ \\
\hline$\alpha, \beta, \gamma\left(^{\circ}\right)$ & $90.000,90.000,90.000$ \\
\hline Resolution $(\AA)$ & $56.01-2.17(2.43-2.17)$ \\
\hline$R_{\text {merge }}$ & $0.118(0.616)$ \\
\hline CC (1/2) & $0.994(0.945)$ \\
\hline$l / \sigma l$ & $8.9(2.9)$ \\
\hline Completeness (\%) & 99.9 (99.9) \\
\hline Redundancy & $6.3(6.5)$ \\
\hline No. reflections & $62975(17880)$ \\
\hline No. uniq reflections & 9952 (2763) \\
\hline \multicolumn{2}{|l|}{ Refinement } \\
\hline Resolution $(\AA ̊)$ & $29.2-2.3(2.43-2.3)$ \\
\hline$R_{\text {work }} R_{\text {free }}$ & $0.22 / 0.28$ \\
\hline No. atoms & 1262 \\
\hline Protein & 1080 \\
\hline Ligand/ion & $62 / 0$ \\
\hline Water & 120 \\
\hline \multicolumn{2}{|l|}{ B-factors } \\
\hline Protein & 61.00 \\
\hline Ligand & 50.68 \\
\hline Water & 47.92 \\
\hline \multicolumn{2}{|l|}{ R.m.s deviations } \\
\hline Bond lengths ( $(\AA)$ & 0.012 \\
\hline Bond angles (o) & 1.44 \\
\hline
\end{tabular}

*Highest resolution shell is shown in parenthesis

Table S5. Data collection and refinement statistics 


\section{References}

1. Wang, S.; Tsui, V.; Crawford, T. D.; Audia, J. E.; Burdick, D. J.; Beresini, M. H.; Côté, A.; Cummings, R.; Duplessis, M.; Flynn, E. M.; Hewitt, M. C.; Huang, H.-R.; Jayaram, H.; Jiang, Y.; Joshi, S.; Murray, J.; Nasveschuk, C. G.; Pardo, E.; Poy, F.; Romero, F. A.; Tang, Y.; Taylor, A. M.; Wang, J.; Xu, Z.; Zawadzke, L. E.; Zhu, X.; Albrecht, B. K.; Magnuson, S. R.; Bellon, S.; Cochran, A. G. GNE-371, a Potent and Selective Chemical Probe for the Second Bromodomains of Human Transcription-Initiation-Factor TFIID Subunit 1 and Transcription-Initiation-Factor TFIID Subunit 1-like. J. Med. Chem. 2018, 61, 9301-9315.

2. Demont, E. H.; Chung, C.-W.; Furze, R. C.; Grandi, P.; Michon, A.-M.; Wellaway, C.; Barrett, N.; Bridges, A. M.; Craggs, P. D.; Diallo, H.; Dixon, D. P.; Douault, C.; Emmons, A. J.; Jones, E. J.; Karamshi, B. V.; Locke, K.; Mitchell, D. J.; Mouzon, B. H.; Prinjha, R. K.; Roberts, A. D.; Sheppard, R. J.; Watson, R. J.; Bamborough, P. Fragment-Based Discovery of Low-Micromolar ATAD2 Bromodomain Inhibitors. J. Med. Chem. 2015, 58, 5649-5673.

3. Watson, R. J.; Bamborough, P.; Barnett, H.; Chung, C.-W.; Davis, R.; Gordon, L.; Grandi, P.; Petretich, M.; Phillipou, A.; Prinjha, R. K.; Rioja, I.; Soden, P.; Werner, T.; Demont, E. H. GSK789: A Selective Inhibitor of the First Bromodomains (BD1) of the Bromo and Extra Terminal Domain (BET) Proteins. J. Med. Chem. 2020, 63, 9045-9069.

4. Bouché, L.; Christ, C. D.; Siegel, S.; Fernández-Montalván, A. E.; Holton, S. J.; Fedorov, O.; Laak, A. t.; Sugawara, T.; Stöckigt, D.; Tallant, C.; Bennett, J.; Monteiro, O.; Díaz-Sáez, L.; Siejka, P.; Meier, J.; Pütter, V.; Weiske, J.; Müller, S.; Huber, K. V. M.; Hartung, I. V.; Haendler, B. Benzoisoquinolinediones as Potent and Selective Inhibitors of BRPF2 and TAF1/TAF1L Bromodomains. J. Med. Chem. 2017, 60, 40024022.

5. Gorrec, F. The MORPHEUS protein crystallization screen. J. Appl. Cryst. 2009, 42, 1035-1042.

6. Kabsch, W. XDS. Acta Cryst. 2010, D66, 125-132.

7. Evans, P. R.; Garib, N. M. How good are my data and what is the resolution? Acta Crystallogr. D: Biol. Crystallogr. 2013, 69, 1204-1214.

8. McCoy, A. J.; Grosse-Kunstleve, R. W.; Adams, P. D.; Winn, M. D.; Storoni, L. C.; Read, R. J. J. Appl. Cryst. 2007, 40, 658-674.

9. Collaborative Computational Project, Number 4. The CCP4 suite: programs for protein crystallography. Acta Cryst. D Biol. Crystallogr. 1994, D50, 760-763.

10. Emsley, P.; Cowtan, K. Coot: model-building tools for molecular graphics. Acta Cryst. 2004, D60, 21262132.

11. Bricogne, G.; Blanc, E.; Brandl, M.; Flensburg, C.; Keller, P.; Paciorek, W.; Roversi, P.; Sharff, A.; Smart, O. S.; Vonrhein, C.; Womack, T. O.; (2017). BUSTER . Cambridge, United Kingdom: Global Phasing Ltd 